University of Louisville

ThinkIR: The University of Louisville's Institutional Repository

Electronic Theses and Dissertations

8-2014

\title{
IL-12 induced modulation of tumor derived myeloid cell inflammatory responsiveness.
}

Courtney Jetun Mitchell

University of Louisville

Follow this and additional works at: https://ir.library.louisville.edu/etd

Part of the Microbiology Commons

\section{Recommended Citation}

Mitchell, Courtney Jetun, "IL-12 induced modulation of tumor derived myeloid cell inflammatory responsiveness." (2014). Electronic Theses and Dissertations. Paper 991.

https://doi.org/10.18297/etd/991

This Doctoral Dissertation is brought to you for free and open access by ThinkIR: The University of Louisville's Institutional Repository. It has been accepted for inclusion in Electronic Theses and Dissertations by an authorized administrator of ThinkIR: The University of Louisville's Institutional Repository. This title appears here courtesy of the author, who has retained all other copyrights. For more information, please contact thinkir@louisville.edu. 


\title{
IL-12 INDUCED MODULATION OF TUMOR DERIVED MYELOID CELL INFLAMMATORY RESPONSIVENESS
}

\section{By}

\author{
Courtney Jetun Mitchell \\ B.S. Clark Atlanta University, 2007 \\ M.D. University of Louisville, 2014

\begin{abstract}
A Dissertation
Submitted to the Faculty of the

University of Louisville School of Medicine

in Partial Fulfillment of the Requirements

for the Degree of
\end{abstract} \\ Doctor of Philosophy \\ Department of Microbiology and Immunology \\ University of Louisville \\ Louisville, KY
}

August, 2014 
Copyright 2014 by Courtney Jetun Mitchell

All rights reserved. 



\section{IL-12 INDUCED MODULATION OF TUMOR DERIVED MYELOID CELL INFLAMMATORY RESPONSIVENESS}

\section{By}

Courtney Jetun Mitchell

B.S. Clark Atlanta University, 2007

M.D. University of Louisville, 2014

\section{A Dissertation Approved on May 23, 2014}

by the following Dissertation Committee:

Jill Suttles

Haval Shirwan

Nejat Egilmez

Jason Chesney 


\section{DEDICATION}

Dedicated to my beloved mother, Jacqueline Marie Green (1964-2007). 


\section{ACKNOWLEDGMENTS}

Many have been instrumental in getting me to this point. First, I would like to thank the late Dr. Robert "Bob" Stout. Bob was such a great mentor. No matter what time of day or what else he had going on as chair of the department; he always had an open door for me. He was always ready to engage and discuss my next great idea, no matter how far-flung it might have been. He cared deeply about the students in the department, and supported me whole-heartedly during my project. Even at the close of his life, he was concerned with my path to getting my PhD. He challenged my thinking, and provided an example of strength under tremendous suffering. I will always be indebted to him for all he taught me and his unwavering support of all my research ambitions. Thank you Bob. I hope that this work is a reflection of the great man and scientist you were.

Dr. Jill Suttles, thank you for picking up the baton and stepping in to make sure I finished this part of my training. You have been an amazing woman of strength and resilience. I am proud to have worked for you and eternally grateful for the hand you had in my training. Literally, if it had not been for you, this project would not have been possible. Thanks for your patience, flexibility, and support. I owe my greatest appreciation to you for all you have done to help me.

I would like extend special thanks to the MD/PhD program for giving me the opportunity to pursue this path. Dr. Binks Wattenberg, thank you for seeing 
something in me and allowing me to join the program. Victoria King, thank you for your support and encouragement during my 7 years here. Things would not have gone as smoothly as they have without you.

To my committee members, Dr. Haval Shirwan and Dr. Jason Chesney, thank you for you insightful suggestions and flexibility with committee meetings and my defense date. Dr. Nejat Egilmez, thank you for stepping in on such short notice to help me finish this final step. I really appreciate all of your help in this endeavor.

I have been extremely blessed to work with some amazing people while in the lab. Thank you, Kimberly Head for all your expertise and advice and for keeping the lab running like a machine. Thank you, Lihua Zhang for being my office buddy and western blot whisperer. Your skills were invaluable to this project, and I really appreciate you all's help. To Dr. Yangfang "Pei Pei", Zhu, Dr. Kelly Casey Carroll, and Dr. Ashley Triplett, thank you all for being my sounding board in the lab. Thank you all for listening to me laugh, sing, and cry. You all made hard days in the lab a little easier. I am extraordinarily lucky to have found friends like you all. To Dr. Katharine Richardson, thanks for showing me the ropes when I first started in the lab. To the other current and former lab members, Shunmugavadiv "Meena" Vanchinathan, Bing Li, Jonathan Brown, Christina Akimana, Tad Dryden, Carolyn Roberson, thank you for making the Suttles/Stout lab a pleasant place to work.

To my husband, Marion Mitchell, thank you for being a patient and supportive partner. You have encouraged me every step of the way. When I felt 
like giving up, you were the one who told me that I could do it. Thank you for helping me care for my brother and for being a generous and unselfish person. Without you, I would not have made it. I am appreciative of everything you have done to help me and I love you dearly.

To my Louisville medical school friends, Dr. Heather Lee, Jayci Roney, Esq., Dr. Suma Chennubhotla, Dr. Sally Diebold, Dr. Nichole Sonderman, Dr. Beth Dicken Todd, and Dr. Aman Ghotra, you all are amazing. I love each and every one of you. You have made my time spent in the Louisville the best. You were right there to through this whole process and always knew how to make me feel good about myself. Thanks for being awesome friends.

To my mother, thank you for believing in me and telling me I could do whatever I dreamed. Thank you for giving me my carefree spirit and loving me unconditionally. I think of you every day and I miss you terribly.

To all my friends and family in Itta Bena, Mississippi, Chicago, Illinois, Birmingham, Alabama, and everywhere in between (who are too numerous to list individually) thanks for all the love and support. I am so lucky to have such a rock solid support system. You all have had a tremendous part in my success. To my brother, Couric Green, thank you for helping me become a responsible adult. I am proud of the man you are becoming. I hope that you will continue to push for excellence in all aspects of your life. You all are my inspiration and motivation.

Thanks to the University of Louisville School of Medicine, Department of Microbiology and Immunology for being a nurturing and supportive place to learn and grow. 
Thanks to the National Institutes of Health, National Cancer Institute, Ruth Kirchstein Predoctoral Fellowship F31 Award, MD/PhD program, Susan G. Komen, and Jennie C Benedict Scholarship for providing financial support during my training.

Finally, I praise God for his continued blessings and the opportunities He has allowed in my life. 


\section{ABSTRACT \\ IL-12 INDUCED MODULATION OF TUMOR DERIVED MYELOID CELL INFLAMMATORY RESPONSIVENESS}

Courtney Jetun Mitchell

May 23, 2014

Tumor infiltrating and tumor associated myeloid cells (TIMs and TAMs) elaborate an array of factors that promote tumor growth and metastasis. IL-12, a potent inflammatory cytokine has been shown to induce regression of many cancers. We hypothesize that IL-12 augments the ability of TIMs and TAMs to respond to inflammatory stimuli providing a window in which these stimuli are more likely to promote tumor destruction. Related to this hypothesis, we asked two questions: (1) Does IL-12 directly change signaling events associated with inflammatory signal transduction? (2) Is IFNy required for the entirety of IL-12 induced enhancement of the response of TIMs to inflammatory stimuli? First, we looked broadly at the in vivo effects of microspheres containing IL-12 on the growth and metastasis of $4 \mathrm{~T} 1$ tumors. We also did studies with tumor cell-dendritic cell fusion for future examination of the impact of IL-12 and myeloid cells on the efficacy of tumor cell-dendritic cell fusion vaccines in mice. Most of this dissertation 
focuses on in vitro work using TIMs and TAMs isolated from wild-type BALB/C or IFNY deficient mice bearing the 4T1 mammary carcinoma. TIMs and TAMs were pretreated in vitro with IL-12 followed by LPS. TNF $\alpha$, IL-6, and IL-10 cytokine and mRNA levels were measured. We also examined the impact of IL-12 on the response 4T1 TIMs to tumor derived products. The phosphorylation of a number molecules involved in inflammatory signaling pathways, including MAPK proteins, were assessed by Western Blot. We found that treatment of TIMs with IL-12 followed by exposure to LPS enhances the amount of IL-6 and TNF $\alpha$ with a reciprocal decrease in IL-10. This observation is associated with increases in the phosphorylation of MAPKs. The presence of IFNY is only partially necessary for these effects. We observed that IL-12 only significantly impacted the production of IL-10 from 4T1 TAMs in response to LPS. IL-12 caused a significant increase in the amount of TNFa and IL-6 in response to tumor derived products without affecting IL-10. Our results provide additional insight into direct changes induced by IL-12 to the functional phenotype of TIMs and TAMs in response to inflammatory stimuli. 
TABLE OF CONTENTS

PAGE

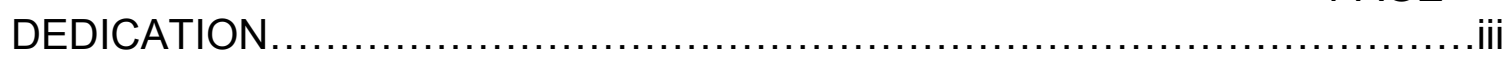

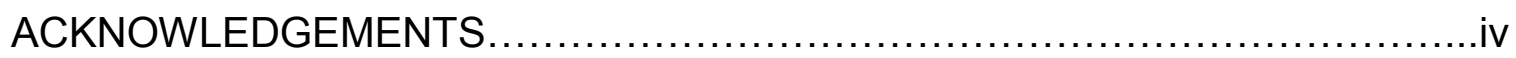

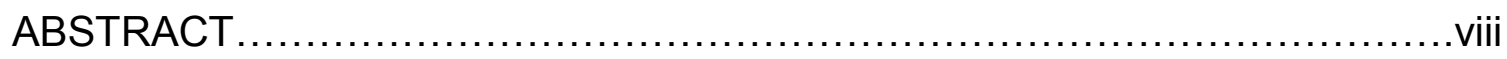

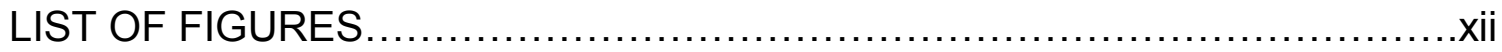

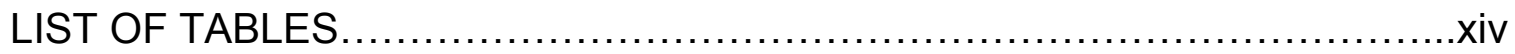

CHAPTERS

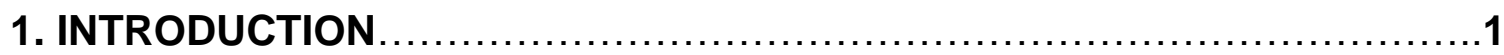

2. IL-12 REDUCES THE IN VIVO GROWTH OF THE 4T1 MAMMARY CARCINOMA

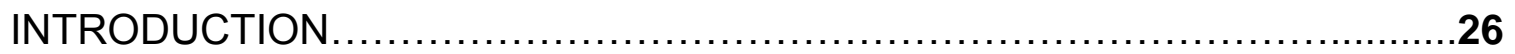

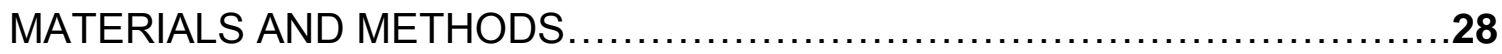

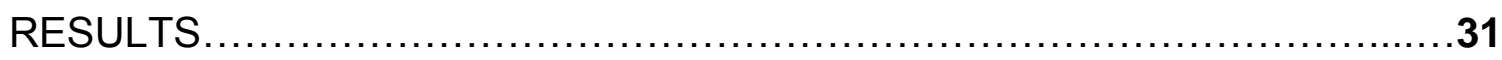

In vivo administration of IL-12 microspheres diminishes 4T1 growth and lung metastasis...........................................................

Polyethylene glycol facilitates $4 T 1$ and dendritic cell fusion................32

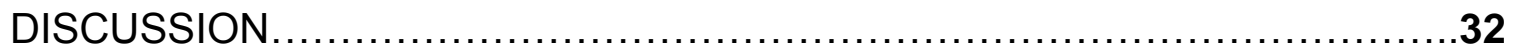




\section{IL-12 MODIFIES RESPONSE OF TUMOR ASSOCIATED AND TUMOR INFILTRATING MYELOID CELLS TO LPS VIA IFNY INDEPENDENT AND DEPENDENT MECHANISMS}

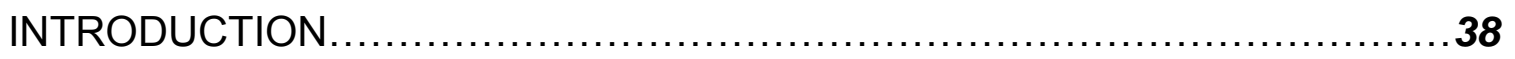

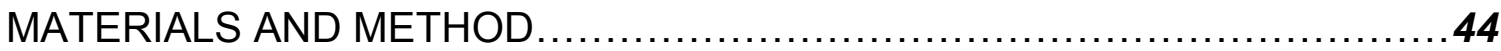

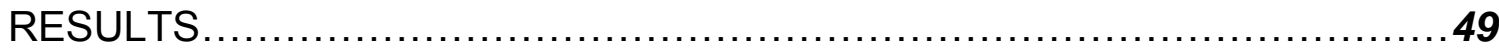

IL-12 impacts the response of $4 T 1$ tumor associated myeloid cells to LPS

$4 T 1$ peritoneal TAMs produce less IFNY than control peritoneal myeloid cells in the presence of IL-12.

Absence of IFNY affects the response of 4T1 TAMs to IL-12 and LPS

IL-12 modulates the response of $4 T 1$ tumor-infiltrating myeloid cells to LPS

IL-12 increases pro-inflammatory cytokine produced by 4T1 TIMs in response to $4 T 1$ tumor derived products.

IL-12 modulates the response of IFNY-deficient, 4T1 tumor-infiltrating myeloid cells to LPS.

IFNY partially impacts the response of $4 T 1$ TIMs to IL-12 and LPS.

IL-12 alters the 4T1 TIMs activation of MAPK pathway in response to LPS.

DISCUSSION.

REFERENCES. 


\section{LIST OF FIGURES}

\section{FIGURES}

PAGE

1. In vivo IL-12 administration decreases $4 \mathrm{~T} 1$ tumor weights........................34

2. In vivo IL-12 administration decreases the rate 4T1 tumor growth.................35

3. In vivo IL-12 administration decreases $4 \mathrm{~T} 1$ tumor metastasis......................36

4. Polyethylene glycol (PEG) facilitates fusion of $4 \mathrm{~T} 1$ tumor cells and bone marrow-

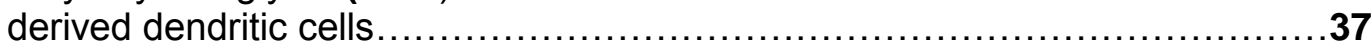

5. IL-12 modulates the response of $4 \mathrm{~T} 1$ peritoneal tumor associated myeloid cells

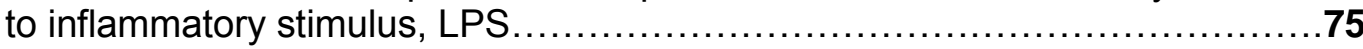

6. 4T1 peritoneal TAMs produce less IFNy than control peritoneal myeloid cells in

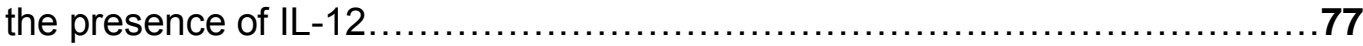

7. The absence of IFNy affects the response of 4T1 TAMs to IL-12 and LPS.......79

8. IL-12 modulates the response of $4 \mathrm{~T} 1$ tumor-infiltrating myeloid cells to inflammatory stimulus, LPS.

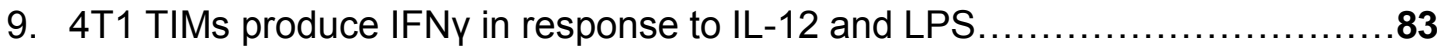

10. IL-12 increases pro-inflammatory cytokines produced by $4 \mathrm{~T} 1 \mathrm{TIMs}$ in response to $4 \mathrm{~T} 1$ supernatant.

11. Innate immune cells isolated from WT and IFNY-deficient 4T1 tumor have similar myeloid associated surface markers

12. IL-12 modulates the response of IFNy-deficient, $4 \mathrm{~T} 1$ tumor-infiltrating myeloid

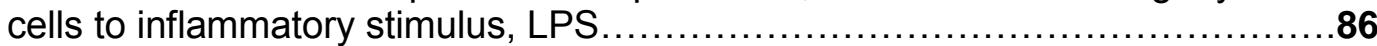

13. IFNy partially impacts the inflammatory gene profile of $4 \mathrm{~T} 1$ tumor-infiltrating myeloid cells to IL-12 and LPS. 
14. IL-12 enhances 4T1 tumor-infiltrating myeloid cell activation of MAPK pathway in

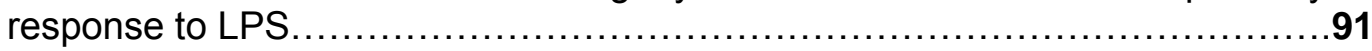




\section{LIST OF TABLES}

TABLES

PAGE

1. IFNy partially impacts the cytokine response of $4 \mathrm{~T} 1$ tumor-infiltrating myeloid

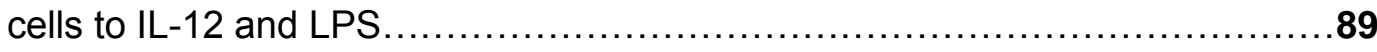




\section{CHAPTER I \\ INTRODUCTION}

\section{Myeloid Derived Cell Phenotypic and Functional Diversity}

Myeloid derived cells are heterogeneous innate immune cells from the myeloid lineage of bone marrow-derived hematopoietic stem cell precursors. These cells include monocytes, macrophages, neutrophils, dendritic cells, and myeloid derived suppressor cells. Macrophages are phagocytic cells broadly distributed in tissues within the body, and are mature forms of circulating blood monocytes (1). These cells are critical for innate immune responses and assist in priming the adaptive immune system to attack pathological insults (1).

Macrophages are remarkably dynamic and display an array of functions and activities. In addition to their phagocytic properties, macrophages are capable of presenting antigen to adaptive immune cells, secreting factors important for wound healing, and establishing the extracellular matrix (1). Interestingly, many macrophage functions are in direct opposition to one another. Inflammation provides an excellent illustration of the diverse functions of macrophages. In the formative stages of inflammation, macrophages secrete pro-inflammatory cytokines, chemokines as well as cytotoxic factors that activate surrounding immune and stromal cells, attract auxiliary innate immune cells and specialized adaptive immune cells. All of these functions work 
together to initiate the killing or clearance of the offending inflammatory agent ( 2 , 3). As inflammation progresses, macrophages secrete less pro-inflammatory cytokines and begin to elaborate factors that aid in the resolution of inflammation, wound healing, and angiogenesis $(2,3)$.

As evidence of the spectrum of functions macrophages may exhibit, several subsets of macrophages have been described in the literature. Discussions continue as to whether these subsets are distinct lineages of myeloid cells locked into a particular functional state or transient cellular phenotypes that change given the stimulus or the environment (2-5). A simplistic classification of macrophages based on T-helper cell categorization was introduced by Mills, labeling macrophages as either M1 or classically activated and M2 or alternatively activated (6). Macrophage secretion of pro-inflammatory cytokines, such as TNF-alpha (TNF $\alpha$ ), IL-1 beta (IL-1 $\beta$ ), IL-12, IL-6, IL-15, metalloproteinases (MMPs) and nitric oxide, and expression of pro-inflammatory genes, such as iNOS and co-stimulatory molecules B7 and major histocompatability class II molecules (MHC II) in response to IFN gamma (IFNY) followed by LPS treatment, generally characterize classically activated macrophages $(7,8)$. Conversely, macrophages exposed to IL-13 in combination with IL-4 display the alternative activated phenotype characterized by the secretion of anti-inflammatory cytokines like IL-10, transforming growth factorbeta (TGF $\beta$ ), vascular endothelial growth factor (VEGF) and the expression of anti-inflammatory genes including, arginase I and mannose receptor I (9). Attempts to incorporate the complex and diverse functional phenotypes of 
macrophages have been made by the use of sub-classifications of the original M1-M2 paradigm (7) or a color wheel for macrophage classification based on the functional environment, the major examples being immune regulation, wound healing, and host defense $(3,10,11)$. Overall, macrophages are remarkably diverse cells that display a plethora of functional phenotypes under the influence of various environmental factors.

\section{Macrophage Activation and Counter-Regulation}

\section{Activation}

Macrophages can be induced to display various functional phenotypes by many activating agents. Upon encountering various signals in the environment, macrophages can be activated to secrete cytokines and mediators of inflammation, present antigens for adaptive immune cell activation, and kill intracellular and extracellular bacteria. Specific examples of macrophage activators include bacterial lipopolysaccharide (LPS), CD40 ligand (CD40L or CD154), and IFNY.

The activation of macrophages via LPS has been extensively studied. Macrophage stimulation with LPS leads to a variety of effector functions through the integration of many complex intracellular signaling pathways. LPS is a component of the outer membrane of gram-negative bacteria (12). LPS acts as an endotoxin and binds to the pattern recognition receptor (PRR), toll-like receptor 4 (TLR4) and co-receptors CD14 and MD-2 on macrophages (13-15). Intracellular signals from the LPS/TLR4/MD-2 complex are transmitted via 
adaptor proteins, myeloid differentiation factor 88 (MyD88) or TIR-containing adaptor molecule (TRIF) (16). Early TLR4 signaling via the MyD88 pathway is responsible for elaborating most of the pro-inflammatory cytokines classically associated with LPS activation of macrophages (17). The MyD88 pathway leads to the degradation of inhibitors of kappa beta (IKBs), which allows for the activation and nuclear translocation of NF-KB (18). NF-KB is a protein complex consisting of dimers of any of its 5 family members that include p65, p50, Rel, A, Rel B, and c-Rel (19). The dimerization of the p65 and p50 subunits is associated with LPS stimulation (20). The delayed MyD88 independent, TRIF-biased pathway signals through tumor necrosis factor receptor-associated factor (TRAF) family member associated NF-KB-activator binding kinase (TBK1) to activate IFN response factor 3 (IRF3) (21-23). This leads to the release of type I interferons such as interferon $B$ (IFN $\beta$ ) (21). The TRIF-biased pathway can also lead to the delayed activation of NF-kB (23)

The CD40 signaling pathway in macrophages has also been thoroughly investigated (24). CD40 is a member of the tumor necrosis factor receptor (TNFR) family $(25,26)$. This co-stimulatory molecule is found on the surface of macrophages, B-cells, T cells, dendritic cells, and endothelial cells (27-30). Engagement of CD40 on macrophages, by its ligand, CD154 leads to secretion of pro-inflammatory cytokines and elaboration of reactive oxygen species (3133). CD154 is a member of the TNF family of proteins (34). It can be found bound to the cell surface of various immune cells or in a soluble form (34). Introduction of CD154 in tumor bearing mice has been shown to decrease the 
number of suppressive myeloid cells and increase T cell activation(34). Signaling events downstream of CD40 include the phosphorylation of protein tyrosine kinases (PTKs), such as Janus activated kinase 3 (JAK3) (35), which can lead to the activation of transcription factor signal transducer and activator of transcription 3 (STAT3) and STAT6 $(35,36)$. CD40 ligation has been shown to lead to activation of serine/threonine kinases: c-jun amino-terminal kinase/stress activated protein kinase (JNK/SAPK), p38 mitogen-activated protein kinase (MAPK), and extracellular signal-regulated mitogen-activated kinase $(E R K)(37,38)$. Activation of CD40 by CD154 also enlists tumor necrosis factor receptor-associated factors (TRAFs) to transmit signaling cascades to downstream transcriptional mediators (39). TRAF2, TRAF3, TRAF5, and TRAF6 have shown to play a role in CD40 signaling (40). CD40 signaling can result in the activation of NF-KB via TRAF2 and TRAF6, and the activator protein 1 (AP1), and nuclear factor of activated T cells (NF-AT), all of which can mediate inflammatory cytokine production (40-43).

Another example of a macrophage activator is IFNy. IFNy is the sole member of the type II interferon group (44). Th1 lymphocytes, NK cells, and macrophages produce IFNy, which is a potent endogenous activator of macrophages (45-48). Genes that are upregulated in macrophages in response to IFNy include MHC class I and II, anti-viral proteins, inflammatory cytokines and chemokines $(46,49)$. IFNy binds to its receptor to form a heterodimer of type II cytokine receptors, interferon gamma receptor gamma 1 and 2 (IFNGR1 and 2) 
that leads to the activation of JAK1 and JAK2 that subsequently phosphorylate IFNGR1 $(50,51)$. This phosphorylation event provides a docking site for STAT1 (50-52). STAT1 phosphorylation allows it to dimerize and translocate into the nucleus to bind to target genes on interferon response elements $(52,53)$. IFNY has been shown to prime macrophages to be tumoricidal and for subsequent stimulation by activating stimuli such as LPS (54-56). Overall, macrophages are activated by a variety of stimuli that integrate numerous signaling pathways leading to diverse functional phenotypes.

\section{Counter-Regulation}

Of equal importance to macrophage activation is macrophage counterregulation. Excessive inflammation can cause tissue damage and pathology. Thus, the dampening and resolution of macrophage inflammatory activities are very important. The immune system has evolved to include several mechanisms to negatively regulate inflammation. Macrophage activation can be attenuated in several ways.

In addition to the pro-inflammatory cytokines secreted by macrophages in response to LPS, concurrent signaling events lead to the elaboration of IL-10, a potent anti-inflammatory cytokine. Twenty years ago, it was first demonstrated that IL-10 was produced by human monocytes in response to LPS (57). The same study showed that IL-10 inhibited the release of IL-1 $\alpha$ and $\beta, I L-6, T N F \alpha$, and IL-8 in response to LPS and/or IFNY (57). Subsequent reports have unmasked a complex network of activators and signaling components that 
regulate IL-10 expression in macrophages and mediate its downstream antiinflammatory effects. Several transcriptional factors have been implicated in the regulation of IL-10 in macrophages. These include specificity factor (Sp) activators, STATs, c-Musculoaponeurotic Fibrosarcoma (c-MAF), activator proteins (AP-1), CCAAT/Enhancer binding proteins (C/EBP), and CAMP response element binding protein (CREB) (58). Sp1 binds to the G-rich portion of the IL-10 promoter $(59,60)$. Lack of endogenous Sp protein leads to complete ablation of IL-10 promoter activity (59). STAT1 and STAT3 recruitment to the IL10 promoter has been demonstrated, although evidence of direct binding of STAT proteins to existing cis-elements within the IL-10 promoter is not available $(61,62)$. In macrophages, the protoonocogene, c-MAF, a member of the basic leucine zipper family of transcription factors is constitutively present and is ushered to the IL-10 promoter upon TLR ligation in response to LPS (63). C/EBPs can act as homo- and heterodimers in TLR-dependent and independent pathways to impact IL-10 gene expression (58). In response to LPS, C/EBP proteins synergize with Sp1 to enhance IL-10 transcription (64). Alternatively, cAMP stimulation through the adenosine receptor can lead to activation of the IL10 promoter in a MyD88-independent mechanism via C/EBP (65). MyD88independent activation of the IL-10 promoter may also be due to CREB activation (66). In response to CAMP stimulation, CREB is phosphorylated and accompanied into the nucleus with its co-activators, histone acetyl transferases, CREB binding protein (CBP) and p300 $(67,68)$. This leads to hyperacetylation of histones at the IL-10 promoter and ultimately, increased transcription of IL-10 
(69). Phosphorylation of serine 10 on histone $\mathrm{H} 3$ is thought to be a critical epigenetic marker for transcriptional activation of the IL-10 gene (69)

IL-10 binds to its receptor, IL-10 receptor (IL-10R), a tetramer consisting of two heterodimers of the two subunits, IL-10R1 and IL-10R2 (70). Upon ligation, IL-10R1 associates with JAK1 that is then phosphorylated (71). JAK1 phosphorylation and activation leads to the phosphorylation of STAT3, an indispensible mediator of IL-10 anti-inflammatory function (71). STAT3 enters the nucleus and facilitates the transcription of several anti-inflammatory genes including ETS family transcriptional repressor, ETV3, a helicase family corepressor, Strawberry notch homologue 2 (SBNO2), and suppressor of cytokine signaling 3 (SOCS3) (72). SOCS3 is part of an 8-member family of proteins characterized by a Src homology $2(\mathrm{SH} 2)$ domain, a variable $\mathrm{N}$-terminus and a conserved region termed the SOCS box at its C-terminus. Two members of this group, including SOCS3 have a kinase inhibitory region (KIR) at the $\mathrm{N}$ terminal(73). SOCS3 binds phosphorylated tyrosines on cytokine receptors, especially the IL-6 receptor component gp130, to inhibit signal transduction. SOCS3 is thought to be key molecule in distinguishing between IL-10 and IL-6 cellular signaling $(74,75)$. Although both IL-6 and IL-10 induce STAT3 and SOCS3, SOCS3 selective inhibition of the IL-6 receptor component, gp130, disallows IL-6 from displaying anti-inflammatory characteristics associated with IL-10 $(74,75)$. A STAT3 independent pathway for IL-10 gene expression has been elucidated that includes phosphatidylinositol 3' kinase (PI3K), glycogen synthase kinase 3 beta (GSK3 $\beta$ ), and Akt, which controls IL-10 induced 
expression of autotaxin, Egr2, caspase5, and signaling lymphatic activation molecule (SLAM) (76).

Because persistent high levels of IL-10 lead to immunosuppression and render the host susceptible to pathogenic insult, negative regulation of IL-10 is of vital importance. IL-10 induced SOCS3 can inhibit STAT3 activity creating a negative autoregulatory loop (75). Additionally, MHC class II transactivator (CIITA), and poly (ADP) ribose polymerase 1 (PARP-1) (in an allelic specific manner) have been shown to negatively regulate $\mathrm{IL}-10$ expression in innate immune cells $(77,78)$. Interestingly, studies have demonstrated that IFNY can inhibit IL-10 production in response to LPS $(79,80)$. It was shown that IFNY inhbits IL-10 through diminishing the effects of the MAPK pathway, and the $\mathrm{PI3K/Akt/GSK3b}$ pathways (80).

\section{The MAPK signaling pathway}

Optimal intracellular communication in macrophages and other immune cells requires a complex system of highly integrated and tightly controlled signals. Various signaling pathways must converge upon numerous transcription factors and ultimately genes to regulate the function of macrophages. These same pathways may exert post-transcriptional and post-translational modifications to further dictate the macrophage functional phenotype, adding another layer of complexity to the signaling tableau. The MAPK pathway is an example of a single signaling pathway that can influence a broad spectrum of other signaling pathways. This pathway has been shown to be involved in a wide 
variety of signaling cascades that control myeloid cell response to inflammatory stimuli. The expansive influence of the MAPK pathway on the macrophage functional phenotype is evident as this pathway modulates and contributes to the propagation of signals transmitted by LPS, IFNy, and CD40.

MAPKs are family of proteins that form a tiered system for relaying signals within cells (81). In response to a stimulus, MAPK kinase kinases (MAP3Ks) are activated. These activated MAP3Ks go on to activate MAPK kinases (MAP2Ks or MEKs) via phosphorylation of specific serine and threonine residues. Finally, MAP2Ks proceed to activate MAPK family members, ERKs, p38s, and JNKs, through phosphorylation of specific tyrosines and threonines. Once activated MAPKs can bind and activate various transcription factors and enhancers to regulate gene transcription (81).

The first MAPKs discovered were ERK family members including ERK1, ERK2, MAPK1, and MAPK3 (82). ERK family members are encoded by two genes, ERK1 and ERK2 and require dual phosphorylation at Thr203 and Tyr205 (ERK1) and Thr185 and Tyr187 (ERK2) for activation (82). ERKs can be activated by a well-defined pathway initiated by the Ras protooncogene, or via Ras-independent pro-inflammatory stimuli such as TNFa and LPS (83).

JNKs were first described as protein kinases found in the livers of cycloheximide treated rats (83). Like ERKs, JNKs have a variety of activators. JNKs are extremely sensitive to mitogens, environmental stressors like heat shock and ionizing radiation, pro-inflammatory cytokines, endoplasmic reticular (ER) stress, DAMPs, and PAMPs (81). There are 3 JNK family members, JNK1-3 
(81). Genes of the same name encode them, with each family member having several isoforms as a result of alternative splicing. JNKs are dually phosphorylated at Thr 183 and Tyr185 (82). A large number of MAP3Ks have been shown to lead to the activation of JNKs including MEKK1, MEKK2, MLK1, MLK2, and MLK4 (84). These MAP3Ks lead to the phosphorylation of two MAP2Ks, MKK4 and MKK7. Both MKK4 and MKK7 are required for JNK phosphorylation $(85,86)$. A well-known substrate for JNKs is AP-1.

A third MAPK family member is p38. There are four p38 genes and identically named proteins: p38 $\alpha$ (MAPK14), p38 $\beta$ (MAPK11), p38 $\gamma$ (MAPK12), and $\mathrm{p} 38 \delta$ (MAPK13) (83). The $\mathrm{p} 38 \alpha$ and $\mathrm{p} 38 \beta$ isoforms are ubiquitously expressed, while the other isoforms are distributed with more tissue specificity (82). Most literature refers to $p 38 \alpha$ because it is the most abundant of the two ubiquitous forms. Like the two previously mentioned MAPKs, p38 is activated by a wide variety of PAMPs, DAMPs, pro-inflammatory cytokines, and environmental stressors. Activation of p38 requires phosphorylation at Thr180 and Tyr182 (82).

Given the wide distribution and extensive activating signals of the MAPKs, it is not unexpected that it has been shown that these proteins are critical to the macrophage's response to stimuli. In response to LPS TLR4 ligation, ERK1/2, JNK, and p38 are all activated by both the early MyD88 dependent pathways and late MyD88 independent, TRIF dependent routes (82). LPS triggers the activation of the MAP3K, tumor locus progression 2 (Tpl2 aka Cot3 and MAP3K8). Tpl2 activates MKK1 (MAP2K1) and MKK2 (MAP2K2) (87). This leads to ERK1/2 
activation (87). This pathway has been shown to be crucial and required for LPS induced TNF $\alpha$ and prostaglandin E2 (PGE2) secretion (87-89).

Of the three MAPK family members, p38 has been demonstrated to be the most critical MAPK mediator of LPS provoked gene transcription (90). Illustrating the importance of $\mathrm{p} 38 \alpha$ in the inflammatory phenotype of macrophages, conditional deletion of $\mathrm{p} 38 \alpha$ in macrophages significantly decreased the secretion of pro-inflammatory cytokines, TNF $\alpha, \mathrm{IL}-12$, and IL-18 in response to LPS in vitro, and diminished sepsis in two in vivo animal models (91). This is apparently due to the extreme reduction in activation of CREB and CEB/P when p38 $8^{-1-}$ macrophages are exposed to LPS (91). It is thought the MAPK activated protein kinase 2 (MK2) is the downstream target of p38 that controls CREB activation (92). This pathway is also important for IL-10 and COX2 production (92).

The MAPK family proteins are also implicated in the IFNY signaling pathway. Like LPS, IFNy induces p38, ERK1/2, and JNK $(93,94)$. It was shown that p38 is involved with controlling the level of expression of genes required for the innate immune response, including CCL5, CXCL9, and CXCL10; cytokines such as TNF-a; and inducible NO synthase (iNOS). Alternatively, JNK-1 was shown to affect genes involved in antigen presentation like CIITA and MHC class II molecules (93).

\section{Myeloid Cells and Cancer}


As demonstrated by the intricate integration of multiple signaling pathways, understanding the continuously changing macrophage and other myeloid cells functional phenotype under normal physiological conditions is a complex proposition alone. In a diverse and complicated pathological condition such as cancer, deciphering the function and role of macrophages and myeloid cells presents a unique challenge. The idea of inflammation being connected with the initiation of cancer can be traced back to Virchow's 1863 observation of the "lymphoreticular infiltrate" in cancer and his postulation that cancer may arise at sites of chronic inflammation (95). Conversely, the importance of the immune system in defending against cancer has also been appreciated. Activation of the immune system with "Coley's Toxin," a mixture of attenuated bacterial products, was shown to induce the regression of osteosarcoma (96). Later studies have shown that immunization of mice with irradiated tumor cells prevents the growth of the same viable tumor cells but not different, unrelated, viable tumor cells (97). The evidence supporting the influence of the immune system has on initiation, growth, spread, and eradication of cancer prompted Weinberg et al., to list "avoiding immune destruction" and "tumor promoting inflammation" as emerging hallmarks in his latest update of the highly cited Hallmarks of Cancer: The Next Generation $(98,99)$.

Macrophages and other myeloid-derived cells have been shown to be critical for several aspects of tumor initiation, progression, and metastasis. Several groups have shown that the presence of high numbers of myeloid cells within tumors is associated with a poor prognosis in many cancers (100-103). 
Chemically induced, obesity-driven and virus-mediated cancer models provide clear links between inflammation and cancer initiation. A report showing that the anti-inflammatory protein SOCS3 decreases dextran sodium sulfate (DSS) and azoxymethane (AOM) associated tumorigenesis in the gut highlights the role of inflammation in chemically induced cancers (104). A recent study showed that human adipose tissue macrophages (ATMs) induced lipid accumulation and an inflammatory phenotype in human cancer cell lines (105). Additionally, these ATMs displayed genes associated with cancer related pathways and were genetically similar to TAMs (105). Macrophages were also found to be associated with malignant transformation of the human papilloma virus-infected cervix (106). Once tumors are established, macrophages and other myeloid cells including myeloid-derived suppressor cells (MDSCs) display an immunosuppressive, anti-inflammatory phenotype that assists tumor cells in evading immune detection. MDSCs are a heterogeneous subset of immature myeloid cells that can be grouped as either granulocytic $\left(\mathrm{CD} 11 \mathrm{~b}^{+}, \mathrm{Ly}_{6 \mathrm{G}}{ }^{+}\right)$or monocytic $\left(C D 11 b^{+}\right.$, Ly6C $\left.^{+}\right)(107-109)$. It is reasonable to speculate that these cells are a product of the remarkable plasticity of macrophages and myeloid cells and the ability of macrophages to respond to various environmental factors (2). C-C chemokine receptor $2^{+}\left(C C R 2^{+}\right), C D 11 b^{+}$monocytic MDSCs were shown to aid in tumor immune escape by limiting the infiltration of activated T cells into the tumor (110). One study revealed that TAMs in renal cell carcinoma secrete high amounts of chemokine (C-C) ligand 2 (CCL2) and IL-10 that contribute to 
immunosuppression and perpetuate the recruitment and maintenance of more TAMs (111).

The Pollard et al., was one of the first to definitively show that macrophages were vital for cancer metastatic progression when they demonstrated that mice lacking macrophage colony stimulating factor-1 (CSF-1) did not have changes in tumor incidence or growth, but had delayed development of invasive, metastatic cancers (112). This study highlighted one of the most critical roles macrophages perform over the course of a cancer. The ability of macrophages to promote tumor invasiveness and metastasis through modulating stromal elements and supporting abnormal vascularization and angiogenesis has subsequently been thoroughly researched. Hypoxia within the tumor microenvironment causes TAMs to secrete VEGF that supports immature blood vessel formation leading to vascular leakiness, which promotes cancer metastasis (113). A study identified a subset of TAMs that express the angiopoietin receptor, TIE2 that is critical for macrophage induced angiogenesis (114). Also important for tumor spread is degradation of the surrounding stroma and extracellular matrix. Macrophages have been shown to secrete high amounts of MMPs that can degrade tissue and allow metastasis $(115,116)$.

In addition to tumor infiltrating myeloid cells and macrophages found within the tumor that work to suppress the immune system and aid in tumor escape from the original site, several studies have shown that TAMs away from the primary tumor work to prime distal locations for cancer metastasis. It has 
been demonstrated that macrophages are essential for metastasis and growth of tumor cells at distant sites (112). Additionally, it has been illustrated that macrophages in the lung are key in initial stages of cancer cell seeding and extavasation (117). Qian et al., demonstrated that distal tissue stromal cells and early metastatic cancer cells secrete CCL2 that attracts inflammatory monocytes and macrophages (118). This study showed that these macrophages promote the extravasation and growth of tumor cells at distant sites, in part, via the secretion of VEGF (118). Additionally, it was recently reported that tissue factor mediated coagulation helped recruit macrophages to pre-metastatic niches and this recruitment is necessary for metastatic cancer cell survival (119). It has also been shown that macrophages support tumor cell survival at distal sites by expressing a4-integrin on their surface which binds to cancer cell expressed vascular cell adhesion molecule 1 (VCAM-1) (116). This a4-integrin-VCAM-1 interaction leads to the activation of pro-survival signals in the cancer cells via the phosphoinositide 3-kinase (PI3K)/AKT pathway (116).

The dichotomous role of macrophages and myeloid cells in cancer, with their ability to initiate and promote tumor growth, while suppressing their own capability to thwart cancer progression, provide an opportunity for targeting these cells in anti-cancer therapies.

\section{Myeloid Cells and Immunotherapy}

Current Immunotherapeutic Approaches and Challenges 
In addition to the traditional therapeutic approaches to cancer including chemotherapy, radiation therapy, and surgery, immunotherapy has reemerged as a viable component of a successful cancer treatment plan. The recent FDA approval of Sipuleucel-T (Provenge), an autologous immunotherapeutic, illustrates the potential impact of thoughtful and effective immunotherapeutic agents $(120,121)$. Sipuleucel-T treatment requires that a patient's peripheral mononucluear blood cells (PMBC) be removed and exposed to a fusion protein consisting of prostatic acid phosphatase (PAP) and the cytokine, GM-CSF (120, 121). This treatment results in both clinical and statistical improvement of prostate cancer patient outcomes $(120,121)$. Another instance in which the effectiveness of immunotherapy is evident is in the use of Ipilimumab (Yervoy), a human monoclonal antibody that antagonizes a negative regulator of cytotoxic $\mathrm{T}$ cells, cytotoxic T-lymphocyte antigen 4 (CTLA-4), to render cytotoxic T cells more active against melanoma $(122,123)$.

It is generally accepted that a major difficulty in cancer immunotherapy is the robust immunosuppressive environment established in part by myeloid cells. An approach to alleviating this profound immunosuppression is the exploitation of the functional plasticity of myeloid cells. As demonstrated by earlier cited literature, macrophages and other myeloid cells have the remarkable ability to respond to environmental signals including the tumor microenvironment. The strategy of altering the phenotype of macrophages from a tumor and metastasissupportive, immunosuppressive phenotype to an anti-tumorigenic, proinflammatory phenotype would provide an avenue to activate the immune system 
to eradicate cancers. One such agent that has been shown to have anti-tumor effects and changes the functional profile of macrophages is the cytokine IL-12.

The Biology of IL-12

Michiko Kobayashi and Giorgio Trinchieri first described IL-12 in 1989 as NK cell stimulatory factor (NKSF) (124). IL-12 is a heterodimeric cytokine composed of two disulfide-linked subunits, p35 and p40 that together form the p70 unit $(125,126)$. The p35 subunit shares homology with other cytokines such as granulocyte colony stimulating factor (G-CSF) and IL-6, while the p40 heavy chain is shared with IL-23 and is a member of the hemapoietin receptor family along with ciliary neurotrophic factor (CNTF) and the IL-6 receptor (127). IL$12 p 40$ can be secreted as a monomer or a homodimer and is thought to have antagonistic activity, while IL-12p35 is not found in a monomeric form (128). The genes for the IL-12 subunits are located on separate chromosomes. In humans p35 is on chromosome 3 and p40 is on chromosome 5 , while in mice p35 and p40 are on chromosomes 6 and 11, respectively (125). IL-12 is secreted by a variety of immune cells including monocytes and macrophages, neutrophils, dendritic cells, and B cells (129). IL-12 can initiate pro-inflammatory functions in NK cells, T cells, and myeloid cells, making it an attractive, multivalent agent to reverse the strongly immunosuppressive tumor microenvironment (129). IL-12 is a strong inducer of IFNy from T cells, NK cells, and myeloid cells; it also induces immune cell proliferation, and enhances cell-mediated toxicity (129). 
The $I L-12 p 40$ gene is regulated at the transcriptional level (130). The $p 40$ gene can be induced by a variety of microbial products. The p40 promoter has been shown to have binding sites for several transcription factors including NF$\mathrm{KB}$, IRF-1, c-Rel, interferon consensus binding protein, and Ets family members (130-134). Deletion of the cis-elements at the Ets or NF-KB binding site restricts p40 promoter activity (135). Conversely to p40, p35 is ubiquitously expressed and controlled both transcriptionally and translationally (136). Although there is constitutive synthesis of the p35 message in unstimulated cells, scant protein is actually produced due to an inhibitory ATG sequence at the $5^{\prime}$ untranslated region (136). When a stimulus is applied to cells, the transcriptional start site is altered, and the inhibitory region is not included in the message (136).

Many DAMPs and PAMPs can prompt IL-12 production. They include LPS, Lipoteichoic acid (LTA), peptidoglycan, and bacterial (CpG) DNA, and they work independent of T cells $(137,138)$. IL-12 is also made in response to antigen presenting cell CD40 ligation by CD40L on T cells (139). A positive feedback loop is established when IL-12 induced IFNy triggers more IL-12 production in a macrophage cell line $(131,140)$. Alternatively, IL-12 synthesis is attenuated by IL-10, IL-11, IL-13, and type I IFNs (141-143). It has also been demonstrated in macrophages that stimulation of G-coupled protein receptors (GCPRs) including the receptors for MCP-1, prostaglandin E2, histamine, and Fc receptor activation can inhibit IL-12 production (144-147). Interestingly, cholera toxin, an activator of a GPCR subunit, and the measles virus via CD46 inhibit IL-12 production (148151). 
IL-12 binds to it receptor, IL-12 receptor (IL-12R)(152). The IL-12R consists of 2 chains, $\beta 1$ and $\beta 2$ (152). They are members of the type I cytokine receptor family with close homology to IL-6 receptor component, gp130 (127). The human $I L-12 \beta 1$ and $I L-12 \beta 2$ genes are found on chromosomes 19 and 1 in humans and on chromosomes 8 and 6 in mice, respectively. The IL-12 receptor is expressed on NK cells, T cells, dendritic cells, and macrophages. Coexpression of both chains confers optimal responsiveness to IL-12 although the $\beta 2$-subunit is often used to predict IL-12 activity due to the presence of three cytoplasmic tyrosine residues on the $\beta 2$-chain $(127,153)$.

The IL-12 signal is transmitted from the IL-12R via the JAK-STAT pathway (127). The $\beta 1$-receptor chain interacts with JAK2 while the $\beta 2$-receptor subunit associates with the tyrosine kinase, TYK2 $(154,155)$. The previously mentioned tyrosine residues on the $\beta 2$-receptor are phosphorylated upon IL-12 ligation, which allows for the recruitment, phosphorylation, and activation of STAT4. Although it has also been reported that STAT1 and STAT3 are activated by IL12 , STAT4 is thought to be the major component of the IL-12 signaling pathway as STAT4 deficient mice display an identical phenotype to IL-12p40 deficient mice $(156,157)$. STAT4 binds to both the human and murine Ifng gene (157159). IL-12 stimulation also results in the phosphorylation of Src family tyrosine kinase, Lck and the MAPK, p38 (160-162). Activation of p38 by IL-12 appears to be important for IFNy production and Th1 differentiation (162). STAT4 has been shown to be negatively regulated by the ubiquitin E3 ligase, SLIM (163). 
Much of IL-12's physiological influence has been attributed to its activation of adaptive components of the immune system and NK cells and its elicitation of IFNy. IL-12 can directly induce the proliferation of pre-activated T and NK cells and augment the proliferation of resting and naïve cells caused by several mitogenic agents $(153,164)$. IL-12 can also enhance the generation of cytotoxic T lymphocytes (CTL), NK and lymphokine activated (LAK) cells by eliciting the transcription of genes such as those for granzymes, peforin, and adhesion molecules that render these cells more cytotoxic (164). One of the essential roles of IL-12 is the induction of IFNy secretion by T cells, B cells, and NK cells (153, 165). IL-12 alone, or in synergy with IL-18, a member of the IL-1 cytokine family can cause IFNy secretion (166-168). The IL-12-IFNy axis in conjunction with signaling through the $\mathrm{T}$ cell receptor (TCR) and other receptors is crucial for Th1 differentiation (153).

\section{IL-12 and Myeloid Cells}

More attention has been placed on how IL-12 may be involved with other immune cells including myeloid cells. Most of this work has focused on the autocrine effects of IFNy from IL-12 stimulated macrophages. Macrophages have been shown to produce nitric oxide and upregulate surface molecules associated with antigen presentation in response to IL-12 (169). Both of these effects are dependent on IFNY as this phenotype is erased in IFNY-/- mice $(165,170)$. Additionally, IL-12 has been demonstrated to prime macrophages to produce copious amounts of NO in response to LPS and IFNy (171). Some work also 
suggests that IL-12 may regulate TGF- $\beta 1$ production since macrophages from mice deficient in p40 chain of IL-12 secrete high amounts of TGF- $\beta 1$ (172).

\section{IL-12 as a Cancer Immunotherapeutic}

Because IL-12 can activate both the innate and adaptive arms of the immune system, much effort has been used to investigate its effectiveness as an anti-tumor agent and therapeutic vaccine adjuvant. Initial studies in several animal models of cancer yielded promising results regarding IL-12 alone or in combination with other cytokines as an immunotherapeutic drug and vaccine adjuvant. IL-12 has been shown to be very effective in eradicating tumors in mouse models of breast cancer, melanoma, thymoma, renal cell carcinoma, colon cancer, and lung cancer (173-178). However, early clinical trials with IL-12 were unsuccessful, largely due to the profound cytotoxicity associated with systemic administration of IL-12 (179). Researchers continue to work to find safe alternatives for administering IL-12 in humans. There are currently several active clinical trials involving IL-12 and various cancers. These phase I and phase II clinical trials include IL-12 in combination with a dendritic cell breast cancer fusion vaccine (NCT00622401), the heavy chain of the antibody of NHS576 which targets double-stranded and single-stranded DNA that are exposed in areas of necrosis (NCT01417546), a plasmid DNA vaccine for Merkel cell cancer (NCT0144081816), the monoclonal antibodies cetuximab and daclizumab (NCT01468896 and NCT01307618), and T cells engineered to secrete IL-12 in metastatic melanoma (NCT012365718) (clinicaltrials.gov). Most of IL-12's in vivo 
anti-tumor effect has been attributed to $\mathrm{CD} 8+$ and $\mathrm{CD} 4+\mathrm{T}$ cells, as well as $\mathrm{NK}$ cells. It has also been reported that IL-12 can activate NKp46+ lymphoid tissueinducer cells (LTi cells) to induce tumor rejection (177). Recently the impact of IL12 on TAMs has been studied. Our lab showed that IL-12 modified the functional phenotype of TAMs in vivo and in vitro and that TAMs released cytoplasmic IL-15 in response to IL-12 in vivo, and that this event was critical for the initiation of IL12's anti-tumor activity $(173,180)$. It was more recently shown that IL-12 enhances the ability of myeloid cells within tumors to improve the activation and cytotoxicity of CD8+ T cells (175). 


\section{Rationale, Significance, and Hypothesis}

Our attention to the relationship between IL-12 and tumor associated macrophages an myeloid cells is well-founded given the accumulating evidence showing myeloid cells as remarkably plastic, the significant influence these cells have on cancer growth, metastasis, and immunosuppression, and the use of IL12 as an anti-cancer therapy. Understanding the impact of IL-12 on TIMs and TAMs is an important component in deciphering the mechanisms related to IL-12 immunotherapeutic effects.

Recent work has identified TIMs and TAMs as direct targets of IL-12 (175). What is not completely clear is how IL-12 affects the function of macrophages especially independent of IFNy. We hypothesize that IL-12 augments the ability of TIMs and TAMs to respond to inflammatory stimuli providing a window in which these stimuli are more likely to promote tumor destruction. Related to this hypothesis we wanted to investigate whether IL-12 changes signaling events associated with inflammatory signal transduction and determine if IFNy required for all of the IL-12 induced changes in the response of TIMs and TAMs to inflammatory stimuli.

Herein, we use the highly aggressive and metastatic 4T1 mammary carcinoma murine model to look at the impact of IL-12 on the growth 4T1 tumors as well as isolate myeloid cells and study their in vitro response to LPS stimulation as well as tumor derived factors after exposure to exogenous, recombinant IL-12. We also examined the impact of pre-incubation of TIMs with IL-12 followed by LPS treatment on MAPK pathway signaling. Finally, we sought 
to determine if IFNy was compulsory for the increased inflammatory profile and increased MAPK phosphorylation in TIMs exposed to IL-12 followed by LPS.

This work provides insight into role of IL-12 in the context of IFNy and the MAPK pathway, both of which have broad influence in immunology and cancer. This study offers a corollary to the classically identified mechanisms of IL-12 in innate immunity and cancer immunotherapy.

*Note: In this dissertation, TIMs refers to tumor infiltrating myeloid cells and TAMs refers to tumor associated myeloid cells. Previous works refer to TIMs and TAMs as tumor infiltrating macrophages and tumor associated macrophages. We designated TIMs as being directly from within the tumor while TAMs are from distal sites of a tumor bearing mice. Some studies do not make this distinction and use TAMs designation for any macrophage or myeloid cell from within the tumor as well as other tissue sites in a tumor bearing animal. We use the designation of myeloid cells because portions of the pooled CD11b+cells used in experiments displayed markers for macrophages (F4/80+) or MDSCs (Gr1+). 


\section{CHAPTER II}

\section{IL.12 REDUCES THE IN VIVO GROWTH OF THE 4T1 MAMMARY CARCINOMA}

\section{Introduction}

Breast cancer is the most common cancer diagnosis and the second most common cause of cancer deaths among women in the United States (181). The incidence of breast cancer rose from 1973-1990, but then began to decline, while mortality from breast cancer remained steady until recently as annual decreases in mortality have been observed (181). In spite of these statistics, it is well known that breast cancer prognosis is bleak and mortality increases when metastases are present, an indication of late-stage disease (182). The 5-year survival rate for stage IV breast cancer is only $15 \%$ (182). The poor clinical outcomes that accompany late-stage breast cancer provide an impetus to identify new and effective treatment strategies, especially ones that focus on disrupting immunosuppression and inhibiting metastatic processes associated with breast cancer.

In this chapter, we observed the growth of the 4T1 mammary carcinoma in syngeneic BALB/C mice and measured the impact of IL-12 microspheres on tumor progression. Fred Miller and colleagues first isolated the spontaneously 
occurring mouse 4T1 mammary carcinoma (183). It reliably metastasizes to lung, liver, and brains when implanted (183).

As previously stated, initial cancer clinical trials in human using IL-12 were unsuccessful due in large part to systemic cytotoxicity and short half-life of free cytokine (184). In our in vivo experiments, we use recombinant IL-12 encapsulated in polylactic acid to facilitate slow, sustained release of IL-12, and to circumvent IL-12-associated cytotoxcity.

Prior studies in our laboratory have demonstrated that IL-12 has a profound impact on tumor associated macrophages in the Lewis lung carcinoma (LLC) mouse model (180). Therefore we sought to expand our understanding of IL-12's impact on TIMs and TAMs in a breast cancer cell line. Because the 4T1 cell line is a syngeneic mice model with consistent metastasis, it is a good system to monitor the role of macrophages in both early stages of tumor initiation as well later metastatic events. Additionally, this model is an excellent platform to study agents such as IL-12 that modulate the immune system with regards to the tumor microenvironment.

There is current interest in developing therapeutic cancer vaccine as opposed to prophylactic vaccine such as those associated with preventing human papilloma virus (HPV), which subsequently prevents cervical carcinoma. One approach to developing therapeutic vaccines is the fusion of dendritic cells and tumor cells. Dendritic cells are innate immune cells that are the primary antigen-presenting cells (APCs) within the immune system. Fusion of dendritc cells and tumor cells allows for combination of antigen presentation machinery, 
such as CD80, CD86, and MHC molecules, and tumor-associated, and tumorspecific antigen (185). This fusion optimizes tumor antigen presentation through both the class I and II MHC pathways to generate potent immune responses from adaptive immune cells, such as $\mathrm{CD}^{+}$and $\mathrm{CD}^{+} \mathrm{T}$ cells (185). Clinical trials using patient bone marrow-derived dendritic cells and autologous cancer cells have been successful in treating cancers (186-188). This aim looks to confirm the anti-tumor effects of IL-12 in the $4 \mathrm{~T} 1$ breast cancer model, as well begin to understand if and how IL-12 may impact the efficacy of a dendritic cell fusion vaccine.

\section{Methods and Materials}

\section{Mice and cell lines}

Seven to eight week old female BALB/c mice were obtained from Jackson Laboratories. All animal care was in compliance with relevant protocols, guidelines, and regulations approved by the University of Louisville Institutional Animal Care and Use Committee. 4T1 cells were obtained from ATCC. Tumor cells were maintained through in vivo passage with limited intermittent in vitro culture.

\section{In vivo tumor injections}

BALB/c mice were injected subcutaneously near the left, rear mammary fat pad with $2 \times 10^{4} 4 \mathrm{~T} 1$ cells. Tumors were measured at 3 -day intervals with calipers at two bisecting diameters. An approximate volume was calculated using 
the formula $\left(\text { Length }{ }^{*} \text { Width }^{2}\right)^{*} 6 / \pi$. Tumor weights were also measured upon harvest.

\section{IL-12 treatment}

Microspheres containing 250ng/mg of IL-12 or empty control microspheres were prepared by phase inversion nanoencapsulation and were supplied by $\mathrm{Dr}$. Nejat Egilmez (University of Louisville School of Medicine). Microspheres were resuspended at $2 \mathrm{mg} / 100 \mu \mathrm{L}$ in sterile phosphate buffered saline (PBS). At the indicated time point, mice received one intratumoral injection of $4 \mathrm{mg}$ of IL-12 or control microspheres.

\section{Lung harvest and staining}

The lungs of $4 \mathrm{~T} 1$-bearing BALB/c mice were perfused with $30 \mathrm{~mL}$ of Dulbecco's PBS (Cellgro) supplemented with $2 \%$ fetal bovine serum (FBS) (Atlanta Biologicals) using a $30 \mathrm{~mL}$ syringe and a $20 \mathrm{G} 1 / 2$ needle. Lungs were placed in Omnisette tissue cassettes (Fisher Scientific), and the cassettes were submerged in $10 \%$ formalin solution, neutral buffered (Sigma) for 24 hours. Lung containing cassettes were then added to $70 \%$ ethanol for further processing. Lungs were paraffin-embedded and sections were stained with Hematoxylin Eosin (Embedding and staining performed by the University of Louisville Special Procedures Laboratory). 


\section{Bone marrow derived dendritic cells (BMDCs) cell generation}

The femurs and tibias of BALB/c mice were flushed with DPBS $+2 \% \mathrm{FBS}$ using a $1 \mathrm{~mL}$ syringe and $26 \mathrm{Ga}$ needle. Cells were passed through a nylon filter (Bellco), and red blood cells were lysed using Gey's solution. Cell were plated in 100mm dishes in RPMI 1640 (Hyclone) containing, 5\% FBS, 1M HEPES (Sigma), $10 \mathrm{mg} / \mathrm{mL}$ Gentamicin sulfate (Sigma), 20ng/mL GM-CSF (R\&D Systems), and 1:100 Glutamax (Invitrogen) for 7 days at $37^{\circ} \mathrm{C}$. Media was refreshed at days 2 and 5.

\section{T1 and BMDCs fusion and selection}

4T1 tumor cells and BMDCs were mixed at a ratio of 1:5 in FBS-free RPMI 1640 containing $1 \mathrm{M}$ HEPES and $10 \mathrm{mg} / \mathrm{mL}$ Gentamicin sulfate and polyethylene glycol (PEG) (Sigma Hybrimax) at $37^{\circ} \mathrm{C}$. CD11c positive cells were selected using EasySep mouse CD11c+ selection kit and magnet (StemCell Technologies). Cells were plated for 1 week and loosely adherent fused cells collected for further use.

\section{Flow cytometry}

Cells were stained with $1 \mathrm{ug} / 10^{6}$ cells anti-CD32/CD16 Fc block (BD Pharmingen). Cells were then stained with $0.2 \mathrm{ug} / \mathrm{uL}$ anti-CD326 APC (eBioscience), rat anti-IgG PE (BD Pharmigen) and rat anti-lgG2a APC 
(eBioscience). Acquisitions were performed using FACScaliber (BD Biosciences) and analysis was done using Flowjo (Tree Star).

\section{Statistics}

Significant differences between groups were determined using 2-tailed student's T test.

\section{$\underline{\text { Results }}$}

In vivo administration of IL-12 microspheres diminishes 4T1 growth and lung metastasis

We aimed to validate that microspheres loaded with recombinant IL-12 reduced in vivo tumor growth and metastasis in the $4 \mathrm{~T} 1$ model of breast cancer. Our results demonstrate that a single intratumoral injection of IL-12 microspheres precipitated significant decreases in tumor growth. Injection of IL-12 microspheres at day 12 resulted in a significant decrease in tumor weights (Figure 1). The growth curve of tumors injected with IL-12 microspheres at day 5 was significantly altered with IL-12 treated tumors showing a decreased rate of expansion (Figure 2). We were also interested in validating the impact of IL-12 on 4T1 tumor metastasis. We observed that injection of IL-12 microspheres at day 9 had a substantial effect on tumor metastasis as lungs from 4T1-bearing animals had diminished metastasis when compared to controls (Figure 3). 


\section{Polyethylene glycol facilitates 4T1 and dendritic cell fusion}

Additionally, we sought to fuse $4 \mathrm{~T} 1$ cell and dendritic cells to investigate how IL-12 affects the efficacy of a fusion vaccine. Our long-term interests include investigating whether IL-12 induced changes in the macrophages contribute to enhancing the efficacy of a tumor dendritic cell vaccine. Initial attempts at $4 \mathrm{~T} 1$ and dendritic cells fusion using polyethylene glycol (PEG) were successful. We were able to facilitate approximately $27 \%$ fusion of $\mathrm{CD}_{11} \mathrm{c}^{+}$dendritic cells with 4T1 cells as indicated by cells double positive for the epithelial marker, CD326 and CD11c (Figure 4).

\section{Discussion}

Results in this aim demonstrate that in vivo treatment with IL-12 reduces both 4T1 growth and metastasis. Also, our data illustrates that exposing 4T1 and dendritic cells to PEG is a reasonable method to facilitate adequate fusion of these cells for eventual use as a tumor vaccine in mice. One of the drawbacks of IL-12 cytokine therapy is its transient effect when used as a singular treatment $(189,190)$. Subsequent studies to understand the mechanisms by which IL-12 exerts it effects on TIMs and TAMs will assist in prolonging and exploiting the positive effects of IL-12. It is important that the window of decreased immunosuppression initiated by $\mathrm{IL}-12$ be used to introduce anti-cancer treatments such as therapeutic vaccines.

TIMS and TAMs are clear mediators of the profound immunosuppression

within the tumor microenvironment. Studies directly linking role of TIMS and TAMs in cancer immunosuppression and obstacles to effective cancer 
therapeutic vaccination are important to expanding the number effective immunotherapeutic options available. Studies have shown that depletion of TIMs and TAMs improved the effects of chemotherapeutic agents (191-193), but little data exist directly showing that changing the functional profile of myeloid cells within the tumor microenvironment is sufficient and/or necessary to positively impact the efficacy of chemotherapeutic agents or therapeutic vaccines. Work in this aim is a precursor for future studies that will investigate the potential roles of TIMs, TAMs, and IL-12 in establishing long-term cancer remission in response to therapeutic vaccination. Our future goals include ascertaining the in vivo duration of the change in myeloid cell function after exposure to IL-12. We would also like to examine whether IL-12 prompted myeloid cell conversion to a proinflammatory, anti-tumorigenic phenotype will improve the efficacy of a dendritic cell-based vaccine. 
Figure 1

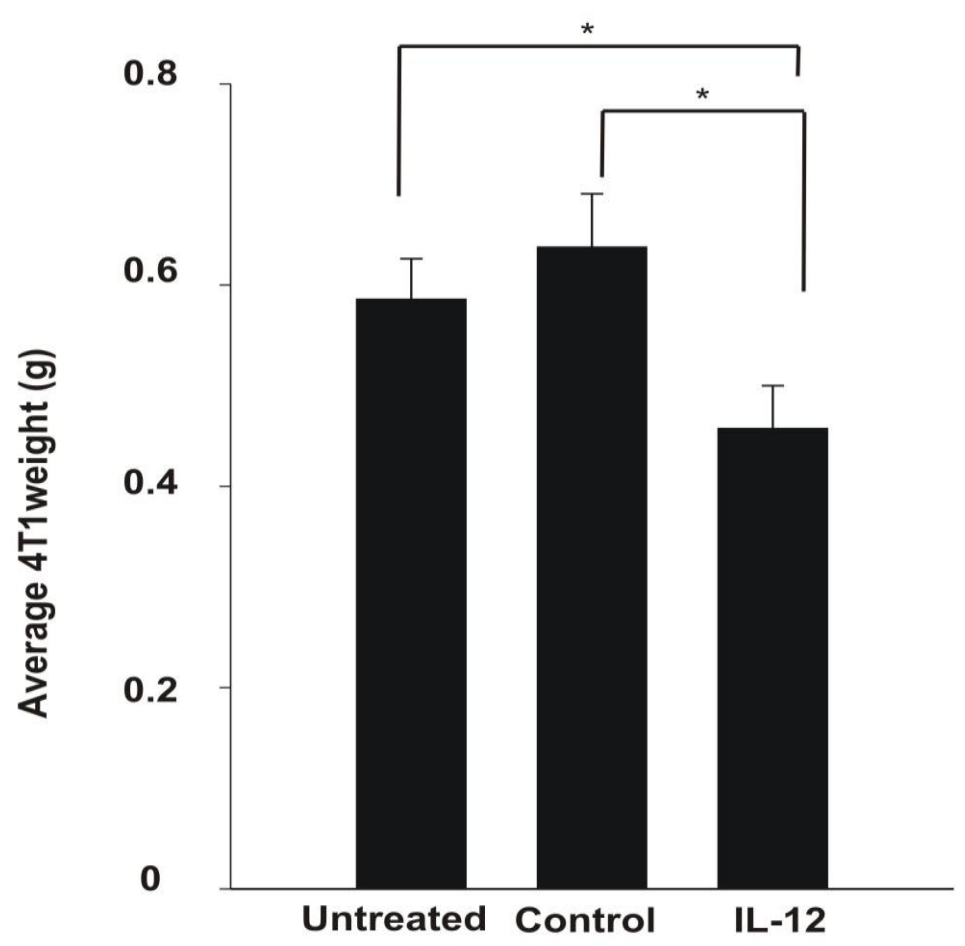

Figure 1. In vivo IL-12 administration decreases $4 \mathrm{~T} 1$ tumor weights. BALB/C mice were challenged with $2 \times 10^{4} 4 \mathrm{~T} 1$ cells. At day 12 , mice were treated intratumorally with $4 \mathrm{mg}$ of control microspheres or microspheres containing $1000 \mathrm{ng}$ of $r m \mathrm{~L}-12$. At day 26 , tumors were resected and weighed. The average tumor weights were determined. $n=7$ for untreated group, $n=8$ for control group, $\mathrm{n}=7$ for IL-12 group. ${ }^{*} \mathrm{p}<0.05$ for untreated $v s$. IL-12 and control vs. IL-12. Error bars $=S E M$ 
Figure 2

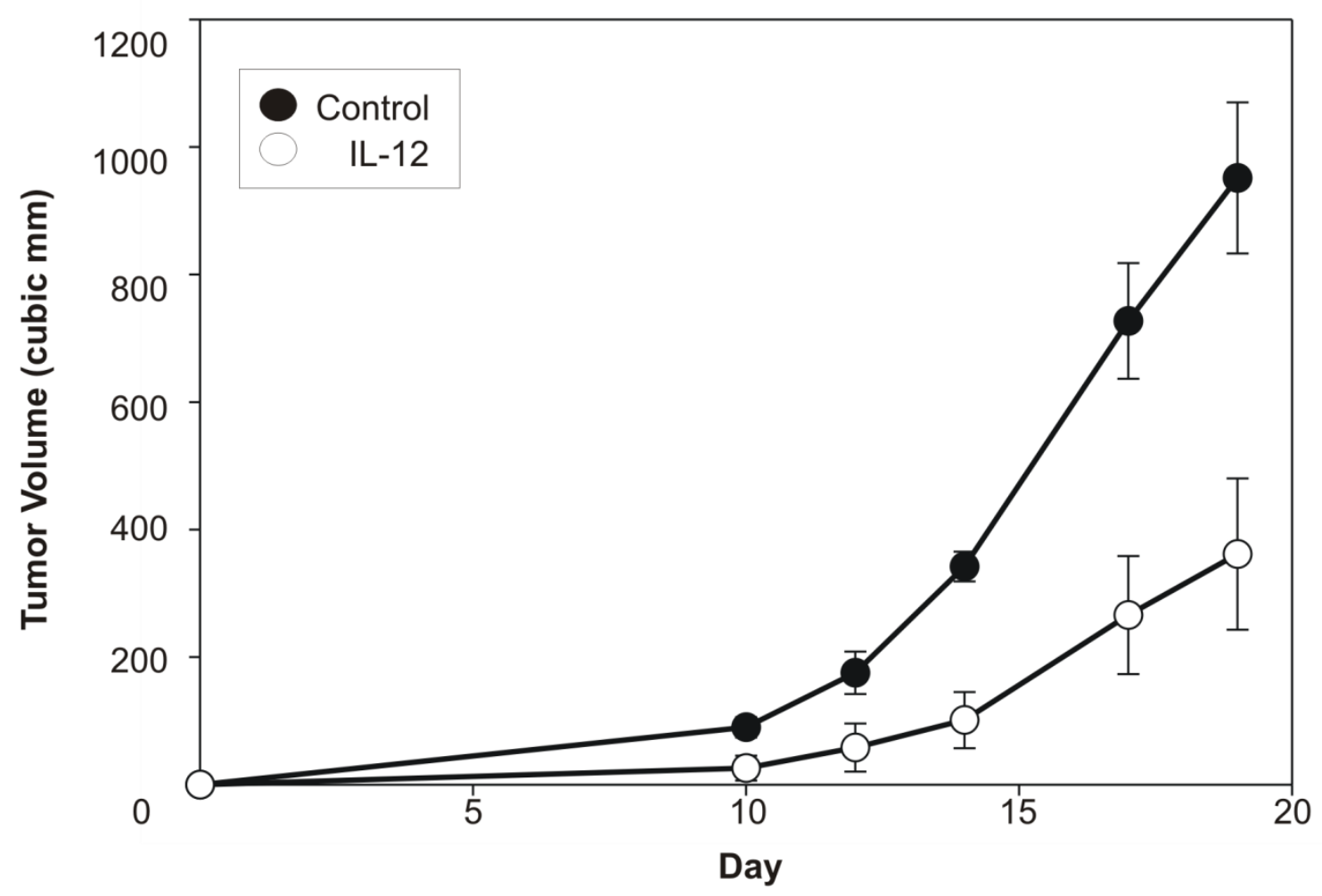

Figure 2. In vivo IL-12 administration decreases the rate of 4T1 tumor growth. BALB/c mice were challenged with $2 \times 10^{4} 4 \mathrm{~T} 1$ cells. At day 5 , mice were treated intratumorally with $4 \mathrm{mg}$ of microspheres containing $1000 \mathrm{ng}$ of $r \mathrm{~mL}-12$ or 1000ng of blank microspheres as a control group. At set intervals, tumors were measured manually with calipers. Tumor volume was determined using the formula $\left(L^{*} W^{2}\right)^{*} 6 / \pi$. Average tumor volume was calculated for each day. $n=5$ for control and IL-12 groups. $p$ value $<0.05$ for difference between groups at day 14 , 17, and 19. Error bars $=S E M$ 
Figure 3

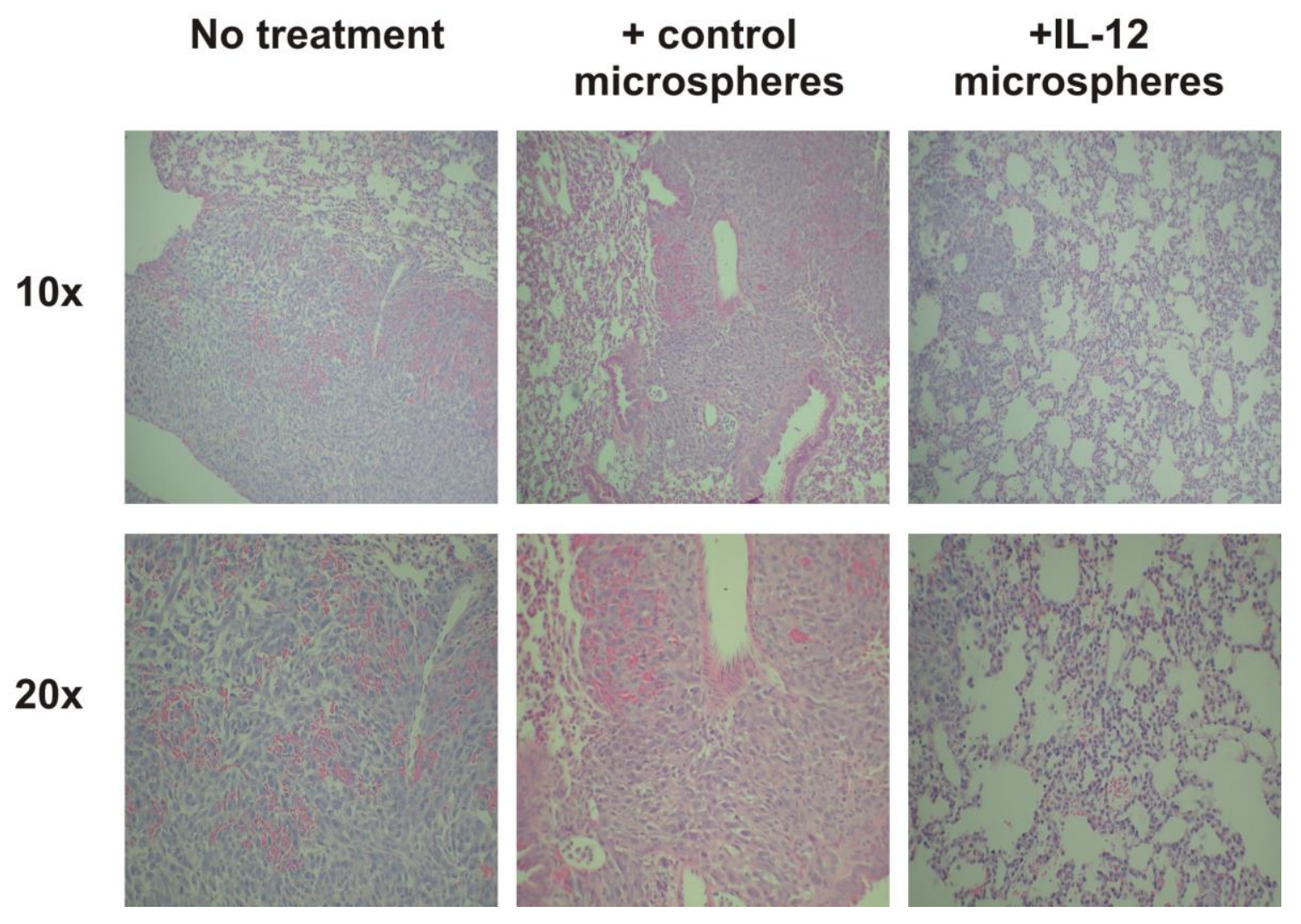

Figure 3. In vivo IL-12 administration decreases 4T1 tumor metastasis. BALB/c mice were challenged with $2 \times 10^{4} 4 \mathrm{~T} 1$ cells. At day 9 , mice were treated intratumorally with $4 \mathrm{mg}$ control microspheres or microspheres containing $1000 \mathrm{mg}$ of $r \mathrm{mLL}-12$ or left untreated as a control group. Lungs were harvested at day 26. H\&E staining was performed and lung metastasis visually observed. Results are representative images of 5 lungs per treatment group. 
Figure 4

A

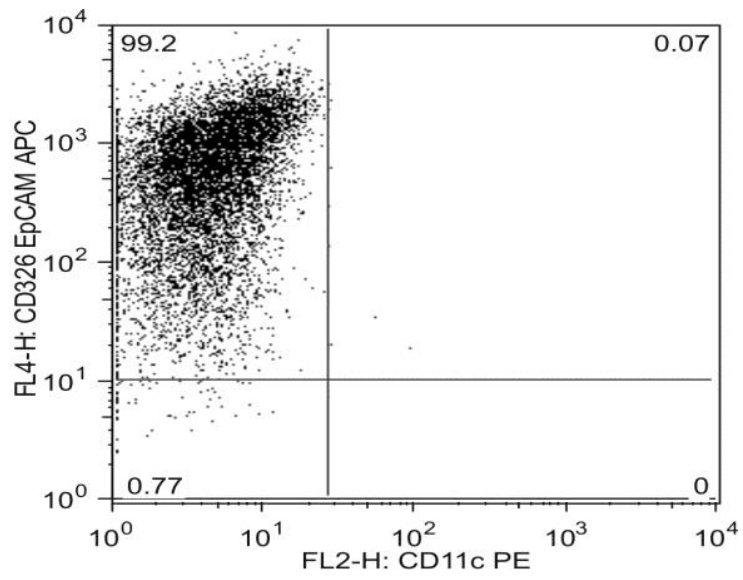

B

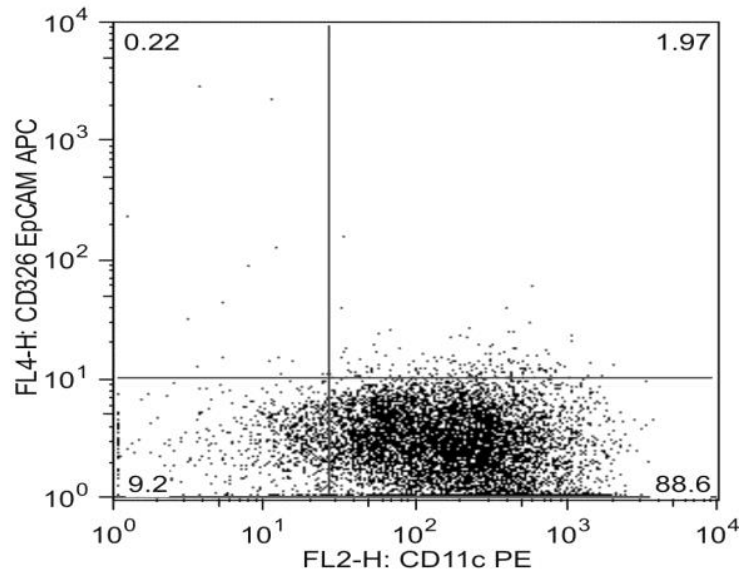

C

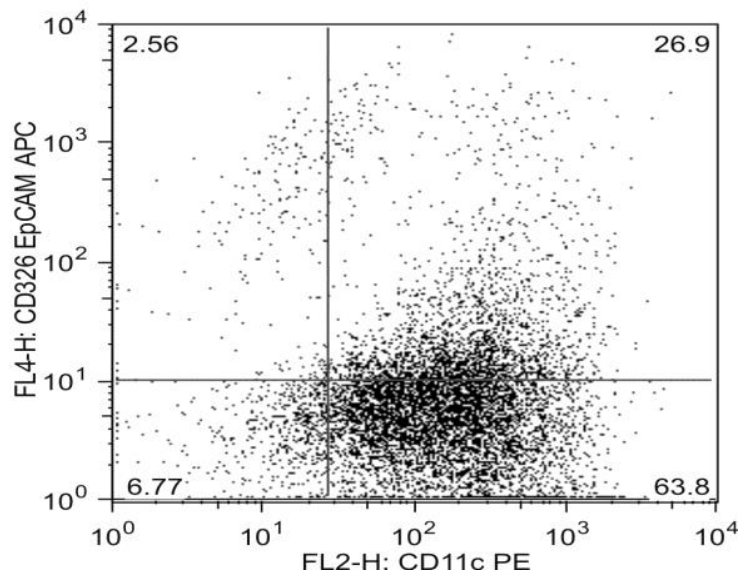

Figure 4. Polyethylene glycol (PEG) facilitates fusion of $4 \mathrm{~T} 1$ tumor cells and bone marrowderived dendritic cells. Bone marrow derived dendritic cells were fused with $4 \mathrm{~T} 1$ tumor cells at a ratio of 1:5 (4T1:DC) using 50\% PEG. Fused CD11c+ cells were positively selected. A.) Epithelial cell marker, CD326, but not dendritic cell marker, CD11c, is expressed on $4 \mathrm{~T} 1$ cells. B.) CD11c, but not CD326 is expressed on dendritic cells. C.) CD11c+/CD326+ cells after fusion (upper right quadrant). Data is representative of 2 independent experiments. 
CHAPTER III

\section{IL.12 MODIFIES RESPONSE OF TUMOR ASSOCIATED AND TUMOR INFILTRATING MYELOID CELLS TO LPS VIA IFNY INDEPENDENT AND DEPENDENT MECHANISMS}

\section{Introduction}

The functional profile of macrophages and myeloid cells within tumors is an important determinant of the immune system's ability to defend against the growth and spread of the tumor. A plethora of research has shown that macrophages play a multi-faceted role in the initiation and progression of cancers. Research has expanded our understanding of the link between inflammation and cancer. This new knowledge has evolved into a model that describes cancer-related inflammation through the intrinsic or extrinsic pathways $(5,194)$. The intrinsic pathway refers to changes in oncogenes and tumor suppressor genes that contribute to initiation of inflammation (195). Alterations in genes such as RET, RAS, and MYC lead to the elaboration of pro-inflammatory cytokines and growth factors (5). These cytokines and growth factors activate immune cells including macrophages within the vicinity, which perpetuates the inflammatory state and can eventually lead to tumor formation (5). Conversely, the extrinsic pathway describes external factors such as chronic infection or chemical and environmental exposures that promote inflammation (195). Chronic 
infection increasing the risk for cervical cancer (194) or ultraviolet radiation associated inflammation ultimately progressing to skin cancer are examples of the extrinsic pathway of cancer related inflammation. The intrinsic and extrinsic pathways both lead to the activation of transcription factors such as NF-KB and STAT3 $(194,195)$ Macrophages and myeloid cells are critical in these formative steps in cancer related inflammation. Macrophages within this inflammatory milieu produce TNF $\alpha$, IL-6, COX2, reactive nitrogen and oxygen species that have been shown to promote cancer formation in a number of ways. Reactive nitrogen and oxygen species promote cancer formation by inducing mutagenesis and genetic instability by disrupting the activity of p53 and enhancing the activity of DNA methytransferases, which leads to errant transcription $(196,197)$. IL-6 and TNF $\alpha$ promote carcinogenesis by stimulating angiogenesis and cell proliferation (198).

Inflammation is tightly control process that integrates various signals that initially promote, but eventually down-regulate inflammatory mediators. In cancerrelated inflammation, homeostatic controls are still present although they are likely deranged. Changes in the functional phenotype of the macrophage and myeloid derived cells are integral in the shift towards immunosuppression in the tumor microenvironment (199). After chronic inflammation has persisted and cancer has been established, signaling pathways in macrophages and myeloid cells are activated that aid in thwarting the activities of immunocompetent cells which allows for tumor cell evasion and escape. A recent report showed that the non-canonical Wnt protein, Wnt5a induces a tolerogenic phenotype in TAMs 
through a negative feedback loop with NF-KB (200). This study also reported that Wnt5a leads to the accumulation of immunosuppressive macrophages in breast cancer patients (200). Others have shown that perturbations in NF-KB signaling such as the formation of non-canonical p50 homodimers may be pivotal in the macrophages immunosuppressive phenotype specifically via increased IL-10 secretion $(201,202)$.

It has been shown that TIMs from a mouse sarcoma produced significantly less pro-inflammatory IL-6, TNF $\alpha$, and IL-1 $\beta$ and more anti-inflammatory cytokines IL-10 and TGF $\beta$ and IFN-inducible chemokines MCP1, CCL5, CXCL9, CXCL10, and CXCL16 than thioglycollate-elicited peritoneal macrophages in response to LPS (203). This observation is attributed to defective MyD88 activation of NF-KB, but intact stimulation of the MyD88-independent IRF3 and STAT1 signaling pathway in TAMs and TIMS (203). More recent studies suggest that TLR4 stimulation of TAMs results in enhanced ERK1/2 phoshorylation that induces IRAK-M expression, a known inhibitor of MyD88 (204).

The association between the presence of large tumor infiltrates of macrophages and myeloid cells and poor patient prognosis for several different cancers is widely recognized $(100-102,205)$. This observation initially prompted research that looked to eradicate macrophages and myeloid cells within the tumor environment to improve outcomes in cancer patients (191) (206). Additionally, reports showed that macrophages within the tumor microenvironment displayed the "M2" phenotype that is immunosuppressive and tumor supportive $(199,207)$. This information further promoted the view that 
macrophage eradication was a plausible approach to alter the microenvironment and positively impact patient outcomes. Clodronate, a bisphosphonate initially used to decrease hypercalcemia in multiple myeloma patients, was adapted for use to systemically eliminate myeloid cells and macrophages. Although this approach yields reduced cancer immunosuppression, the use of clodronate is limited by its systemic toxicity (207). This approach also fails to appreciate the plastic nature of macrophages and myeloid cells and their pro-inflammatory potential. So rather than removing macrophages from the tumor microenvironment completely, efforts to understand how to exploit the manipulability of macrophages may be more suitable to cancer immunotherapeutic endeavors (4).

Our lab is interested in the impact of IL-12 on macrophages and myeloid cells within the tumor microenvironment. We propose that IL-12 facilitates the opening of an pro-immunological window in TIMS and TAMs which deems them more permissive to subsequent inflammatory stimuli. We have previously demonstrated that polarized TAMs and TIMs can be converted from immunosuppressive and tumor-supportive to pro-inflammatory and immunogenic in vivo and in vitro which may contribute to tumor eradication after exposure to IL-12 (180). In addition, work in this laboratory showed that in vivo introduction of IL-12 in tumor-bearing mice leads to rapid release of IL-15 for TIMs which is critical for cancer regression and is not dependent on the presence of NK cells (173). Others revealed that IL-12 enhances the ability of myeloid cells within the tumors to activate CD8+ T cell cytotoxicity (175). These reports demonstrate IL- 
12 as a modulator of the functional phenotype of macrophages and myeloid cells in the tumor microenvironment.

The relationship between IL-12 and IFNY is well established as previously discussed in the first chapter of this dissertation. IL-12 induction of IFNy from NK cells, macrophages, and T cells is pivotal to adaptive immune responses (208). Studies have shown that IFNY is very important in IL-12 induced changes in macrophages and IL-12's overall anti-tumorigenic effects $(175,209)$. For example a study showed that IL-12 induced IFNy caused cell cycle arrest T-regulatory cells and enhanced tumor clearance (210). Less research has focused on any IFNy independent IL-12 effects on macrophages and myeloid cells in the tumor microenvironment. In a series of experiments, Kerkar et al., showed that although IFNy was required for IL-12 induced tumor regression, the host's endogenous cells (immune cells included) ability to respond to IFNy was only partially required (175). This report showed that when wild-type (WT) and IFNY-/- CD8+ T cells transduced with melanoma antigen, pmel TCR, and IL-12 were adoptively transferred into WT mice bearing B16 melanoma tumors, both the WT and IFNY-/-p-mel/IL-12 T cells induced a similar degree of tumor regression. Conversely, in the IFNY-/- mice bearing B16 melanoma, anti-tumor responses were significantly impaired with both WT and IFNY-/- p-mel/IL-12 T cells. This showed that IL-12 induced IFNY from endogenous cells in the tumor microenvironment was required to elicit anti-tumor response. Interestingly, when IFNgr-/- mice bearing B16 melanoma were injected with WT p-mel/IL-12 T cells there was only a partial reduction in IL-12 anti-tumor 
effects. This suggests that although IFNY production by endogenous cells is required for IL-12's anti-tumor effects, the endogenous cell (including immune cells) response to IFNy is not the sole determinant of IL-12 induced tumor regression. This data presents the possibility that IL-12 effects on endogenous cells including immune cells that are independent of IFNY as well as IFNy's direct interaction with tumor cells may also be components of IL-12 anti-tumor mechanisms.

Although research has thoroughly investigated many components of the IL-12 signaling pathway such as JAK2, TYK2, and STAT4, not as much focus has been placed on other downstream mediators of IL-12 signaling, especially in the context of myeloid-derived cells. As discussed in the dissertation's introduction, there are many signaling elements that play a role in determining how myeloid cells respond to inflammatory stimuli. These include NF-k $\beta$, WNT, AKT, AMPK, and SOCS among others. One pathway that has been explored in the context of IL-12, but deserves more attention because of its broad influence over inflammatory pathways is the MAPK pathway. Most of the published data concerning IL-12 and the MAPK pathway addresses the pathway's involvement in IL-12 synthesis in response inflammatory stimuli such as LPS. Very little work explores how IL-12 stimulation itself affects this pathway. It has been shown in the macrophage cell line, J774E, that IL-12 induces p38 phosphorylation, but not JNK or ERK1/2 (211). Zhang et al., demonstrated that in T cells, p38 activation is required for IL-12 induced IFNy production (212). However, this requirement 
has not been established in primary macrophages, macrophage cell lines, TIMS, TAMs, or MDSCs.

In this study, we hypothesize that IL-12 alters how TIMs and TAMs from the 4T1 mammary carcinoma respond to inflammatory stimuli. LPS is used as a model stimulus to demonstrate that IL-12 provides an immunological window that enhances the response of TIMS and TAMs to subsequent stimuli in a manner similar to vaccine adjuvants. Given the strong association between IL-12 and IFNy immunological effects, we also focus on whether IFNy is required for IL-12 induced changes in TIMs in response to LPS. Because several pathways contribute to the inflammatory profile of myeloid cells, we also sought to identify if IL-12 affects common signaling pathways associated with myeloid responses to LPS in order to begin to understand how this proposed immunological window is established. We evaluated if IL-12 impacted the status of several inflammatory intracellular signaling molecules including mitogen activated protein kinases (MAPKs) after LPS stimulation of 4T1 TIMs.

\section{Materials and Methods}

\section{Mice}

Wild type BALB/C and IFNY-deficient BALB/c (C.12S7(B6)-ifng $\left.{ }^{\mathrm{tm} 1 \mathrm{Ts}} / \mathrm{J}\right)$ were obtained from Jackson Laboratories (Bar Harbor, Maine, USA). Animals were maintained in the University of Louisville's Research Resources Facility. All animal care and experimental procedures were performed using protocols and 
guidelines approved by the University of Louisville Institutional Animal Care and Use Committee.

\section{Tumor harvesting and cell isolation}

4T1 cells were obtained from ATCC (Manassas, Virginia, USA). Tumor cells were maintained through in vivo passage with limited intermittent in vitro culture. Seven-to-eight weeks-old BALB/c or IFNY-deficient mice were injected with $2 \times 10^{4} 4 \mathrm{~T} 1$ cells subcutaneously at the rear, left mammary fat pad. Tumors were harvested at approximately day 26. Tumors from WT and IFNY-deficient mice were pooled for isolation of $\mathrm{CD} 11 \mathrm{~b}+$ cells. Tumors were processed using Tumor Dissociation Kit and gentleMACS tissue dissociator (Miltenyi Biotec, Auburn, California, USA). CD11b+ cells were selected using anti-CD11b magnetic microbeads, LS columns and MACS magnet system (Miltenyi Biotec, Auburn, California, USA). For peritoneal cell harvest, peritoneal fluid was obtained using a $21 \mathrm{G} 1$ needle and DPBS containing $2 \%$ FBS. Red blood cells were lysed using a balanced salt solution. Cells were depleted of CD19+ and CD5+ followed by positive selection of CD11b+ using LS columns and the MACS magnet system. Cell isolation purity was confirmed by flow cytometry and exceeded $95 \%$ for both tumor and peritoneal cell isolation.

\section{Reagents}

LPS (Escherichia coli serotype O11:B4) was purchased from SigmaAldrich (St. Louis, Missouri, USA). Recombinant mouse IL-12 was obtained from 
R\&D Systems (Minneapolis, Minnesota, USA). Western blot detection of protein used the following primary antibodies: anti-phospho-p38 (Thr180/Tyr182), antip38, anti-phospho-JNK/SAPK (Thr183/Tyr185), anti-JNK/SAPK, anti-phosphop44/42 (Thr202/Tyr204), anti-p44/42 (Cell signaling Technology, Beverly Massachusetts, USA) and anti-B-actin (Sigma-Aldrich, St. Louis, Missouri, USA).

\section{In vitro treatment protocol}

For protein, CD11b+ cells were treated with $100 \mathrm{ng} / \mathrm{mL}$ LPS, $100 \mathrm{ng} / \mathrm{mL}$ IL12 , or IL-12 + LPS at the same concentrations for 18 hours in RPMI with $5 \%$ fetal bovine serum. For IL-12 pretreatment, CD11b+ cells were treated with $100 \mathrm{ng} / \mathrm{mL}$ IL-12 for 2 hours followed by $100 \mathrm{ng} / \mathrm{mL}$ LPS for 18 hours. For $m R N A$, CD $11 \mathrm{~b}+$

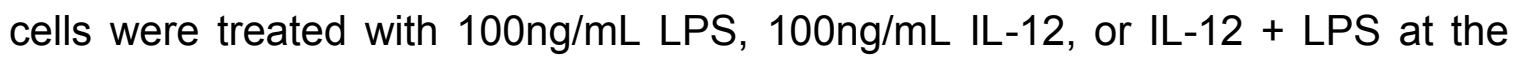
same concentrations for 2 hours in RPMI with 5\% fetal bovine serum. For IL-12 pretreatment, CD11b+ cells were treated with $100 \mathrm{ng} / \mathrm{mL} \mathrm{IL}-12$ for 2 hours followed by $100 \mathrm{ng} / \mathrm{mL}$ LPS for 2 hours. All incubations were done at $37^{\circ} \mathrm{C}$.

\section{Cytokine measurement}

Tumor infiltrating and peritoneal $\mathrm{CD} 11 \mathrm{~b}+$ cells were harvested as described above. Following stimulation, TNFa, IL-6, and IL-10 protein levels were measured using the Cytometric Bead Array Mouse Inflammation Kit (BD Biosciences, San Jose, California, USA) according the manufacturer's instructions. Analysis was performed using FACSCalibur cytometer and FCAP array software (BD Biosciences, San Jose, California, USA). 


\section{Real-time PCR analysis}

MACs One-step cDNA Kit (Miltenyi Biotech, Auburn, California, USA) was used for RNA and cDNA synthesis. cDNAs were amplified using a $20 \mu \mathrm{L}$ reaction containing SYBR green (New England Biolabs, Ipswich, Massachusetts, USA). QuantiTECT primers assays for mouse TNFa, IL-6, IL-10, and B-actin (Qiagen, Hilden, Germany) were used and PCR reactions were performed and captured by DNA Opticon 2 (MJ Research/Bio-rad, Hercules, California, USA). The relative expression software tool (REST 2009) was used to calculate relative fold changes among treatment groups.

\section{Western blot analysis}

Cells were lysed in buffer containing $125 \mathrm{mM}$ Tris (pH 6.8), $2 \%$ SDS, $20 \%$ glycerol, 200 $\mu \mathrm{M}$ PMSF, protease inhibitor mixture (Promega, Madison, Wisconsin, USA), phosphatase inhibitor mixture (ThermoFisher Scientific, Rockford, Illinois, USA). Total protein content for each sample was assessed by BCA protein assay (ThermoScientific, Rockford, Illinois, USA). Equal amounts of protein were separated on $10 \%$ Criterion gels (Bio-rad, Hercules, California, USA), by SDS-PAGE. Proteins were transferred to nitrocellulose membranes using Trans-blot Turbo Transfer system (Bio-rad, Hercules, California, USA). Antibody-bound proteins were detected using an ECL western blot system (GE Healthcare, Pittsburgh, Pennsylvania, USA), and the membranes were exposed 
to UltraCruz 5x7 autoradiography film (Santa Cruz Biotechnology, Santa Cruz, California, USA)

\section{Flow cytometry}

Single cell suspensions of WT and IFNy-deficient CD11b+tumor infiltrating cells were stained with fluorescently conjugated antibodies against murine CD11b, F4/80, pan Gr1, Ly6G, Ly6C (all but anti-F4/80 obtained from BD Biosciences, San Jose, California, USA; anti-F4/80 obtained from Affymetrix/eBiosciences, San Diego, California, USA) for 30 minutes at $4^{\circ} \mathrm{C}$, washed and analyzed using FACSCalibur flow cytometer and FlowJo software (Tree Star, Ashland, Oregon, USA).

\section{T1 supernatant production}

Primary 4T1 cells were harvested directly from tumor bearing animals by mashing the tumor mass through a 100 micron filter cup and then passage over a 70 micron nylon filter were plated in $10 \mathrm{~cm}$ dishes overnight at $10^{7}$ cells/dish in normal RPMI 1640 with 5\% FBS. After overnight culture, tissue debris and stroma were removed from the plates by pipetting away the supernatant and replacing with fresh media. The cell cultures were maintained at $37^{\circ} \mathrm{C}$ and $5 \% \mathrm{CO}_{2}$ and allowed to grow to $70 \%$ confluency. At this point, cells were split and transferred for expansion. Once desired growth was achieved, supernatants were collected from the flasks and centrifuged at $450 \mathrm{~g}$ for 5 minutes. The pellet was discarded and the clarified supernatants were then centrifuged a $2000 \mathrm{~g}$ for 
10 minutes. The supernatant was then applied to a Vivacell 100kd MWCO concentrator (Sartorius) and centrifuged in multiple 10-15 minute spins until the volume of the retentate was reduced to a final volume of approximately $3-4 \mathrm{ml}$. The retentate was aliquotted into $500 \mu \mathrm{l}$ amounts and stored at $-20^{\circ} \mathrm{C}$ until use. Concentrated retentate was tested for endotoxin by LAL (Limulus Amebocyte Lystate) Test (Lonza, QCL-1000 assay). The concentrate was also screened for mycoplasma using MycoAlert Assay (Lonza). Protein concentration was determined by BCA (Pierce). Optimal stimulation dose was determined by dose response curve and typically was $100-300 \mathrm{ng} / \mathrm{ml}$. Verified concentrate was then used to stimulate macrophages in in-vitro assays.

\section{Statistical analysis}

Statistical significance was calculated using unpaired student's t test when comparing two groups. One-way ANOVA was used for statistical difference when analyzing greater than two groups. $p<0.05$ was considered to be statistically significant.

\section{Results}

IL-12 impacts the response of $4 T 1$ tumor associated myeloid cells to LPS

It has been reported that TIMs and TAMs from mice bearing established tumors are polarized towards a functional phenotype that promotes immunosuppression and immune evasion as well as metastasis $(213,214)$. Additionally, TIMs and TAMs have been implicated in decreasing the efficacy of chemotherapeutic agents (215). TIMs and TAMs express high levels of anti- 
inflammatory cytokines, IL-10 and TGF $\beta$, and low levels of pro-inflammatory cytokines such as TNFa, IL-12, IFNy, and IL-6 (213) Introduction of a priming molecule that would allow for a more robust TIM and TAM response to a subsequent pro-inflammatory stimulus could help overcome this profound immunosuppression and even improve the effects of chemotherapeutic agents.

To test the hypothesis that IL-12 acts a primer and impacts the ability of TIMs and TAMs to respond to an inflammatory stimulus, CD11b+ cells were isolated from the peritoneum of $4 \mathrm{~T} 1$ bearing $\mathrm{BALB} / \mathrm{c}$ mice and from non-tumor bearing control BALB/c mice. These TAMs and control peritoneal myeloid cells were treated with IL-12 alone, LPS alone, IL-12 + LPS simultaneously for 18 hours, or pretreated with IL-12 for 2 hours followed by LPS for 18 hours. This treatment protocol allowed for examination of whether IL-12 immediately changed TAMs response to LPS or if there was a temporal effect seen with IL-12 pretreatment followed by LPS treatment.

We measured the levels of pro-inflammatory cytokines, TNFa and IL-6, and the anti-inflammatory cytokine, IL-10 using a cytometric bead array (CBA). We then compared our treatment groups in both $4 \mathrm{~T} 1$ peritoneal TAMs $(5 A, D, G)$ and control peritoneal myeloid cells (Fig. 5B, E, and H). We also compared each treatment group between 4T1 peritoneal TAMs and control peritoneal myeloid cells side-by-side (Fig. 5C, F, and I).

We found that IL-12 alone did not elicit any TNFa from either control peritoneal myeloid cells or 4T1 peritoneal TAMs (Fig. 5A and B). LPS alone significantly increased the amount of TNFa secreted by control peritoneal 
myeloid cells and 4T1 peritoneal TAMs (Fig. 5A and B). When directly comparing the amount of TNFa secreted by control peritoneal myeloid cells and 4T1 peritoneal TAMs in response to LPS, we show that there was an overall decrease in TNFa produced by 4T1 peritoneal TAMs, but this decrease was not significant (Fig. 5C). When peritoneal myeloid cells were treated with IL-12+LPS simultaneously, we again saw an increase in TNFa production as compared to untreated and IL-12 treated groups in both control peritoneal myeloid cells and 4T1 peritoneal TAMs (Fig. 5A and B). When we directly compared, IL-12+LPS treatment between control peritoneal macrophages and 4T1 peritoneal TAMs, there was no difference in TNFa cytokine production (Fig. 5C). When control peritoneal myeloid cells and 4T1 peritoneal TAMs were pretreated with IL-12 followed by LPS, we observed increased TNFa secretion over untreated and IL12 treated control peritoneal myeloid cells and 4T1 peritoneal TAMs. There was no significant difference in the amount of TNFa produced after IL-12 pretreatment followed by LPS when we directly compared peritoneal myeloid cells from control and 4T1-bearing mice (Fig. 5C). There was a significant decrease in the amount of TNFa produced in response to IL-12+LPS when compared to LPS alone and IL-12 pretreatment followed by LPS in control peritoneal myeloid cells (Fig. 5A). Although not statistically significant, a similar trend was noticed in 4T1 peritoneal TAMs. Overall, pretreatment of control peritoneal myeloid TAMs and 4T1 peritoneal TAMs did not result in a significant increase in the amount of TNFa secreted in response to LPS. Simultaneously treatment of control myeloid cells and 4T1 peritoneal TAMs caused a decrease in the amount of TNFa produced 
when compared to cells treated with LPS alone or IL-12 pretreatment followed by LPS.

We noted that when both control peritoneal myeloid cells and 4T1 peritoneal myeloid cells were exposed to LPS, IL-12+LPS, and IL-12 pretreatment followed by LPS, both cells types produced significantly higher amounts of IL-6 as compared to untreated and IL-12 treated cells (Fig. 5D and E). We also observed, although not statistically significant that pretreatment of peritoneal myeloid cells from both control and 4T1-bearing mice with IL-12 followed by LPS enhanced the amount of IL-6 produced as compared to LPS or IL-12+LPS treatment (Fig. 5A and B). When compared directly, control peritoneal myeloid cells and 4T1 peritoneal TAMs secreted similar amounts of IL-6 in response to each treatment (Fig. 5F).

Control peritoneal myeloid cells and 4T1 peritoneal TAMs secreted similar amounts of $\mathrm{IL}-10$ in response to LPS alone and IL-12+LPS which was a significant increase over cells that were untreated or treated with IL-12 alone (Fig. 5G and H). Interestingly, both control peritoneal myeloid cells and 4T1 peritoneal TAMs secreted significantly less IL-10 after being pretreated with IL12 followed by LPS as compared to treatment with LPS alone or IL-12+LPS (Fig. $5 G$ and $H$ ). When we compared each treatment group directly between control peritoneal myeloid cells and $4 \mathrm{~T} 1$ peritoneal TAMs, there was a significant difference in the amount IL-10 produced in response to IL-12+LPS (Fig. 5I). Overall, pretreatment with IL-12 followed by LPS treatment of control peritoneal 
myeloid cells and $4 \mathrm{~T} 1$ peritoneal TAMs resulted in a significant decrease in the amount of IL-10 produced as compared to LPS alone and IL-12+LPS.

$4 T 1$ peritoneal TAMs produce less IFNY than control peritoneal myeloid cells in the presence of IL-12.

Because of the strong association between the immune effects of IL-12 and IFNy, we observed the amount of IFNY produced by control peritoneal myeloid cells and $4 \mathrm{~T} 1$ peritoneal TAMs. We wanted to determine if there was difference in the amount of IFNy produced by control peritoneal myeloid cells and 4T1 peritoneal myeloid cells. When we looked at mRNA levels of IFNy, we noted that all treatments of both control peritoneal myeloid cells significantly affected the level of IFNy mRNA expression (Fig 6A and B). First, we compared the mRNA levels when each treatment group for control peritoneal myeloid cells and 4T1 peritoneal TAMs was normalized to untreated cells of the same type (Fig. 6A). We found that there was significantly more IFNy mRNA expressed in control peritoneal myeloid exposed to IL-12, IL-12+LPS, and IL-12 pretreatment followed by LPS as compared to 4 T1 peritoneal TAMs. Secondly, we compared the IFNY mRNA levels between control peritoneal myeloid cells and 4T1 peritoneal TAMs when all treatments for both cell types were normalized to untreated control peritoneal myeloid cells (Fig. 6B). We found that $4 \mathrm{~T} 1$ peritoneal TAMs expressed significantly less IFNy mRNA as compared to control peritoneal myeloid cells (Fig. 6B), and this observation was unchanged with the addition of IL-12 alone or LPS alone. The addition of IL-12 simultaneously with LPS or as pretreatment 
before LPS significantly increased the amount of IFNY mRNA in both control peritoneal myeloid cells and 4T1 peritoneal TAMs (Fig 6A). There was still, however, a large difference in the amount of IFNY mRNA between control peritoneal myeloid cells and 4T1 peritoneal TAMs in response to IL-12+LPS and IL-12 pretreatment followed by LPS when untreated control peritoneal myeloid cells were used as the reference (Fig. 6B).

We also compared IFNy cytokine produced in response to each treatment in control peritoneal myeloid cells and $4 \mathrm{~T} 1$ peritoneal myeloid cells. We found that IL-12 alone and LPS alone resulted in a small increase in IFNy secretion in both control peritoneal myeloid cells and 4T1 peritoneal TAMs, and that there was no difference between the two groups with either treatment. When myeloid cells from the peritoneum of control and 4T1-bearing mice were exposed to IL$12+$ LPS and IL-12 pretreatment followed by LPS, they both secreted significantly more IFNy as compared to treatment with IL-12 or LPS (Fig. 6C). 4T1 peritoneal TAMs secreted significantly less IFNy in response to IL-12+LPS and IL-12 pretreatment followed by LPS (Fig. 6C). From these data, we show that 4T1 peritoneal TAMs express less IFNy mRNA and cytokine levels at baseline. The addition of IL-12+LPS and IL-12 pretreatment followed by LPS increases the amount of IFNy produced in 4T1 peritoneal TAMs, but not to the same extent as in control peritoneal myeloid cells.

Absence of IFNY affects the response of 4T1 TAMs to IL-12 and LPS 
Next, we evaluated whether the absence of IFNy would affect the production of TNFa, IL-6, and IL-10 by 4T1 peritoneal TAMs. 4T1 TAMs were isolated from the peritoneums of IFNY-deficient mice and treated as mentioned above. We compared the mRNA and proteins levels of each cytokine from wildtype and IFNY-deficient 4T1 peritoneal TAMs. We found 4T1 peritoneal TAMs from IFNY-deficient mice secreted significantly less TNFa in response to LPS, IL12+LPS, and IL-12 pretreatment followed by LPS as compared to wild-type 4T1 peritoneal TAMs (Fig 7A). The level of TNFa mRNA expression was consistently lower in IFNY-deficient 4T1 peritoneal TAMs than in wild-type 4T1 peritoneal TAMs for treatment with LPS, IL-12+LPS, and IL-12 pretreatment followed by LPS although this difference was only statistically significant for IL-12 pretreatment followed by LPS (Fig. 7D).

Wild-type 4T1 peritoneal TAMs secreted slightly more IL-6 in response to LPS, IL-12+LPS, and IL-12 pretreatment followed by LPS than IFNY-deficient 4T1 peritoneal TAMs, but there was no significant difference in the values (Fig 7B). When comparing IL-6 mRNA expression between the two groups, we observed that IFNY-deficient 4T1 peritoneal TAMs had increased IL-6 mRNA after stimulation with LPS, IL-12+LPS, and IL-12 pretreatment followed by LPS (Fig. 7E).

Finally, our data shows that IFNY-deficient 4T1 peritoneal TAMs produced significantly more IL-10 in response to LPS, IL-12+LPS, and IL-12 pretreatment followed by LPS as compared to wild-type 4T1 peritoneal TAMs (Fig 7C). Additionally, IL-10 mRNA levels were higher in IFNy-deficient 4T1 peritoneal 
TAMs relative to wild-type 4T1 peritoneal TAMs in response to LPS, IL-12+LPS, and IL-12 pretreatment followed by LPS (Fig. 7F).

It should also be noted that if the cytokines data for IFNY-deficient 4T1 peritoneal TAMs is observed in isolation, pretreatment with $\mathrm{IL}-12$ results increased TNF $\alpha$ and IL-6 and decreased IL-10 in response to LPS as compared to LPS alone and IL-12 + LPS treatment (Figs. 7A-C). The pattern was retained in IFNy-deficient 4T1 peritoneal TAMs mRNA expression data for IL-6 (Fig. 7E) and IL-10 (Fig. 7F), but lost for TNFa (Fig. 7D).

Overall, this data demonstrates that IFNy is important for IL-12 induced changes in TNFa production in response to LPS in 4T1 peritoneal TAMs. Conversely, our data suggests that IFNy is not necessary for the modification of IL-6 gene and cytokine expression seen with IL-12 pretreatment followed by LPS, and may even negatively influence IL-6 production in 4T1 peritoneal TAMs. We also show that IFNy is not required for decreased IL-10 production seen with IL12 pretreatment followed by LPS in 4T1 peritoneal TAMs, even though IFNYdeficient 4T1 peritoneal TAMs produced more IL-10.

IL-12 modulates the response of 4T1 tumor-infiltrating myeloid cells to LPS.

We also tested whether IL-12 impacts the ability of myeloid cells to respond to an inflammatory stimulus by using CD11b+ cells isolated from $4 \mathrm{~T} 1$ tumors. These $4 T 1 \mathrm{CD} 11 \mathrm{~b}+$ tumor infiltrating myeloid cells (4T1 TIMs) were then exposed to the following treatments in vitro: IL-12 alone, LPS alone, IL-12 plus LPS simultaneously, or IL-12 pretreatment followed by LPS. Cytokine production was 
measured using a cytometric bead array (CBA). We observed that IL-12 alone does not induce significant production of TNFa, IL-6, or IL-10 (Fig. 8A-F) or their respective mRNAs (Fig. 8A, C, E). Conversely, LPS alone and IL-12 plus LPS given simultaneously, resulted in significant production of TNFa, IL-6, and IL-10 (Fig. 8A, C, E) and their respective mRNAs (Fig. 8A, C, E). When 4T1 TIMs were pretreated with IL-12 and then exposed to LPS, we observed a significant increase in the protein and mRNA levels of TNFa and IL-6 as compared to treatment with LPS alone or IL-12 plus LPS (Fig. 8A-D). On the other hand, pretreatment with IL-12 followed by LPS treatment of 4 T1 TIMs resulted in a significant decrease in the amount of IL-10 (Fig. 8E-F).

We also assessed if IL-12 increased the amount of IFNY produced by 4T1 TIMs in response to LPS. We show that IL-12 induced a significant amount of IFNy mRNA and cytokine from 4T1 TIMS as compared untreated 4T1 TIMs (Fig. 9A and B). 4T1 TIMS produced significantly more IFNy when treated with IL-12 +LPS or pretreated with IL-12 followed by LPS than when treated with LPS alone (Fig. 9A and B).

IL-12 increases pro-inflammatory cytokine produced by $4 T 1$ TIMs in response to $4 T 1$ tumor derived products

We have demonstrated that IL-12 enhances the production of proinflammatory cytokines, IL-6 in 4T1 peritoneal TAMs, TNF $\alpha$ and IL-6 in 4T1 TIMs and decreases the secretion of IL-10 by 4 T1 peritoneal TAMs and 4T1 TIMs in response to LPS. We used LPS as a model stimulus to demonstrate that IL-12 
augments how TIMs and TAMs respond to inflammatory stimuli. It has been proposed that the tumor secrete products with pro-inflammatory and antitumorigenic potential but because of chronic exposure to these signals, immunosuppression is induced leading to continued immune evasion, tumor growth, and metastasis (216). We investigated whether IL-12 could also augment the response of $4 \mathrm{~T} 1$ TIMs to tumor derived products. We concentrated supernatants from ex vivo harvested $4 \mathrm{~T} 1$ tumors, and treated $4 \mathrm{~T} 1 \mathrm{TIMs}$ with IL12 or $4 \mathrm{~T} 1$ supernatant alone, IL-12+4T1 supernatant, IL-12 pretreatment followed by $4 \mathrm{~T} 1$ supernatant. We found that treatment with $4 \mathrm{~T} 1$ supernatant led to a small but significant amount of TNFa and IL-6 from 4T1 TIMs (Figs. 10A and 10B). We also noted the 4T1 supernatant alone caused a tremendous increase in the amount IL-10 secreted from 4T1 TIMs (Fig. 10C). A major finding was that IL-12 pretreatment led to a significant enhancement of the amount of pro-inflammatory cytokines, TNFa and IL-6, produced in response to 4T1 supernatants (Figs. 10A and B). Interestingly, treating 4T1 TIMs with IL-12+4T1 supernatants simultaneously or pretreating with IL-12 followed by $4 \mathrm{~T} 1$ supernatant did affect the amount of IL-10 produced (Fig. 10C). Overall, this data shows that IL-12 changes the response of $4 \mathrm{~T} 1 \mathrm{TIMs}$ to $4 \mathrm{~T} 1$ supernatant from predominantly IL-10 to a phenotype that includes proinflammatory cytokines, TNFa and IL-10 in addition to IL-10.

IL-12 modulates the response of IFNY-deficient, 4T1 tumor-infiltrating myeloid cells to LPS. 
IFNy is well known activator of myeloid cells and IL-12 has been shown to induce IFNy production by myeloid cells (217). Additionally, it has been shown that much of IL-12's anti-tumor influence can be attributed to $\operatorname{IFNY}(175,210,218)$. Conversely, there are studies that demonstrate that IL-12 has immune properties that are independent of IFNy $(219,220)$. Therefore, we sought to determine if IFNy was important for our observed finding that pretreatment of 4T1 TIMs with IL-12 increased the amount of pro-inflammatory cytokines, TNFa and IL-6 and decreased anti-inflammatory cytokine, IL-10 produced in response to LPS. To approach this question, 4T1 TIMs were isolated from IFNy-deficient mice and treated in the same manner as their wild-type counterparts.

To determine if there were differences in the myeloid cell population of 4T1 tumors harvested from wild-type and IFNy-deficient mice, CD11b+ cells from the tumors of both animal types were analyzed using flow cytometry. The level of expression of myeloid cell markers Gr1, F4/80, Ly6C, and Ly6G were insignificant between wild-type and IFNY-deficient 4T1 TIMs (Fig 11).

When IFNy-deficient 4T1 TIMs were stimulated, we found that IL-12 alone stimulated minimal TNFa, IL-6, and IL-10 (Fig. 12A-F). IFNY-deficient 4T1 TIMs produced similar amounts of TNFa, IL-6, and IL-10 in response to LPS and IL-12 plus LPS (Fig. 12A, C, E). IL-12 pretreatment followed by LPS exposure caused a significant increase in TNFa and IL-6 cytokine production and a reciprocal decrease in IL-10 cytokine production by IFNy-deficient 4T1 TIMs (Fig. 12A, C, E). However, no differences in gene expression were observed between LPS alone, IL-12 plus LPS, and IL-12 pretreatment followed by LPS in IFNy-deficient 
4T1 TIMs (Fig. 12B-D). Overall, the absence of IFNY in 4T1 TIMs did not significantly affect the increase in TNF $\alpha$ and IL-6 cytokine levels and reciprocal decrease in IL-10 seen with IL-12 pretreatment followed by exposure to LPS. Conversely, there was no increase in TNFa and IL-6 gene expression and no decreased IL-10 gene expression seen in IFNY-deficient 4T1 TIMs pretreated with IL-12 followed by LPS. This data suggest that the priming effects of IL-12 works through various mechanisms at both the transcriptional and translational levels, and may have an IFNy independent component.

IFNY partially impacts the response of $4 T 1$ TIMs to IL-12 and LPS

The data previously described shows cytokine and gene expression when comparing our various treatment groups in either wild-type 4T1 TIMs exclusively or IFNY-deficient 4T1 TIMs exclusively. This data shows that even in the absence of IFNy, pretreatment of 4T1 TIMs with IL-12 increases the amount of TNFa, IL-6 cytokine produced, and decreases the amount of IL-10 cytokine produced in response to LPS. Conversely, we demonstrate that increased TNF $\alpha$ and IL-6 gene expression and decreased IL-10 gene expression induced by IL-12 pretreatment followed by LPS is no longer present in IFNY-deficient 4T1 TIMs. These observations prompted us to directly compare each treatment group between wild-type and IFNY-deficient 4T1 TIMs to more clearly understand the influence of IFNy. To directly compare each treatment between WT and IFNYdeficient 4T1 TIMs, we reanalyzed our gene data with both wild-type and IFNYdeficient 4T1 TIMs mRNA levels for each gene normalized to wild-type untreated 
4T1 TIMs. At baseline, we found that there was no difference in TNFa gene expression between untreated wild-type and IFNY-deficient 4T1 TIMs (Fig. 13A). There was, however, a small but significant difference in IL-6 gene expression between untreated wild-type and IFNY-deficient 4T1 TIMs that was not affected by IL-12 treatment (Fig 13B). Additionally, there was significantly less IL-10 gene expression in untreated IFNY-deficient 4T1 TIMs as compared to wild-type 4T1 TIMs (Fig. 13C). This difference in IL-10 mRNA levels between wild-type and IFNY-deficient 4T1 TIMs was decreased with IL-12 treatment (Fig 13C). We found that TNFa gene expression was significantly lower in the IFNY-deficient 4T1 TIMs as compared to wild-type 4T1 TIMs in response to LPS alone, IL-12 plus LPS, and IL-12 pretreatment followed by LPS (Fig. 13A). There was no significant difference in IL-6 gene expression between wild-type and IFNYdeficient 4T1 TIMs treated with LPS, IL-12 plus LPS, and IL-12 pretreatment followed by LPS (Fig. 13B). For IL-10 gene expression, there was no difference in the IL-10 gene response of wild-type and IFNy-deficient TIMs to IL-12 pretreatment followed by LPS, but there was a significant difference in IL-10 gene expression between wild-type and IFNY-deficient 4T1 TIMs in response to IL-12 plus LPS (Fig. 13C). Although the difference in IL-10 gene expression in response to LPS was not significant between wild-type and IFNY-deficient TIMs, there was noticeable variance between the two TIM populations (Fig. 13C).

To directly compare cytokine levels of wild-type and IFNY-deficient TIMs in response to our treatments, we combined cytokine data from figures 1 and 2 in table form. When directly comparing cytokine production between wild-type and 
IFNY-deficient 4T1 TIMs for each treatment, we observed lower amounts of TNFa in IFNY-deficient $4 \mathrm{~T} 1 \mathrm{TIMs}$ for all treatment groups although there was only a significant decrease in TNFa for the IL-12 pretreatment followed by LPS group (Table I). There was no significant difference in IL-6 cytokine production between wild-type and IFNY-deficient 4T1 TIMs for any of the treatment groups (Table I). Finally, although there was an overall decrease in IL-10 cytokine production in IFNy-deficient 4T1 TIMs for all treatment groups, there was only a significant difference in the IL-12 treatment group when comparing the two populations (Table I).

In summary, by directly comparing gene expression and cytokine production in wild-type and IFNY 4T1 TIMs, we show that IFNY is necessary for the increase in TNF $\alpha$ after IL-12 pretreatment followed by LPS. Conversely, our data demonstrate that the effect of IL-12 pretreatment on the response of $4 \mathrm{~T} 1$ TIMs to LPS in terms of IL-6 gene expression and cytokine production is independent of IFNy. Finally, we show that IL-12 decreases the amount of IL-10 cytokine produced, but not IL-10 gene expression by 4T1 TIMs in the absence of IFNY.

IL-12 alters the 4T1 TIMs activation of MAPK pathway in response to LPS

Our data thus far has shown that IL-12 affects the response of TIMs to LPS in a manner that is partially independent of IFNy. We observed the levels of TNFa, IL6, and IL-10 in response to IL-12 and LPS. There are many pathways involved in the production of these cytokines in myeloid cells in response to inflammatory 
stimuli such as LPS including signal transducer and activator of transcription (STATs), NF-K $\beta, A P-1$, and AKT (12). The MAPK signaling cascade is wellstudied and has been shown to be important in the signaling pathway of TNFa, IL-6, IL-10, and LPS $(81,87,90)$. These same signaling pathways also trigger the resolution of inflammation through feedback inhibition loops that lead to activation of suppressor of cytokine signaling (SOCS) proteins and IL-10 production (12). IL-12 signaling is propagated via JAK2 and STAT4 $(156,157)$. It has also been reported that IL-12 activates the MAPK pathway (161). We hypothesized that IL-12 may affect the activation status of one or more of these pathways to augment the inflammatory profile of $4 \mathrm{~T} 1 \mathrm{TIMs}$ in response to LPS. Additionally, given the evidence that the MAPK pathway is involved in both IL-12 and LPS signaling, we postulated that the MAPK pathway may be affected in 4T1 TIMs exposed to IL-12 followed by LPS.

First, we investigated the impact of $\mathrm{IL}-12$ on several inflammatory signaling components. We found that IL-12 did not affect the phosphorylation status of NF-k $\beta$ p65 in 4T1 TIMs (Fig. 14A) In addition to this finding, we found no change in total amount of NF-K $\beta$ p50 in 4T1 TIMs (Fig 14A). We also looked at the influence of IL-12 on 4T1 TIM expression of cyclooxygenase-2 (COX-2), which has been shown to be important in cancer-related inflammation (89). We observed no change in 4T1 TIM expression of COX-2 in response to IL-12. We also noted that IL-12 did not affect the phosphorylation of GSK3 $\beta$ and AKT in 4T1 TIMs (data not shown). 
Next, we evaluated the effect of IL-12 on the MAPK pathway. For these experiments, we also gauged how pretreatment with IL-12 affected the MAPK pathway after exposure to LPS. When wild-type 4T1 TIMs were exposed to LPS alone, there was phosphorylation of MAPK proteins $\mathrm{p} 38$, JNK, and p44/42 that diminished over time (Fig. 14B). Conversely, IL-12 alone elicited a very low level of phosphorylation of the MAPK protein p38, but no p44/42 or JNK phosphorylation at the observed time points (Fig. 14B). When TIMs were pretreated with IL-12 for 2 hours and then exposed to LPS, there was significant enhancement of phosphorylation of p38, JNK, and p44/42 as compared to IL-12 or LPS alone (Fig. 14B).

Finally, we examined MAPK protein phosphorylation in IFNy-deficient 4T1 TIMs in response to IL-12 and LPS. We wanted to assess if the enhancement of MAPK signaling seen with IL-12 pretreatment of $4 \mathrm{~T} 1$ TIMS was at all IFNY independent. We observed that treatment of IFNy-deficient 4T1 TIMs with LPS alone resulted in a similar pattern of phosphorylation of p38, JNK, and p44/42 as seen in wild-type 4T1 TIMs (Fig. 14C). IL-12 caused some phosphorylation of p38, as well as p44/42 MAPK proteins in IFNy-deficient 4T1 TIMs (Fig. 14C). Finally, pretreatment of IFNY-deficient 4T1 TIMs with IL-12 did not cause a notable increase in p38 and JNK phosphorylation, as seen in wild-type 4T1 TIMs (Fig. 14C). However, pretreatment of IL-12 followed LPS treatment did cause increased phosphorylation of p44/42 at an earlier time point (15 minutes) when compare to LPS alone (Fig. 14C). 
Overall we demonstrate that IL-12 does not impact activation or expression of NF-K $\beta$ in 4T1 TIMs. Additionally, the pro-inflammatory enzyme, COX-2 was not affected by IL-12 treatment of $4 \mathrm{~T} 1$ TIMs. We do show that IL-12 enhances the phosphorylation of MAPK proteins after LPS stimulation in 4T1 TIMs. Our data suggests that the enhanced phosphorylation of p38 and JNK is dependent on IFNy as this enhancement was lost when IFNY-deficient 4T1 TIMs were pretreated with IL-12 followed by LPS. We did, however, identify that in the absence of IFNy, IL-12 enhances the phosphorylation of p44/42 in response to LPS in 4T1 TIMs at an earlier time point. 


\section{Discussion}

Myeloid-derived cells are remarkably dynamic and display an array of functions and activities. The dynamic nature of myeloid cells is especially evident in cancer. Myeloid cells in cancer have the ability to initiate and promote tumor growth, as well as suppress their own and other cell types' capability to thwart cancer progression which provides an opportunity for targeting these cells in anticancer therapies. Many have sought ways to exploit the functional plasticity of myeloid cells in cancer in order to aid in eradicating established tumors. Recent approaches that have been shown to modulate the functional phenotype of TAMs and TIMs and improve anti-tumor immunity include engagement and activation of TAMs and TIMs via TLR4 (221), local low-dose irradiation (222), and administration of biological nanoparticles combined with chemotherapeutic agents (223). IL-12 can activate both the innate and adaptive arms of the immune system and much effort has been used to investigate its effectiveness as an anti-tumor agent and therapeutic vaccine adjuvant. In this study, we explore how IL-12 impacts the tumor associated and tumor infiltrating myeloid cell's response to the inflammatory stimulus, LPS, as well as tumor derived products. We use LPS solely as a model inflammatory stimulus to demonstrate that IL-12 produces an immunological window in which TAMs and TIMs are more able to respond to subsequent pro-inflammatory and anti-tumor signals. Interestingly, it has been shown that ex-vivo treatment with LPS of tumor-associated macrophages from the ascites and blood of ovarian cancer patients leads to enhances activation and tumor cell cytoxicity of NK cells (221). 
Our data show that IL-12 enhances the amount of TNFa and IL-6 and decreases the amount of IL-10 4T1 TIMs secrete in response to LPS (Fig. 8). This result aligns with data using TIMs from the 3LLC lung cancer (180). An important distinction in this study include showing that exposure of TIMs for only 2 hours versus overnight pre-culture with IL-12 conferred a similar cytokine response to LPS in vitro. Additionally, treating TIMs with IL-12 and LPS simultaneously did not impact the cytokine and mRNA levels to the degree that pre-treatment with IL-12 followed by LPS treatment. This observation suggests that although $\mathrm{IL}-12$ does not induce the production of cytokines and mRNA measured in TIMs, it does initiate a temporal and internal change in myeloid cells that alters its response to subsequent stimuli.

In 4T1 peritoneal TAMs, adding IL-12 simultaneously with LPS led to a slight decrease in TNFa secretion (Fig. 5B). This difference was no longer present when 4T1 peritoneal TAMs were pretreated with IL-12 followed by LPS (Fig 5B). We saw an increase in IL-6 cytokines levels when 4T1 TAMs were pretreated with IL-12 then LPS as compared to LPS alone or IL-12+LPS (Fig. 5E). Overall, IL-12 had no significant impact on the amount TNFa and IL-12 secreted by $4 \mathrm{~T} 1$ peritoneal TAMs in response to LPS.

Much of IL-12's impact on myeloid cells has been attributed to its elicitation of IFNy which further stimulates myeloid cells in an autocrine fashion and activates NK cells and T cells in a paracrine fashion. Macrophages have been shown to produce nitric oxide and upregulate surface molecules associated with antigen presentation in response to IL-12 (169). Both of these effects are 
dependent on IFNY as this phenotype is erased in IFNY-/- mice $(170,224)$. Additionally, IL-12 has been demonstrated to prime macrophages to produce copious amounts of NO in response to LPS (225).

In this study, we demonstrate that IFNy is important for the IL-12 induced increase in TNFa from 4T1 TIMs and 4T1 peritoneal TAMs in response to LPS. (Fig. 13A, Table I, Fig 7A and B). It has been previously shown that IFNY potentiates the cytoplasmic accumulation of TNFa mRNA (226). It has also been reported that activated monocytes regulate TNFa gene expression both transcriptionally and post-transcriptionally in response to IFNy (227). A more recent publication showed that IFNY induced TNFa transcription via transcription factors, IRF-1, IRF-8, and Pu.1 (228). Our data illustrates that 4T1 TIMs from IFNY-deficient mice produced significantly less TNFa mRNA and protein in response to IL-12 and LPS as compared to wild-type 4T1 TIMs (Fig. 13A) suggesting that the transcriptionally-controlled component of TNFa gene expression in 4T1 TIMs is dependent on IFNy. Interestingly, although the mRNA levels of TNFa were significantly impacted by the absence of IFNy, pretreatment of 4T1 TIMs from both wild-type and IFNY-deficient 4T1 TIMs with IL-12 followed by LPS resulted in a significant increase in TNFa cytokine levels (Fig. 8A, 12A). This presents the possibility that post-transcriptional control of TNFa gene expression in 4T1 TIMs may be IFNy independent because even in the absence of IFNy, IL-12 pretreatment of TIMs led to a significant increase in TNFa cytokine production. 
Our results show that there was a small but significant difference in the amount of IL-6 gene expression between wild-type and IFNY-deficient 4T1 TIMs that was not affected by the addition of IL-12 alone (Fig. 13B). We also found that IL-6 gene expression and cytokine production was not significantly different between wild-type and IFNY-deficient 4T1 TIMs for any of the treatment groups (Fig 13B, Table I). This suggests that enhancement of IL-6 gene and cytokine expression seen in 4T1 TIMs pretreated with IL-12 followed by LPS is independent of IFNY. In 4T1 peritoneal TAMs, the absences of IFNY did not significant impact on the amount IL-6 cytokine produced in response IL-12 and LPS (Fig. 7B). There was, however, a significant increase in IL-6 gene expression in IFNy deficient 4T1 peritoneal TAMs in response to LPS, IL12+LPS, and IL-12 pretreatment followed by LPS when compared to WT 4T1 periotneal TAMs (Fig. 7E). IL-6 is a cytokine with a wide variety of cellular effects and has been implicated in a number of pathological states including cancer. Gene expression of IL-6 is controlled by a number of transcriptional factors, including NF-K $\beta, \mathrm{C} / \mathrm{E} \beta \mathrm{P}, \mathrm{AP}-1$, and Notch signaling proteins $(229,230)$. Studies have shown that IFNy enhances the amount of IL-6 secreted in response to LPS in various types of cells $(231,232)$. Our study shows that IL-12 also increases the amount of IL-6 secreted by 4 T1 TIMs in response to LPS in a manner that is independent of IFNy. This is an important demonstration that IL-12 has a proinflammatory impact on TIMs that is not dependent on IFNy.

We also examined the effect of treatment with IL-12 and LPS on the amount of the anti-inflammatory cytokine, IL-10 secreted from WT 4T1 TIMs and 
peritoneal TAMs and IFNY-deficient 4T1 TIMs and peritoneal TAMs. In our studies, IL-10 cytokine secretion was decreased when 4T1 TIMs from both WT and IFNY-deficient animals were treated with IL-12 prior to exposure to LPS (Figs. 8E, 12E). We show that there is an overall diminution in the amount of IL10 secreted by IFNY-deficient 4T1 TIMs in response to IL-12 and LPS. Our data also demonstrate, however, that the absence of IFNY did not cause a difference in the amount of IL-10 secreted in any treatment group except for IL-12 alone that was statistically significant when directly comparing WT and IFNY-deficient 4T1 TIMs (Table I). The amount of IL-10 secreted from TIMs in response to IL12 was decreased significantly in the absence of IFNy, although the amount of IL-10 was very low in both groups (Table I). We also observed that pretreatment of 4 T1 peritoneal TAMs with IL-12 followed by LPS led to a sharp decrease in the amount of IL-10 as compared to LPS alone and IL-12+LPS (Fig 5H).

It is clear from our data that IFNy is an important factor in IL-10 gene expression after IL-12 and LPS treatment. When comparing wild-type and IFNYdeficient 4T1 TIMs directly, there were significant differences in the amount of IL10 gene expressed in the untreated group and the IL-12 plus LPS group (Fig. 4C). Additionally, there was a difference in IL-10 gene expression in wild-type and IFNY-deficient 4T1 TIMs in response to LPS alone although it did not reach statistical significance (Fig 4C). We found that IFNY deficient 4T1 peritoneal TAMs secreted higher amounts of IL-10 and had significantly increased IL-10 gene expression when treated with IL-12 and LPS compared to WT 4T1 peritoneal TAMS (Fig. 7C and F). It has been demonstrated that IL-10 production 
is controlled both transcriptionally and post-transcriptionally in manner similar to TNF $\alpha$ by a number of transcription factors, microRNAs, and signaling molecules $(233,234)$. IFNY can block IL-10 production through the PI3-kinase-GSK3ß-AKT pathway (80). Our results show that even in the absence of IFNy, IL-12 decreases the amount of IL-10 produced in response to LPS and may affect the post-transcriptional handling of IL-10 in an IFNY-independent manner. The decreased amount of IL-10 in response to LPS after IL-12 pretreatment may be important in the maintenance or prolongation of IL-12 induced pro-immunological window.

Untreated WT and IFNy deficient 4T1 TIMs and peritoneal TAMs did not express high levels of IL-10 cytokine that is classically associated with the TIM M2-like phenotype. This observation could be explained by the timing of the measurements of cytokine levels of the untreated group, which was done after overnight incubation. It is reasonable to expect that TIMs lysed immediately after harvest and selection, the IL-10 data may have been different. Several published reports have shown data using TIMs and TAMs from 4T1 and 3LLC tumors with very low levels of IL-10 cytokine expression $(180,235-237)$. It is hard to determine from in vitro results what would be a functional or physiological relevant amount of IL-10 in vivo. Even so, our data clearly shows that pretreatment of TIMs and TAMs with IL-12 significantly decreases the amount of IL-10 produced in response to the inflammatory stimulus, LPS regardless of the presence of IFNY. This suggests that IL-12 may prolong the action of other 
inflammatory mediators by diminishing the reflexive production the antiinflammatory cytokine, IL-10.

We expected that IL-12 would confer similar effects on the cytokine profile of $4 \mathrm{~T} 1 \mathrm{TIMs}$ and peritoneal TAMs. We found that although there were some similarities in their response to IL-12 and LPS (i.e. decreased IL-10 after IL-12 pretreatment followed by LPS as compared to LPS alone and IL-12+LPS and IFNy not required for IL-6 cytokine increases with IL-12 pretreatment), the overall picture was not exactly the same for both TIMs and TAMs. When thinking about possibilities for these differences, two factors come to the forefront. First, all of our experiments were at one set time point ( 2 hours for mRNA and 18 hours for cytokine data both with 2 hour IL-12 pretreatments). It is possible that this timepoint was optimal for capturing the observation that supported our stated hypothesis for $4 \mathrm{~T} 1 \mathrm{TIMs}$, but was suboptimal for observing similar data in $4 \mathrm{~T} 1$ peritoneal TAMs. The second factor that may have contributed to differences in the cytokine profile between $4 \mathrm{~T} 1 \mathrm{TIMs}$ and $4 \mathrm{~T} 1$ peritoneal TAMs is the makeup of the myeloid population each group. These pooled samples of CD11b+ cells were not sorted to separate F4/80+ macrophages from Gr1+ monocytic and granulocytic MDSCs or other myeloid cells. We did some simple flow analysis of each group and there were some differences in percentages of different types of cells (data not shown), but a more in depth analysis of the myeloid cell populations of each group of cells would provide more information and might help decipher why there were differences in the response to our stimuli. 
We also examined how IL-12 affected the cytokine profile of 4T1 TIMS exposed to tumor derived products. We saw that IL-12 pretreatment significantly enhanced the amount TNFa and IL-6 produced by 4T1 TIMs in response to 4T1 supernatant. IL-12 pretreatment did not affect the high levels of IL-10 secreted from 4T1 TIMs. Assays to determine if myeloid cells pretreated with IL-12 followed by tumor-derived products expressed higher levels of antigen presentation machinery or promoted the activation of $\mathrm{T}$ cells would be an interesting follow up experiment. Additionally, determining if IFNy were necessary for this observation would be an interesting question to pursue. Importantly, this result shows that IL-12 does affect how myeloid cells respond subsequent stimulate and that the tumor microenvironment contains factors with inflammatory potential.

Finally, we examined how several intracellular signaling pathways, including the MAPK pathway, were affected by our treatment of 4T1 TIMs from wild-type and IFNY-deficient mice with IL-12 and LPS. There is extensive research describing the role of the MAPKs in LPS signaling in macrophages and other myeloid cells $(20,90,238)$. Most of the published data concerning IL-12 and the MAPK pathway addresses the pathway's involvement in IL-12 synthesis in response to inflammatory stimuli such as LPS. Very little work explores how IL12 stimulation itself affects this pathway. It has been shown in the macrophage cell line, J774E, that IL-12 induces p38 and p44/42 phosphorylation (211). Zhang et al., demonstrated that in T cells, p38 activation is required for IL-12 induced IFNy production (212). However, this requirement has not been established in 
primary macrophages, macrophage cell lines, TIMS, TAMs, or MDSCs. We found that IL-12 alone only induced minimal phosphorylation of the MAPKs wildtype and IFNY-deficient 4T1 TIMs (Fig. 14). We also observed, as expected, that LPS alone induced phosphorylation of the MAPK pathway in 4T1 TIMs (Fig. 14). Phosphorylation of the MAPK pathway by LPS in 4T1 TIMs was not impacted by the absence of IFNy (Fig 14). A major observation from these studies is that the increase in MAPK phosphorylation in response to LPS after IL-12 pre-treatment in wild-type 4T1 TIMs was lost in IFNy-deficient 4T1 TIMs (Fig. 14). Importantly, however, in the IFNY-deficient 4T1 TIMs, IL-12 pretreatment followed by LPS caused increased phosphorylation of $\mathrm{p} 44 / 42$ at an earlier timepoint when compared to LPS alone (Fig. 14). The early activation of p44/42 in IFNy-deficient 4T1 TIMs may also contribute to the increases in TNFa and IL-6 with IL-12 pretreatment followed by LPS even in the absence of IFNY although it would not fully explain the decrease of IL-10 with that same treatment as increased $\mathrm{p} 44 / \mathrm{p} 42$ is associated with increased IL-10 expression. 


\section{Figure 5}
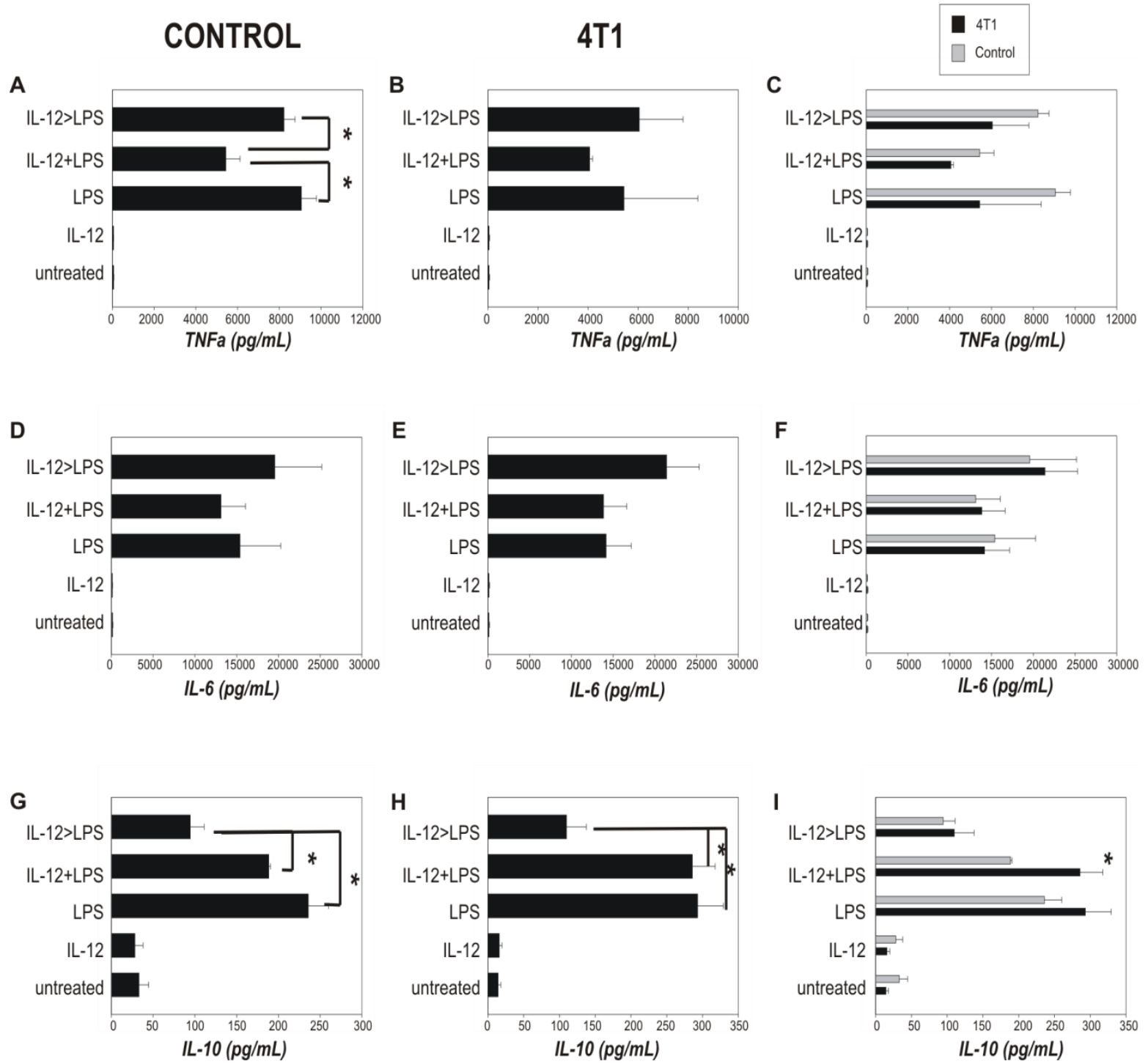

Figure 5. IL-12 modulates the response of 4T1 peritoneal tumor associated myeloid cells to inflammatory stimulus, LPS. CD5/CD19/CD $11 \mathrm{~b}^{+}$cells isolated from peritoneum of BALB/cJ mice with (4T1 TAMs) or without (control) implanted 4T1 tumors were treated with IL-12, LPS, or IL-12 and LPS for 18 hours, pretreated with IL-12 for 2 hours and then treated with LPS for 18 hours, or left untreated. $100 \mathrm{ng} / \mathrm{mL}$ of $\mathrm{IL}-12$ and $100 \mathrm{ng} / \mathrm{mL}$ of LPS were used in all 
experiments. TNFa $(A, B, C), \mathrm{IL}-6(D, E, F)$, and IL-10 $(G, H, I)$ protein levels were measured using cytokine bead array. $C, F$, and $I$, shows direct comparison between control and 4T1 peritoneal CD5-/CD19-/CD11b+ for each treatment. Figures shown represent the mean \pm SEM of triplicate data and are representative of at least three independent experiments with similar results. ( ${ }^{*} \mathrm{p}$ $\left.<0.05,{ }^{* *} p<0.001\right)$ 
Figure 6

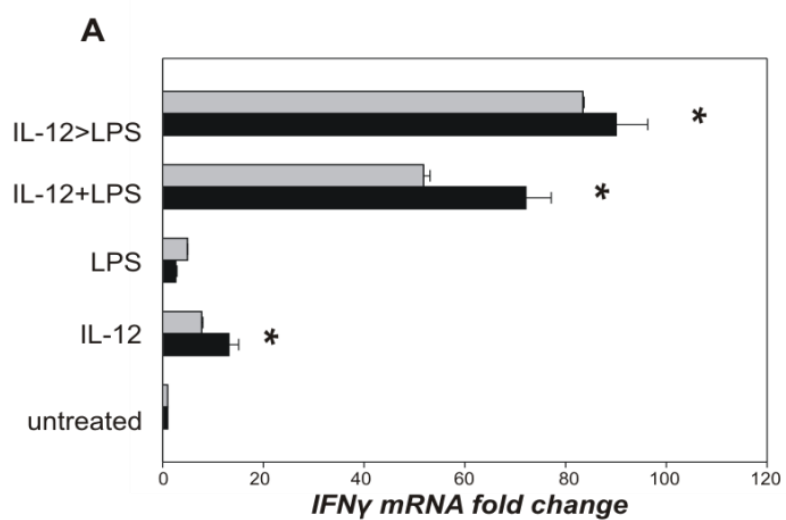

Control peritoneal myeloid cells

4T1 peritoneal myeloid cells (normalized to 4T1 untreated)

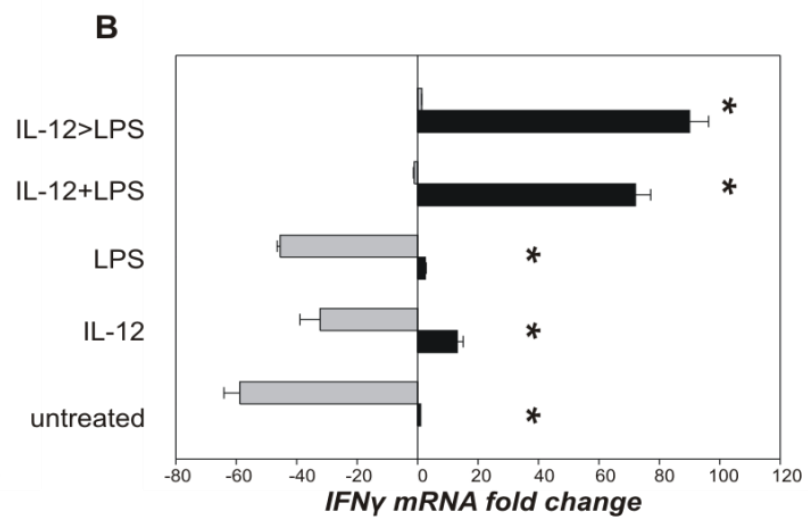

Control peritoneal myeloid cells

4T1 peritoneal myeloid cells (normalized to WT untreated)

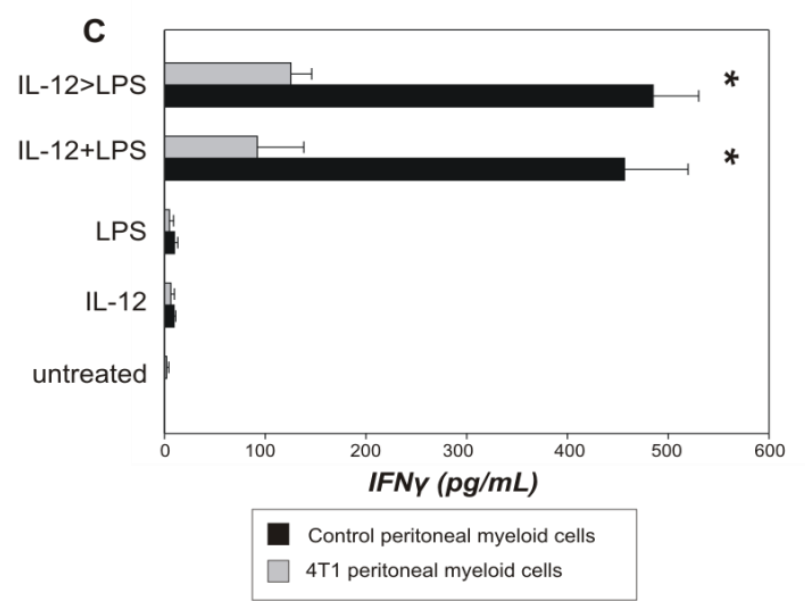

Figure 6. 4T1 peritoneal TAMs produce less IFNy than control peritoneal myeloid cells in the presence of IL-12. For $A$ and $B$, CD5/CD19 /CD $11 b^{+}$cells isolated from peritoneum of BALB/cJ mice with (4T1 TAMs) or without (control) implanted 4T1 tumors were treated with IL-12, LPS, or IL-12+ LPS for 2 hours, pretreated with IL-12 for 2 hours and then treated with LPS for 2 hours, or left untreated. Gene expression was determined by measuring the mRNA levels of IFNy. In $A$, control treatment groups are normalized to control untreated peritoneal myeloid cells, while 4T1 treatment groups are normalized to $4 \mathrm{~T} 1$ 
untreated TAMs. In B, both control and $4 \mathrm{~T} 1$ treatments groups are normalized to control untreated peritoneal myeloid cells. For $C, \mathrm{CD}^{-} / \mathrm{CD} 19^{-} / \mathrm{CD} 11 \mathrm{~b}^{+}$cells isolated from peritoneum of BALB/cJ mice with (4T1 TAMs) or without (control) implanted 4T1 tumors were treated with IL-12, LPS, or IL-12 and LPS for 18 hours, pretreated with IL-12 for 2 hours and then treated with LPS for 18 hours, or left untreated. $100 \mathrm{ng} / \mathrm{mL}$ of IL-12 and $100 \mathrm{ng} / \mathrm{mL}$ of LPS were used in all experiments. IFNY protein levels were measured using cytokine bead array. Figures shown represent the mean \pm SEM of triplicate data and are representative of at least three independent experiments with similar results. ( ${ }^{*} p$ $\left.<0.05,{ }^{* *} p<0.001\right)$ 


\section{Figure 7}

A

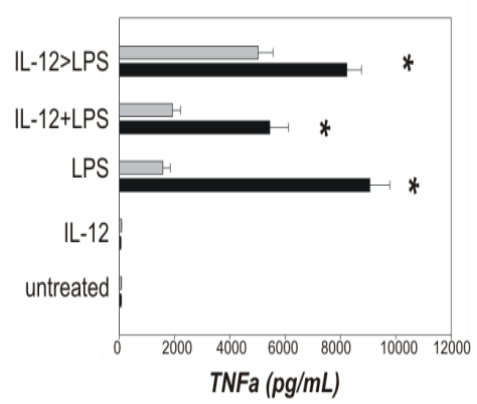

B

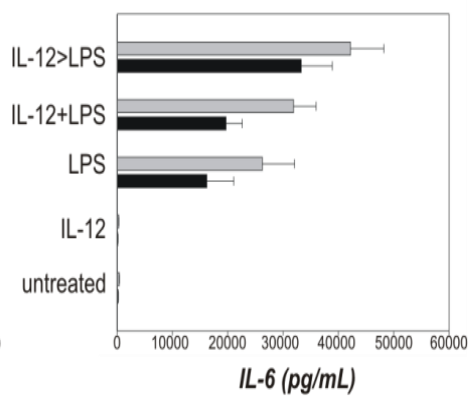

E

D

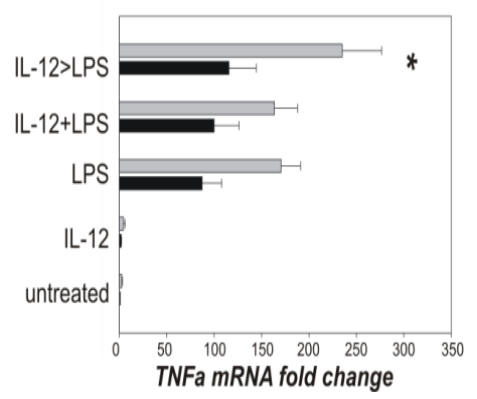

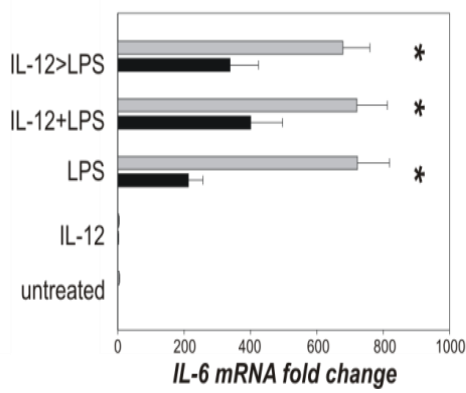

C

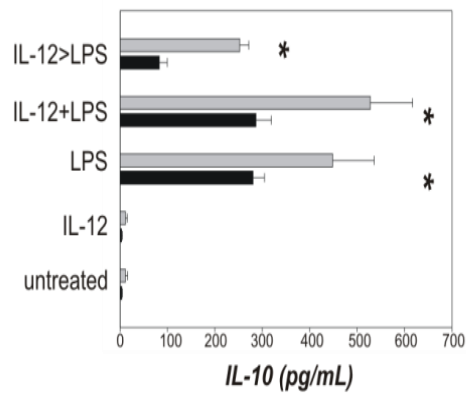

$\mathbf{F}$

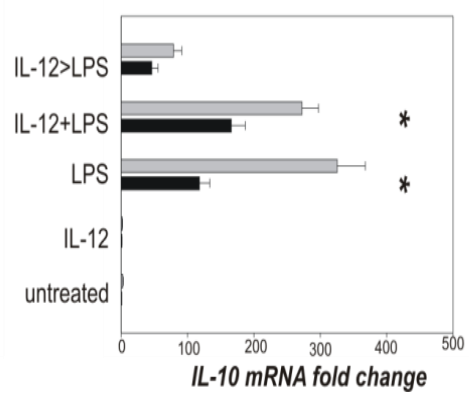

Wild-type $\square$ IFNy-/-

Figure 7. The absence of IFNy affects the response of 4T1 TAMs to IL-12 and LPS. For $A, B$, and $C, C D 5 / C D 19 / C D 11 b^{+}$cells isolated from the peritoneum of wild-type and IFNy-deficient BALB/cJ mice with 4T1 tumors were treated with IL-12, LPS, or IL-12 and LPS for 18 hours, pretreated with IL-12 for 2 hours and then treated with LPS for 18 hours, or left untreated. $100 \mathrm{ng} / \mathrm{mL}$ of IL12 and $100 \mathrm{ng} / \mathrm{mL}$ of LPS were used in all experiments. Cytokine levels were measured using cytokine bead array. For D, E. and F, CD5/CD19 /CD11 ${ }^{+}$cells isolated from the peritoneum of wild-type and IFNY-deficient BALB/cJ mice with 4T1 tumors were treated with IL-12, LPS, or IL-12+ LPS for 2 hours, pretreated with IL-12 for 2 hours and then treated with LPS for 2 hours, or left untreated. Gene expression was determined by measuring the mRNA levels of each TNFa, 
IL-6, and IL-10. All mRNA data shown was normalized to untreated wild-type 4T1 TAMs. Figures shown represent the mean \pm SEM of triplicate data and are representative of at least three independent experiments with similar results. $\left({ }^{*} p\right.$ $\left.<0.05,{ }^{* *} p<0.001\right)$ 
Figure 8

A

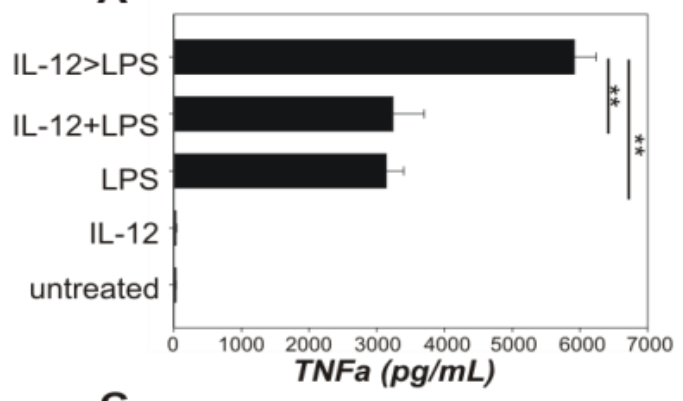

C

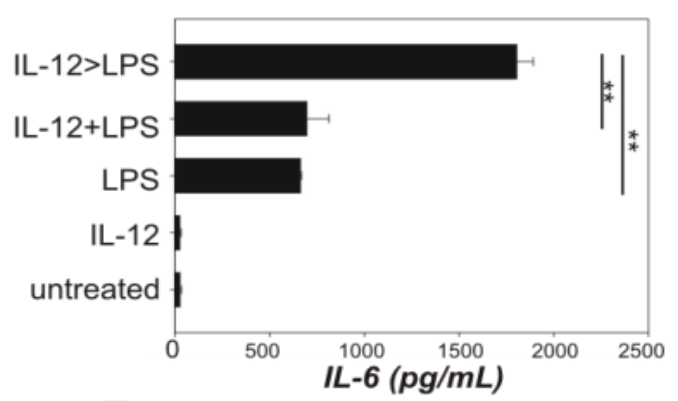

E

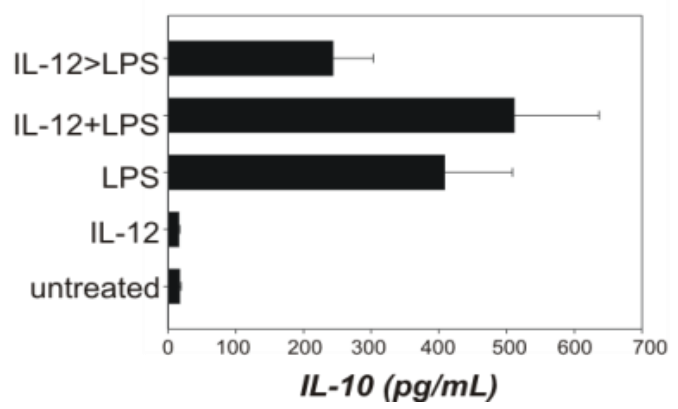

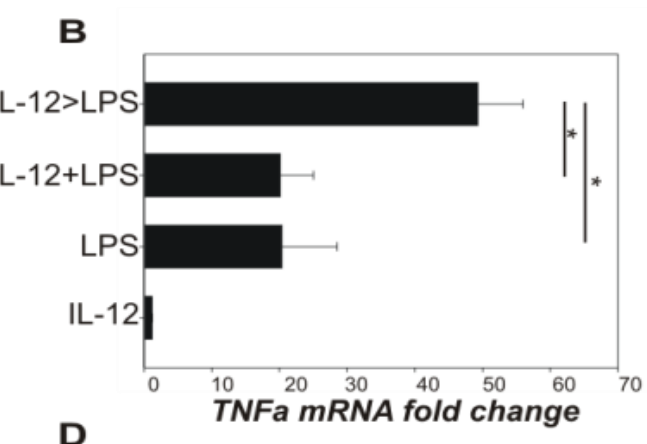

D

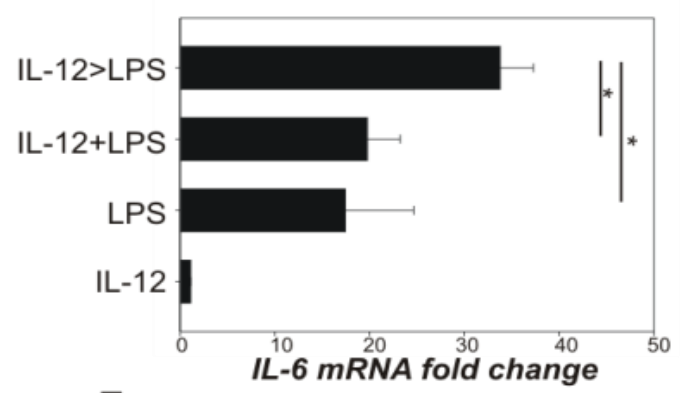

$\mathbf{F}$

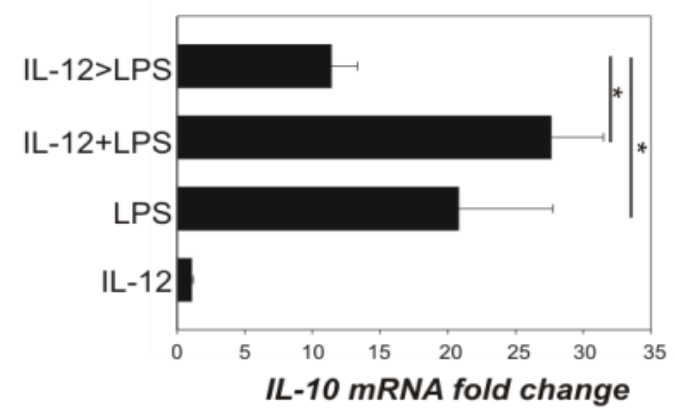

Figure 8. IL-12 modulates the response of $4 \mathrm{~T} 1$ tumor-infiltrating myeloid cells to inflammatory stimulus, LPS. CD11 $\mathrm{b}^{+}$cells isolated from $4 \mathrm{~T} 1$ tumors of BALB/CJ mice were treated with IL-12, LPS, or IL-12 and LPS for 18 hours, pretreated with IL-12 for 2 hours and then treated with LPS for 18 hours, or left untreated. $100 \mathrm{ng} / \mathrm{mL}$ of $\mathrm{IL}-12$ and $100 \mathrm{ng} / \mathrm{mL}$ of LPS were used in all experiments. TNFa $(A), \mathrm{IL}-6(B)$, and IL-10 (C) protein levels were measured using cytokine bead array. For $B, D, E, C D 11 \mathrm{~b}+$ cells were isolated from $4 \mathrm{~T} 1$ 
tumors of BALB/cJ mice and treated with IL-12, LPS, or IL-12+ LPS for 2 hours, pretreated with IL-12 for 2 hours and then treated with LPS for 2 hours, or left untreated. Gene expression was determined by measuring the mRNA levels of TNFa, IL-6, and IL-10 and normalizing to untreated $4 \mathrm{~T} 1 \mathrm{CD} 11 \mathrm{~b}+$ cells. Figures shown represent the mean \pm SEM of triplicate data and are representative of at least three independent experiments with similar results. $\left({ }^{*} p<0.05,{ }^{* *} p<0.001\right)$ 


\section{Figure 9}
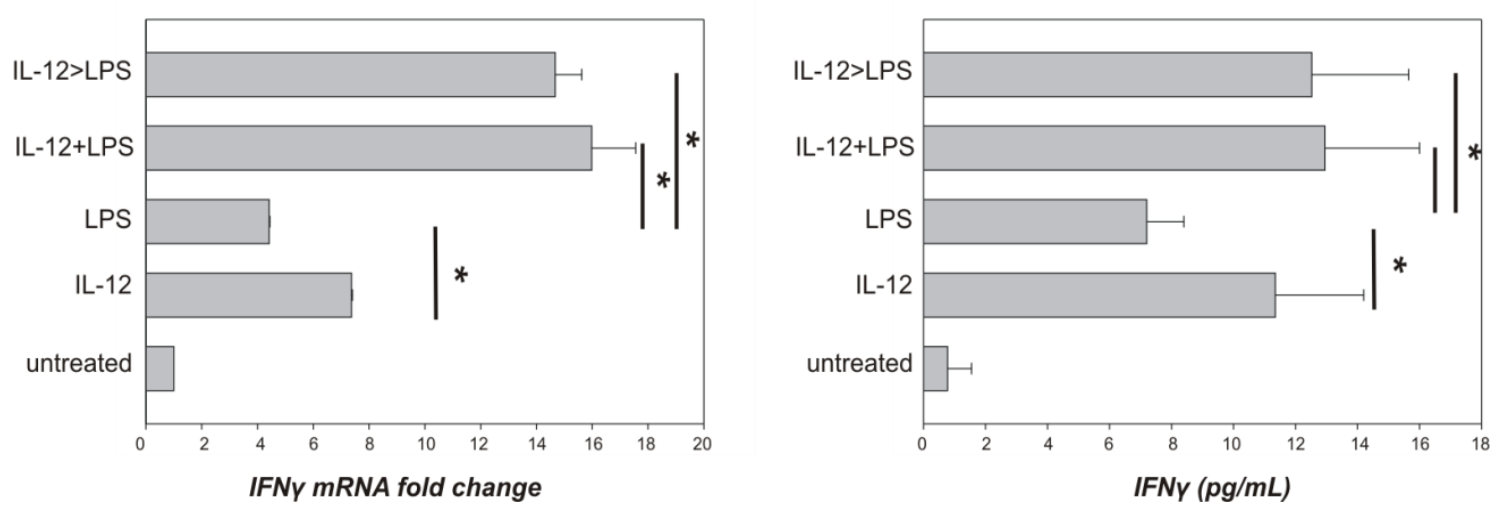

Figure 9. 4T1 TIMs produce IFNy in response to IL-12 and LPS. On left, CD11 $\mathrm{b}^{+}$cells isolated from $4 \mathrm{~T} 1$ tumors of BALB/CJ mice were treated with IL-12, LPS, or IL-12+ LPS for 2 hours, pretreated with IL-12 for 2 hours and then treated with LPS for 2 hours, or left untreated. Gene expression was determined by measuring the mRNA levels of IFNy. All treatment groups are normalized to untreated $4 \mathrm{~T} 1 \mathrm{TIMs}$. On CD11 ${ }^{+}$cells isolated from $4 \mathrm{~T} 1$ tumors of BALB/cJ mice were treated with IL-12, LPS, or IL-12 and LPS for 18 hours, pretreated with IL12 for 2 hours and then treated with LPS for 18 hours, or left untreated. $100 \mathrm{ng} / \mathrm{mL}$ of $\mathrm{IL}-12$ and $100 \mathrm{ng} / \mathrm{mL}$ of LPS were used in all experiments. IFNy protein levels were measured using cytokine bead array. Figures shown represent the mean \pm SEM of triplicate data and are representative of at least three independent experiments with similar results. $\left({ }^{*} p<0.05,{ }^{* *} p<0.001\right)$ 
Figure 10

A

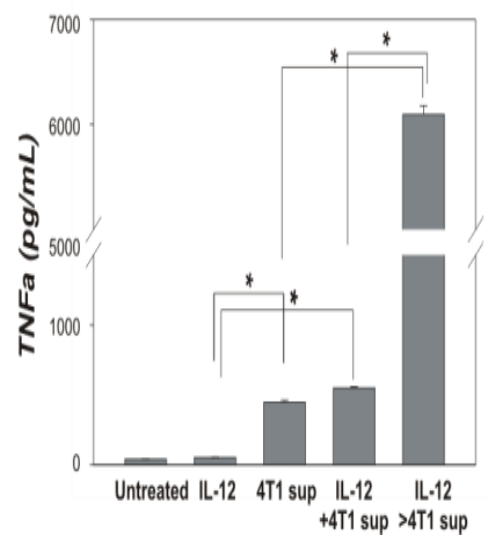

B

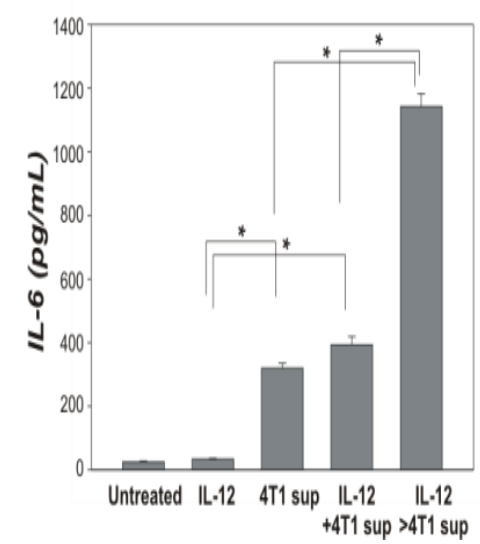

C

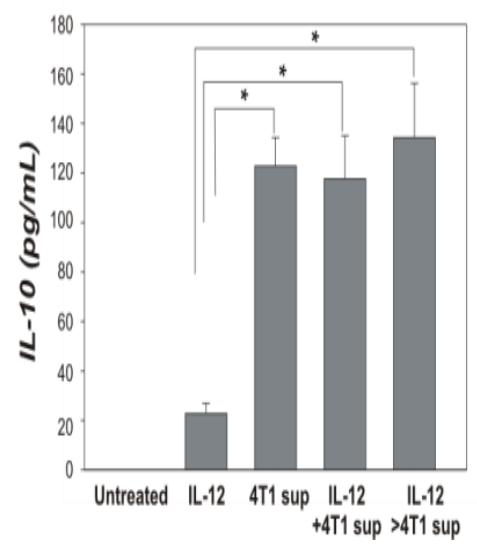

Figure 10. IL-12 increases pro-inflammatory cytokines produced by $4 \mathrm{T1}$ TIMs in response to $4 \mathrm{~T} 1$ supernatant. $\mathrm{CD} 11 \mathrm{~b}^{+}$cells isolated from $4 \mathrm{~T} 1$ tumors of BALB/cJ mice were treated with IL-12, LPS, or IL-12 and 4T1 supernatant for 18 hours, pretreated with IL-12 for 2 hours and then treated with 4T1 supernatant for 18 hours, or left untreated. $100 \mathrm{ng} / \mathrm{mL}$ of IL-12 was used in all experiments. TNF $\alpha(A)$, IL-6 (B), and IL-10 (C) protein levels were measured using cytokine bead array. Figures shown represent the mean \pm SEM of triplicate data and are representative of at least two independent experiments with similar results. ( ${ }^{*} p$ $\left.<0.05,{ }^{* *} p<0.001\right)$ 


\section{Figure 11}
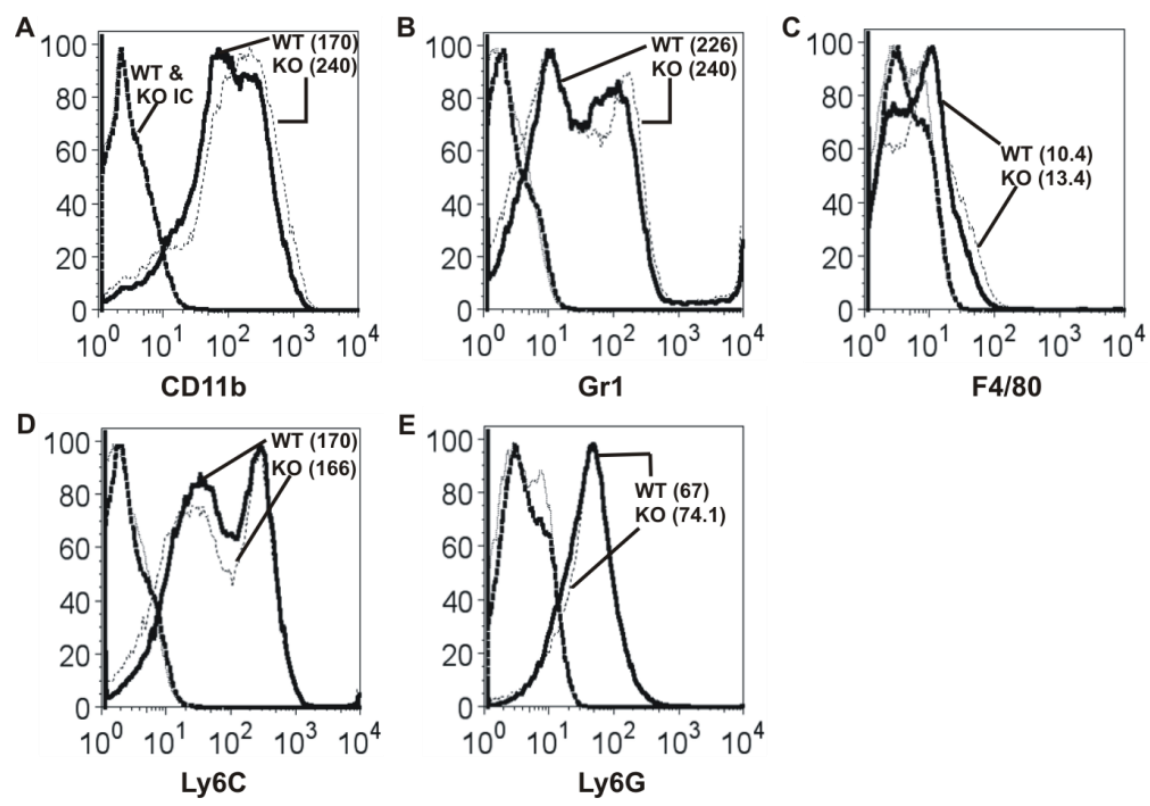

Figure 11. Innate immune cells isolated from WT and IFNY-deficient 4T1 tumor have similar myeloid associated surface markers. Unstimulated CD11b+ cells $(A)$ isolated from 4T1 tumors of WT and Ifng deficient BALB/cJ mice at day 26 were stained with anti-Gr1 $(B)$, anti-F4/80 (C), anti-Ly6C $(D)$, and anti-Ly6G $(E)$. Histograms show fluorescence of each of stained surface marker. Mean fluorescence intensity of surface stain for each group is stated numerically in parenthesis. Curves to the far left of the histogram represent isotype control for WT and IFNY-deficient samples (as labeled in A). Data shown are representative of 3 independent experiments with similar results. 
Figure 12
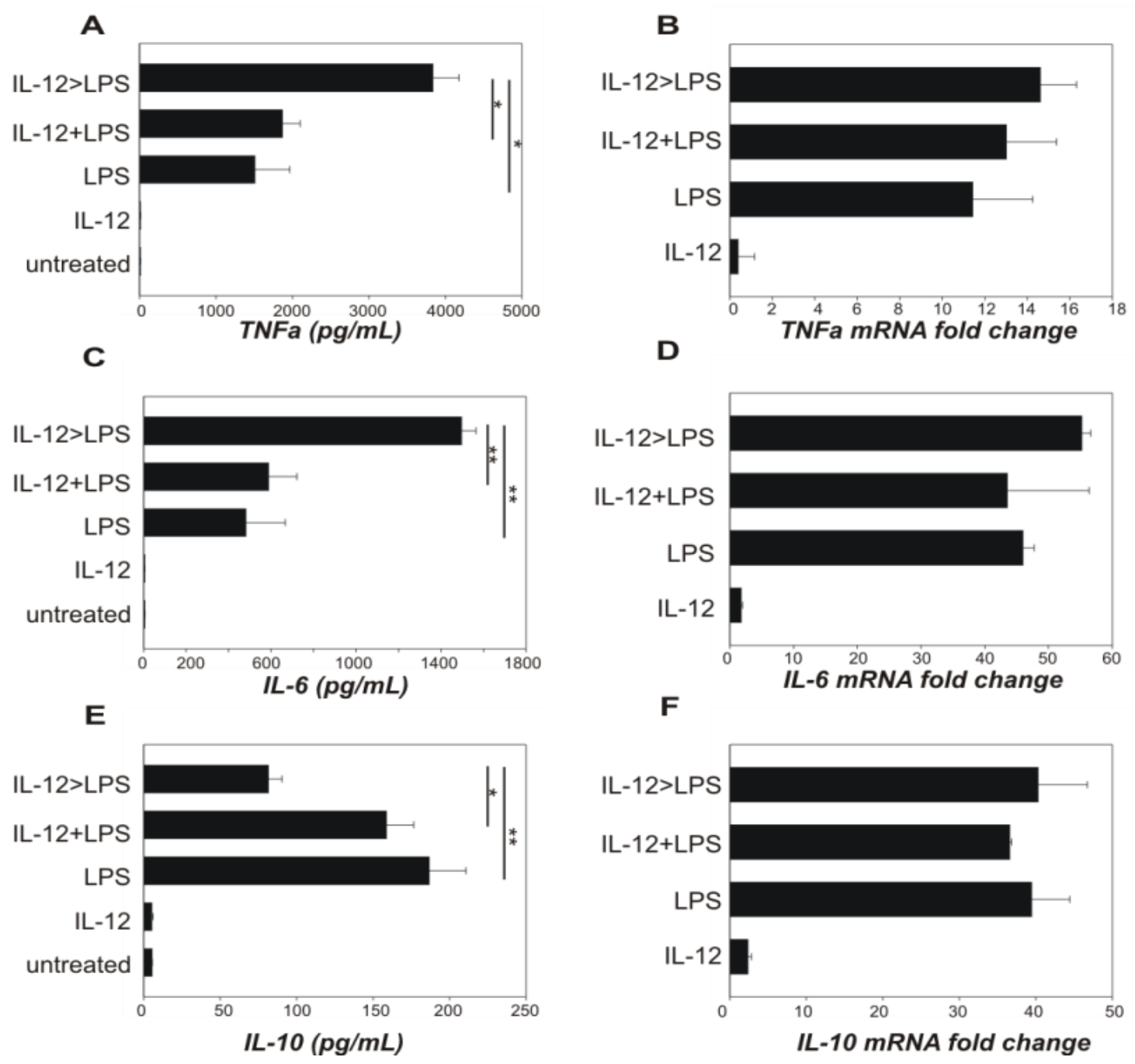

Figure 12. IL-12 modulates the response of IFNy-deficient, 4T1 tumorinfiltrating myeloid cells to inflammatory stimulus, LPS. CD $11 \mathrm{~b}^{+}$cells isolated from 4T1 tumors of Ifng deficient BALB/cJ mice were treated with IL-12, LPS, or IL-12 and LPS for 18 hours, pretreated with IL-12 for 2 hours and then treated with LPS for 18 hours, or left untreated. $100 \mathrm{ng} / \mathrm{mL}$ of IL-12 and $100 \mathrm{ng} / \mathrm{mL}$ of LPS were used in all experiments. TNFa $(A)$, IL-6 (B), and IL-10 (C) protein levels were measured using cytokine bead array. For $B, D, E, C D 11 \mathrm{~b}+$ cells were isolated from 4T1 tumors of Ifng deficient BALB/cJ mice and treated with IL-12, 
LPS, or IL-12+ LPS for 2 hours, pretreated with IL-12 for 2 hours and then treated with LPS for 2 hours, or left untreated. Gene expression was determined by measuring the mRNA levels of $T N F \alpha, I L-6$, and $I L-10$ and normalizing to bactin untreated IFNY-deficient 4T1 CD11b+ cells. Figures shown represent the mean \pm SEM of triplicate data and are representative of at least three independent experiments with similar results. $\left({ }^{*} p<0.05, \quad{ }^{* *} p<0.001\right)$ 


\section{Figure 13}
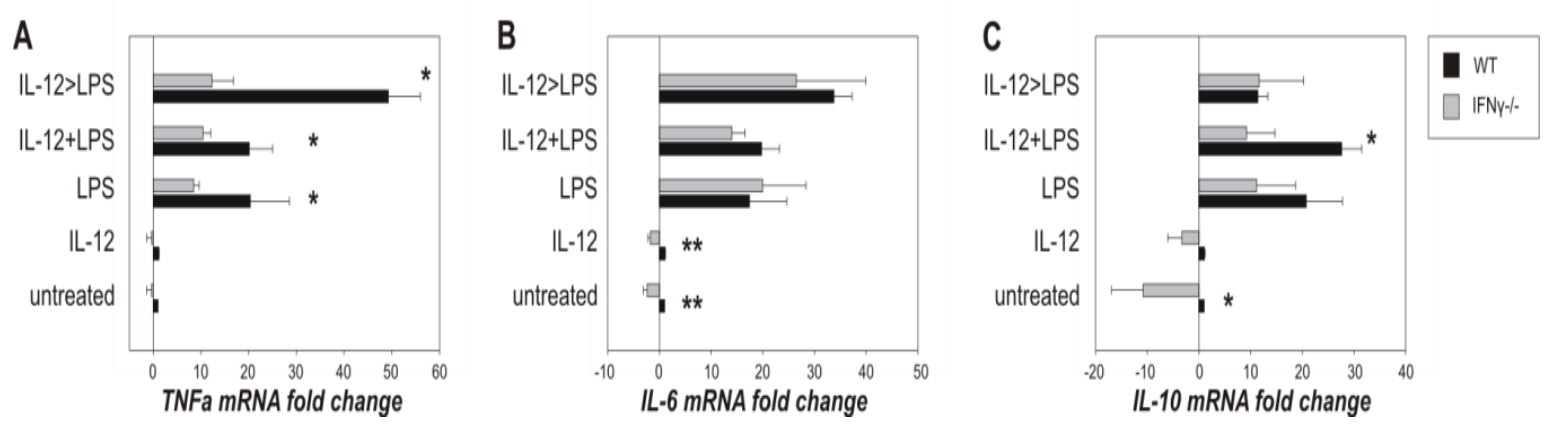

Figure 13. IFNy partially impacts the inflammatory gene profile of $4 \mathrm{~T} 1$ tumor-infiltrating myeloid cells to IL-12 and LPS. CD11b+ cells were isolated from 4T1 tumors of BALB/cJ mice and Ifng deficient BALB/cJ mice and treated with IL-12, LPS, or IL-12+ LPS for 2 hours, pretreated with IL-12 for 2 hours and then treated with LPS for 2 hours, or left untreated. $100 \mathrm{ng} / \mathrm{mL}$ of IL-12 and $100 \mathrm{ng} / \mathrm{mL}$ of LPS were used in all experiments. Gene expression was determined by measuring the mRNA levels of $T N F \alpha, I L-6$, and $I L-10$. mRNA fold change averages for each gene were normalized to WT untreated tumorinfiltrating myeloid cells for each treatment. Figures shown represent the mean \pm SD of triplicate data and are representative of at least three independent experiments with similar results. $\left({ }^{*} p<0.05,{ }^{* *} p<0.001\right)$ 
Table I

\begin{tabular}{|c|c|c|c|c|c|c|}
\hline \multirow{6}{*}{ 蕞 } & 恙 & Б્ & 总 & fิ & & 雨 \\
\hline & क & હે & 总 & 훙 & ఫ্ট్ & $\frac{\vartheta}{\stackrel{\Xi}{二}}$ \\
\hline & $\frac{1}{z}$ & $\ddot{a}$ & $\approx$ & ถู่ & 尚 & 38 \\
\hline & & & & & $\triangle$ & \\
\hline & ஜ & ə̆ & 蒙 & 胥 & $\begin{array}{l}\overline{\bar{g}} \\
\stackrel{\leftrightarrow}{\circ}\end{array}$ & ชิ \\
\hline & $\equiv$ & $\stackrel{\text { o }}{\beth 1}$ & $\stackrel{5}{0}$ & 흘 & 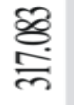 & 象 \\
\hline \multirow{6}{*}{ 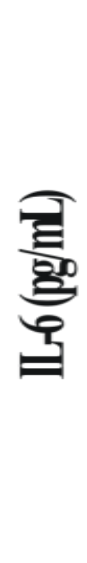 } & 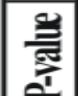 & శ్రి & ஜ̊ठ্亍 & ga & 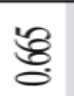 & ర్రి \\
\hline & क & 5 & 营 & $\frac{\text { 专 }}{8}$ & $\stackrel{\vartheta}{\mathscr{\theta}}$ & 雬 \\
\hline & \pm & $n$ & $\approx$ & & $\infty 3$ & \\
\hline & 至 & 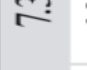 & di & $\alpha$ & ‡゙ & $\underline{\Omega}$ \\
\hline & ๘ & 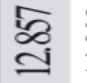 & 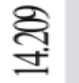 & $\begin{array}{l}\mathscr{8} \\
\stackrel{2}{\not}\end{array}$ & క్తి & 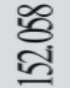 \\
\hline & $\bar{z}$ & 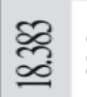 & ชิ & 落 & స్ర్రి & $\begin{array}{l}\text { 疍 } \\
\text { 겅 }\end{array}$ \\
\hline \multirow{6}{*}{ 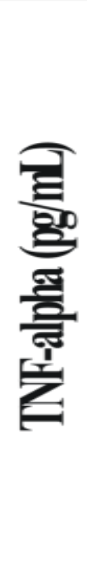 } & 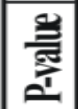 & ฮี & 番 & $\stackrel{\Xi}{\sigma}$ & $\frac{\infty}{0}$ & శ్ \\
\hline & ஜ & $\stackrel{\infty}{3}$ & $\stackrel{\overbrace{}}{\nexists}$ & $\begin{array}{l}\text { d్ర } \\
\text { 충 }\end{array}$ & 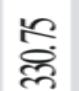 & $\frac{\ddot{D}}{\not{\Phi}}$ \\
\hline & it & 8 & है & $\stackrel{\infty}{3}$ & $\stackrel{8}{8}$ & 8 \\
\hline & - & $\mathcal{\sim}$ & $\Omega$ & 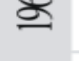 & $\approx$ & \\
\hline & क & $\stackrel{\text { હீ: }}{=}$ & 迢 & ปี & $\overline{\overline{8}}$ & Љ̊ \\
\hline & $\equiv$ & ס्व & ణ్ఞె & $\frac{\infty}{\delta}$ & 曖 & 古 \\
\hline & 胥 & 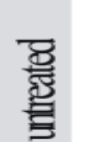 & 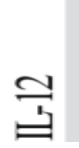 & & $\begin{array}{l}\text { 坣 } \\
\stackrel{\text { 当 }}{=}\end{array}$ & $\frac{\vec{d}}{\vec{\nexists}}$ \\
\hline
\end{tabular}


Table I. IFNy partially impacts the cytokine response of 4T1 tumorinfiltrating myeloid cells to IL-12 and LPS. CD11 $\mathrm{b}^{+}$cells isolated from 4T1 tumors of BALB/cJ mice and Ifng deficient BALB/cJ mice were treated with IL-12, LPS, or IL-12 and LPS for 18 hours, pretreated with IL-12 for 2 hours and then treated with LPS for 18 hours, or left untreated. $100 \mathrm{ng} / \mathrm{mL}$ of IL-12 and $100 \mathrm{ng} / \mathrm{mL}$ of LPS were used in all experiments. TNFa, IL-6, and IL-10 protein levels were measured using cytokine bead array. Average cytokine secretion for each treatment is compared between WT and IFNY-deficient tumor infiltrating myeloid cells. Figures shown represent the mean \pm SD of triplicate data and are representative of at least three independent experiments with similar result. 
Figure 14
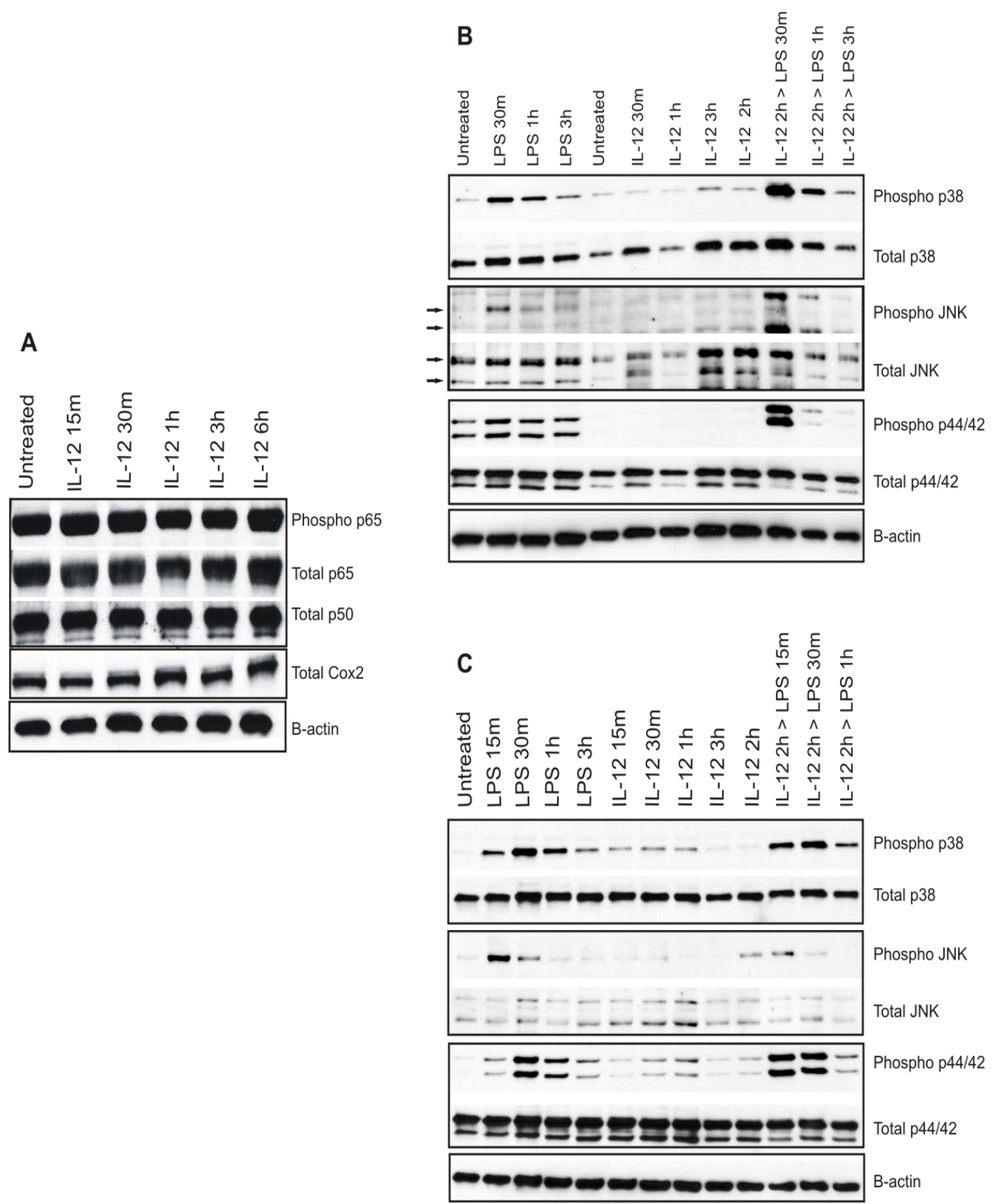

Figure 14. IL-12 enhances $4 \mathrm{~T} 1$ tumor-infiltrating myeloid cell activation of MAPK pathway in response to LPS. (A) CD11 $\mathrm{b}^{+}$cells isolated from $4 \mathrm{~T} 1$ tumors of wild-type BALB/cJ mice were treated with $100 \mathrm{ng} / \mathrm{mL} \mathrm{IL}-12$ for the indicated time points. After cell lysis, Western blot was performed using antibodies against 
phospho NF-k $\beta$ p65 (Ser536), NF-k $\beta$ p65, COX-2, NF-k $\beta$ p50, and B-actin.

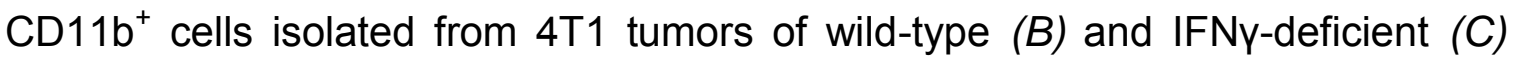
BALB/cJ mice were treated with IL-12, LPS, or IL-12 and LPS, pretreated with IL12 for 2 hours and then treated with LPS, or left untreated for indicated time points. $100 \mathrm{ng} / \mathrm{mL}$ of IL-12 and $100 \mathrm{ng} / \mathrm{mL}$ of LPS were used in all experiments. After cell lysis, Western blot was performed using antibodies against phosphop38 (Thr180/Tyr182), total p38, phospho-JNK/SAPK (Thr183/Tyr185), total JNK/SAPK, phospho-p44/42 (Thr202/Tyr204), total p44/42, and B-actin. Data shown are representative of 3 independent experiments with similar results. 


\section{CHAPTER IV \\ CONCLUSIONS AND FUTURE DIRECTION}

This work contributes to our knowledge of how IL-12 impacts myeloid cells from the cancer environment. It also demonstrates that IL-12 has IFNY independent effects on myeloid cells from tumor-bearing animals specifically with regards to IL-6 and IL-10. The relationship between IL-6 and IL-10 is very complicated and interesting. Our data suggests that IL-12, independent of IFNY, shifts the response to LPS in TIMs and TAMs to more IL-6 and less IL-10. We also show that IL-12 causes increased IL-6 without changes in IL-10 from TIMs in response to tumor derived products. Experiments to determine how IL-12 controls the expression of IL- 6 and IL-10 could lead to a better understanding of how these two cytokines contribute to the functional phenotype of myeloid cells.

One of the larger hurdles of cancer immunotherapy is the strong immunosuppression seen in advanced cancer. Early stage cancer are usually easily treated and/or resected, but it is the larger and disseminated tumors that cause the most morbidity and mortality. Agents that combat this profound immunosuppression are attractive immunotherapeutic candidates. IL-12 is a very common immunotherapeutic agent used in clinical trials. Given the broad interest in its anti-cancer effects, it is vital that there is research that focuses on the effect IL-12 on all aspects of the immune system. An area of focus for future work might 
include in vivo experiments to determine how myeloid cells within tumors respond to IL-12 in the presence and absence of IFNy. We know that IFNy is crucial for IL-12 induced tumor regression (175). This study also showed the IL12 binds to myeloid populations within the cancer to enhance the effects of adoptively transferred cytotoxic T lymphocytes partly independent of IFNY. In vivo and ex vivo experiments that observe intrinsic changes in TIMs in response to IL12 would be helpful in determining the direct impact of IL-12 on TIMs and how that is related to its anti-tumorigenic effects. Our work also shows that IL-12 has IFNy independent modulatory activity on tumor infiltrating myeloid cells. Our work and the Kerkar paper (175) illustrate the need for more in depth studies on how IL-12 impact TIMs and TAMs to improve cancer immunotherapy. Deciphering IFNy-independent effects of IL-12 on myeloid cells within cancer may provide new information on how to harness the plasticity of these cells to decrease the immunosuppression that helps maintain cancer.

One of the most interesting aspects of this dissertation is that IL-12 decreased the amount IL-10 secreted in response to LPS in both 4T1 TIMS and peritoneal TAMs. This provides a clue to a possible mechanism by which IL-12 provides a window for an inflammatory stimulus to be more effective. Inflammation is a usually a tightly controlled physiological process where resolution and immunosuppression are important in preventing pathology. In cancer, however, there is pathologic immunosuppression. IL-12 seems to break this immunosuppression and provide a window for other pro-inflammatory stimulus to be more effective. This may be due to direct effects of IL-12 on 
myeloid cell IL-10 regulation. Our lab is currently interested in how IL-10 is regulated in macrophages and myeloid cells. Our data show that AMPK is a very important regulator of myeloid cell function and plays a large role in IL-10 production $(239,240)$. Work that examines the role of IL-12 on IL-10 and AMPK in TIMs may provide critical answers about IL-10 induced immunosuppression and the role of IL-12 in reversing it. Our results are even interesting given work showing that IL-10 has proinflammatory effects in cancer via activation of CD8+ T cells $(241,242)$. These results reiterate the complexities of immune system alone, as well as, in context cancer. Understanding the multifaceted role of IL-10 in cancer is important in harnessing the power of the immune system to combat cancer.

Research always begets more questions. This work presented here is no exception. Some of these new questions might include: What other signaling pathways are impacted by IL-12 in TIMs? Is the MAPK pathway in TIMs directly involved and necessary for IL-12 induced tumor regression? Are epigenetic changes induced in TIMs after exposure to IL-12 and does this impact the functional phenotype of TIMs? Does IL-12 interaction with the tumor impact the functional phenotype of TIMs? In conclusion, this work provides a small, but important piece of the puzzle as to why and how IL-12 impacts TIMs and TAMs and helps explain its anti-tumorigenic and pro-inflammatory potential.

At the start of this project, although there was great research being done in cancer immunology and immunotherapy, there was also great skepticism about how much cancer immunology and immunotherapy would ultimately 
impact cancer patients. The naming of cancer immunotherapy as Science's Breakthrough of the Year for 2013 is proof that investigating the role of the immune system in cancer is a worthwhile pursuit. And while the work done for this project is several large steps removed from clinical application, it is the asking of simple scientific questions like those proposed in this project that lead to cancer immunotherapy being named Science's 2013 Breakthrough of the Year and hopefully to the ultimate goal of eradicating cancer. 


\section{REFERENCES}

1. Janeway, C., P Travers, M Walport, M Shlomchik 2001. Immunobiology: the immune system in health and disease. Garland Publishing, New York, NY

2. Stout, R. D., C. Jiang, B. Matta, I. Tietzel, S. K. Watkins, and J. Suttles. 2005. Macrophages Sequentially Change Their Functional Phenotype in Response to Changes in Microenvironmental Influences. The Journal of Immunology 175: 342-349.

3. Stout, R. D., and J. Suttles. 2004. Functional plasticity of macrophages: reversible adaptation to changing microenvironments. J Leukoc Biol. 76: 509-513. Epub 2004 Jun 2024.

4. Stout, R. D., S. K. Watkins, and J. Suttles. 2009. Functional plasticity of macrophages: in situ reprogramming of tumor-associated macrophages. Journal of Leukocyte Biology 86: 1105-1109.

5. Schmieder, A., J. Michel, K. Schonhaar, S. Goerdt, and K. Schledzewski. 2012. Differentiation and gene expression profile of tumor-associated macrophages. Semin Cancer Biol. 22: 289-297. Epub 2012 Feb 2013.

6. Mills, C. D., K. Kincaid, J. M. Alt, M. J. Heilman, and A. M. Hill. 2000. M1/M-2 macrophages and the Th1/Th2 paradigm. Journal of immunology 164: 6166-6173.

7. Mantovani, A., A. Sica, S. Sozzani, P. Allavena, A. Vecchi, and M. Locati. 2004. The chemokine system in diverse forms of macrophage activation and polarization. Trends Immunol 25: 677-686.

8. Martinez, F. O., A. Sica, A. Mantovani, and M. Locati. 2008. Macrophage activation and polarization. Front Biosci. 13: 453-461.

9. Gordon, S. 2003. Alternative activation of macrophages. Nat Rev Immunol. 3: 23-35.

10. Stout, R. D., and J. Suttles. 2005. Immunosenescence and macrophage functional plasticity: dysregulation of macrophage function by ageassociated microenvironmental changes. Immunol Rev. 205: 60-71.

11. Mosser, D. M., and J. P. Edwards. 2008. Exploring the full spectrum of macrophage activation. Nat Rev Immunol. 8: 958-969.

12. Rossol, M., H. Heine, U. Meusch, D. Quandt, C. Klein, M. J. Sweet, and S. Hauschildt. 2011. LPS-induced cytokine production in human monocytes and macrophages. Crit Rev Immunol 31: 379-446.

13. Poltorak, A., X. He, I. Smirnova, M. Y. Liu, C. Van Huffel, X. Du, D. Birdwell, E. Alejos, M. Silva, C. Galanos, M. Freudenberg, P. RicciardiCastagnoli, B. Layton, and B. Beutler. 1998. Defective LPS signaling in $\mathrm{C} 3 \mathrm{H} / \mathrm{HeJ}$ and $\mathrm{C} 57 \mathrm{BL} / 10 \mathrm{ScCr}$ mice: mutations in TIr4 gene. Science. 282: 2085-2088. 
14. Nagai, Y., S. Akashi, M. Nagafuku, M. Ogata, Y. Iwakura, S. Akira, T. Kitamura, A. Kosugi, M. Kimoto, and K. Miyake. 2002. Essential role of MD-2 in LPS responsiveness and TLR4 distribution. Nat Immunol. 3: 667672. Epub 2002 Jun 2010.

15. Wright, S. D., R. A. Ramos, P. S. Tobias, R. J. Ulevitch, and J. C. Mathison. 1990. CD14, a receptor for complexes of lipopolysaccharide (LPS) and LPS binding protein. Science. 249: 1431-1433.

16. Kawai, T., O. Takeuchi, T. Fujita, J. Inoue, P. F. Muhlradt, S. Sato, K. Hoshino, and S. Akira. 2001. Lipopolysaccharide stimulates the MyD88independent pathway and results in activation of IFN-regulatory factor 3 and the expression of a subset of lipopolysaccharide-inducible genes. $J$ Immunol. 167: 5887-5894.

17. Kawai, T., O. Adachi, T. Ogawa, K. Takeda, and S. Akira. 1999. Unresponsiveness of MyD88-deficient mice to endotoxin. Immunity. 11: 115-122.

18. Ghosh, S., and D. Baltimore. 1990. Activation in vitro of NF-kappa B by phosphorylation of its inhibitor I kappa B. Nature. 344: 678-682.

19. Perkins, N. D., R. M. Schmid, C. S. Duckett, K. Leung, N. R. Rice, and G. J. Nabel. 1992. Distinct combinations of NF-kappa B subunits determine the specificity of transcriptional activation. Proc Natl Acad Sci U S A. 89: 1529-1533.

20. Guha, M., and N. Mackman. 2001. LPS induction of gene expression in human monocytes. Cell Signal. 13: 85-94.

21. Yamamoto, M., S. Sato, K. Mori, K. Hoshino, O. Takeuchi, K. Takeda, and S. Akira. 2002. Cutting edge: a novel Toll/IL-1 receptor domain-containing adapter that preferentially activates the IFN-beta promoter in the Toll-like receptor signaling. J Immunol. 169: 6668-6672.

22. McWhirter, S. M., K. A. Fitzgerald, J. Rosains, D. C. Rowe, D. T. Golenbock, and T. Maniatis. 2004. IFN-regulatory factor 3-dependent gene expression is defective in Tbk1-deficient mouse embryonic fibroblasts. Proc Natl Acad Sci U S A. 101: 233-238. Epub 2003 Dec 2016.

23. Sato, S., M. Sugiyama, M. Yamamoto, Y. Watanabe, T. Kawai, K. Takeda, and S. Akira. 2003. Toll/IL-1 receptor domain-containing adaptor inducing IFN-beta (TRIF) associates with TNF receptor-associated factor 6 and TANK-binding kinase 1 , and activates two distinct transcription factors, NF-kappa B and IFN-regulatory factor-3, in the Toll-like receptor signaling. J Immunol. 171: 4304-4310.

24. Suttles, J., and R. D. Stout. 2009. Macrophage CD40 signaling: a pivotal regulator of disease protection and pathogenesis. Seminars in immunology 21: 257-264.

25. Braesch-Andersen, S., S. Paulie, H. Koho, H. Nika, P. Aspenstrom, and P. Perlmann. 1989. Biochemical characteristics and partial amino acid sequence of the receptor-like human B cell and carcinoma antigen CDw40. J Immunol. 142: 562-567. 
26. Paulie, S., A. Rosen, B. Ehlin-Henriksson, S. Braesch-Andersen, E. Jakobson, H. Koho, and P. Perlmann. 1989. The human B lymphocyte and carcinoma antigen, CDw40, is a phosphoprotein involved in growth signal transduction. J Immunol. 142: 590-595.

27. Alderson, M. R., R. J. Armitage, T. W. Tough, L. Strockbine, W. C. Fanslow, and M. K. Spriggs. 1993. CD40 expression by human monocytes: regulation by cytokines and activation of monocytes by the ligand for CD40. J Exp Med. 178: 669-674.

28. Caux, C., N. Burdin, L. Galibert, P. Hermann, N. Renard, C. ServetDelprat, and J. Banchereau. 1994. Functional CD40 on B lymphocytes and dendritic cells. Res Immunol. 145: 235-239; discussion 244-239.

29. Hollenbaugh, D., N. Mischel-Petty, C. P. Edwards, J. C. Simon, R. W. Denfeld, P. A. Kiener, and A. Aruffo. 1995. Expression of functional CD40 by vascular endothelial cells. J Exp Med. 182: 33-40.

30. Karmann, K., C. C. Hughes, J. Schechner, W. C. Fanslow, and J. S. Pober. 1995. CD40 on human endothelial cells: inducibility by cytokines and functional regulation of adhesion molecule expression. Proc Natl Acad Sci U S A. 92: 4342-4346.

31. Stout, R. D., J. Suttles, J. Xu, I. S. Grewal, and R. A. Flavell. 1996. Impaired T cell-mediated macrophage activation in CD40 ligand-deficient mice. J Immunol. 156: 8-11.

32. Wagner, D. H., Jr., R. D. Stout, and J. Suttles. 1994. Role of the CD40CD40 ligand interaction in CD4+ T cell contact-dependent activation of monocyte interleukin-1 synthesis. Eur J Immunol. 24: 3148-3154.

33. Tao, X., and R. D. Stout. 1993. T cell-mediated cognate signaling of nitric oxide production by macrophages. Requirements for macrophage activation by plasma membranes isolated from T cells. Eur J Immunol. 23: 2916-2921.

34. Liljenfeldt, L., L. C. Dieterich, A. Dimberg, S. M. Mangsbo, and A. S. Loskog. 2014. CD40L gene therapy tilts the myeloid cell profile and promotes infiltration of activated T lymphocytes. Cancer gene therapy 21: 95-102.

35. Hanissian, S. H., and R. S. Geha. 1997. Jak3 is associated with CD40 and is critical for CD40 induction of gene expression in B cells. Immunity. 6: 379-387.

36. Karras, J. G., Z. Wang, L. Huo, D. A. Frank, and T. L. Rothstein. 1997. Induction of STAT protein signaling through the CD40 receptor in B lymphocytes: distinct STAT activation following surface Ig and CD40 receptor engagement. J Immunol. 159: 4350-4355.

37. Grammer, A. C., J. L. Swantek, R. D. McFarland, Y. Miura, T. Geppert, and P. E. Lipsky. 1998. TNF receptor-associated factor-3 signaling mediates activation of p38 and Jun N-terminal kinase, cytokine secretion, and Ig production following ligation of CD40 on human B cells. J Immunol. 161: 1183-1193.

38. Berberich, I., G. Shu, F. Siebelt, J. R. Woodgett, J. M. Kyriakis, and E. A. Clark. 1996. Cross-linking CD40 on B cells preferentially induces stress- 
activated protein kinases rather than mitogen-activated protein kinases. EMBO J. 15: 92-101.

39. Hu, H. M., K. O'Rourke, M. S. Boguski, and V. M. Dixit. 1994. A novel RING finger protein interacts with the cytoplasmic domain of CD40. J Biol Chem. 269: 30069-30072.

40. van Kooten, C., and J. Banchereau. 2000. CD40-CD40 ligand. J Leukoc Biol. 67: 2-17.

41. Rothe, M., V. Sarma, V. M. Dixit, and D. V. Goeddel. 1995. TRAF2mediated activation of NF-kappa B by TNF receptor 2 and CD40. Science. 269: 1424-1427.

42. Francis, D. A., J. G. Karras, X. Y. Ke, R. Sen, and T. L. Rothstein. 1995. Induction of the transcription factors NF-kappa B, AP-1 and NF-AT during $B$ cell stimulation through the CD40 receptor. Int Immunol. 7: 151-161.

43. Mukundan, L., G. A. Bishop, K. Z. Head, L. H. Zhang, L. M. Wahl, and J. Suttles. 2005. TNF receptor-associated factor 6 is an essential mediator of CD40-activated proinflammatory pathways in monocytes and macrophages. J Immunol 174: 1081-1090.

44. Gray, P. W., and D. V. Goeddel. 1982. Structure of the human immune interferon gene. Nature. 298: 859-863.

45. Wiranowska-Stewart, M., and W. E. Stewart, 2nd. 1981. Determination of human leukocyte populations involved in production of interferons alpha and gamma. J Interferon Res. 1: 233-244.

46. Celada, A., M. J. Klemsz, and R. A. Maki. 1989. Interferon-gamma activates multiple pathways to regulate the expression of the genes for major histocompatibility class II I-A beta, tumor necrosis factor and complement component C3 in mouse macrophages. Eur J Immunol. 19: 1103-1109.

47. Nathan, C. F., H. W. Murray, M. E. Wiebe, and B. Y. Rubin. 1983. Identification of interferon-gamma as the lymphokine that activates human macrophage oxidative metabolism and antimicrobial activity. J Exp Med. 158: $670-689$.

48. Walker, E. B., V. Maino, M. Sanchez-Lanier, N. Warner, and C. Stewart. 1984. Murine gamma interferon activates the release of a macrophagederived la-inducing factor that transfers la inductive capacity. $J$ Exp Med. 159: 1532-1547.

49. Celada, A., and R. A. Maki. 1991. IFN-gamma induces the expression of the genes for MHC class II I-A beta and tumor necrosis factor through a protein kinase C-independent pathway. J Immunol. 146: 114-120.

50. Darnell, J. E., Jr., I. M. Kerr, and G. R. Stark. 1994. Jak-STAT pathways and transcriptional activation in response to IFNs and other extracellular signaling proteins. Science. 264: 1415-1421.

51. Schreiber, R. D., M. A. Farrar, G. K. Hershey, and J. Fernandez-Luna. 1992. The structure and function of interferon-gamma receptors. Int $J$ Immunopharmacol. 14: 413-419. 
52. Shuai, K., C. Schindler, V. R. Prezioso, and J. E. Darnell, Jr. 1992. Activation of transcription by IFN-gamma: tyrosine phosphorylation of a 91-kD DNA binding protein. Science. 258: 1808-1812.

53. Schindler, C., K. Shuai, V. R. Prezioso, and J. E. Darnell, Jr. 1992. Interferon-dependent tyrosine phosphorylation of a latent cytoplasmic transcription factor. Science. 257: 809-813.

54. Gifford, G. E., and M. L. Lohmann-Matthes. 1987. Gamma interferon priming of mouse and human macrophages for induction of tumor necrosis factor production by bacterial lipopolysaccharide. J Natl Cancer Inst. 78: 121-124.

55. Pace, J. L., S. W. Russell, R. D. Schreiber, A. Altman, and D. H. Katz. 1983. Macrophage activation: priming activity from a T-cell hybridoma is attributable to interferon-gamma. Proc Natl Acad Sci U S A. 80: 37823786.

56. Pace, J. L., S. W. Russell, B. A. Torres, H. M. Johnson, and P. W. Gray. 1983. Recombinant mouse gamma interferon induces the priming step in macrophage activation for tumor cell killing. J Immunol. 130: 2011-2013.

57. de Waal Malefyt, R., J. Abrams, B. Bennett, C. G. Figdor, and J. E. de Vries. 1991. Interleukin 10(IL-10) inhibits cytokine synthesis by human monocytes: an autoregulatory role of IL-10 produced by monocytes. J Exp Med. 174: 1209-1220.

58. Iyer, S. S., and G. Cheng. 2012. Role of interleukin 10 transcriptional regulation in inflammation and autoimmune disease. Crit Rev Immunol 32: 23-63.

59. Tone, M., M. J. Powell, Y. Tone, S. A. Thompson, and H. Waldmann. 2000. IL-10 gene expression is controlled by the transcription factors Sp1 and Sp3. J Immunol. 165: 286-291.

60. Brightbill, H. D., S. E. Plevy, R. L. Modlin, and S. T. Smale. 2000. A prominent role for Sp1 during lipopolysaccharide-mediated induction of the IL-10 promoter in macrophages. J Immunol. 164: 1940-1951.

61. Staples, K. J., T. Smallie, L. M. Williams, A. Foey, B. Burke, B. M. Foxwell, and L. Ziegler-Heitbrock. 2007. IL-10 induces IL-10 in primary human monocyte-derived macrophages via the transcription factor Stat3. $J$ Immunol. 178: 4779-4785.

62. Iyer, S. S., A. A. Ghaffari, and G. Cheng. 2010. Lipopolysaccharidemediated IL-10 transcriptional regulation requires sequential induction of type I IFNs and IL-27 in macrophages. J Immunol. 185: 6599-6607. Epub 2010 Nov 6591.

63. Cao, S., J. Liu, L. Song, and X. Ma. 2005. The protooncogene c-Maf is an essential transcription factor for IL-10 gene expression in macrophages. $J$ Immunol. 174: 3484-3492.

64. Chiang, B. T., Y. W. Liu, B. K. Chen, J. M. Wang, and W. C. Chang. 2006. Direct interaction of C/EBPdelta and Sp1 at the GC-enriched promoter region synergizes the IL-10 gene transcription in mouse macrophage. $J$ Biomed Sci. 13: 621-635. Epub 2006 Jul 2027. 
65. Csoka, B., Z. H. Nemeth, L. Virag, P. Gergely, S. J. Leibovich, P. Pacher, C. X. Sun, M. R. Blackburn, E. S. Vizi, E. A. Deitch, and G. Hasko. 2007. A2A adenosine receptors and C/EBPbeta are crucially required for IL-10 production by macrophages exposed to Escherichia coli. Blood. 110: 2685-2695. Epub 2007 May 2624.

66. Avni, D., O. Ernst, A. Philosoph, and T. Zor. 2010. Role of CREB in modulation of TNFalpha and IL-10 expression in LPS-stimulated RAW264.7 macrophages. Mol Immunol. 47: 1396-1403. Epub 2010 Mar 1319.

67. Brenner, S., S. Prosch, K. Schenke-Layland, U. Riese, U. Gausmann, and C. Platzer. 2003. cAMP-induced Interleukin-10 promoter activation depends on CCAAT/enhancer-binding protein expression and monocytic differentiation. J Biol Chem. 278: 5597-5604. Epub 2002 Dec 5518.

68. Platzer, C., E. Fritsch, T. Elsner, M. H. Lehmann, H. D. Volk, and S. Prosch. 1999. Cyclic adenosine monophosphate-responsive elements are involved in the transcriptional activation of the human IL-10 gene in monocytic cells. Eur J Immunol. 29: 3098-3104.

69. Zhang, X., J. P. Edwards, and D. M. Mosser. 2006. Dynamic and transient remodeling of the macrophage IL-10 promoter during transcription. $J$ Immunol. 177: 1282-1288.

70. Donnelly, R. P., H. Dickensheets, and D. S. Finbloom. 1999. The interleukin-10 signal transduction pathway and regulation of gene expression in mononuclear phagocytes. J Interferon Cytokine Res. 19: 563-573.

71. Riley, J. K., K. Takeda, S. Akira, and R. D. Schreiber. 1999. Interleukin-10 receptor signaling through the JAK-STAT pathway. Requirement for two distinct receptor-derived signals for anti-inflammatory action. J Biol Chem. 274: 16513-16521.

72. El Kasmi, K. C., A. M. Smith, L. Williams, G. Neale, A. D. Panopoulos, S. S. Watowich, H. Hacker, B. M. Foxwell, and P. J. Murray. 2007. Cutting edge: A transcriptional repressor and corepressor induced by the STAT3regulated anti-inflammatory signaling pathway. J Immunol. 179: 72157219.

73. Kubo, M., T. Hanada, and A. Yoshimura. 2003. Suppressors of cytokine signaling and immunity. Nat Immunol. 4: 1169-1176.

74. Yasukawa, H., M. Ohishi, H. Mori, M. Murakami, T. Chinen, D. Aki, T. Hanada, K. Takeda, S. Akira, M. Hoshijima, T. Hirano, K. R. Chien, and A. Yoshimura. 2003. IL-6 induces an anti-inflammatory response in the absence of SOCS3 in macrophages. Nat Immunol. 4: 551-556. Epub 2003 May 2018.

75. Niemand, C., A. Nimmesgern, S. Haan, P. Fischer, F. Schaper, R. Rossaint, P. C. Heinrich, and G. Muller-Newen. 2003. Activation of STAT3 by IL-6 and IL-10 in primary human macrophages is differentially modulated by suppressor of cytokine signaling 3. J Immunol. 170: 32633272. 
76. Antoniv, T. T., and L. B. Ivashkiv. 2011. Interleukin-10-induced gene expression and suppressive function are selectively modulated by the PI3K-Akt-GSK3 pathway. Immunology. 132: 567-577. doi: 510.1111/j.1365-2567.2010.03402.x. Epub 02011 Jan 03424.

77. Kang, X., H. J. Kim, M. Ramirez, S. Salameh, and X. Ma. 2010. The septic shock-associated IL-10 -1082 A > G polymorphism mediates allelespecific transcription via poly(ADP-Ribose) polymerase 1 in macrophages engulfing apoptotic cells. J Immunol. 184: 3718-3724. Epub 2010 Feb 3724.

78. Yee, C. S., Y. Yao, Q. Xu, B. McCarthy, D. Sun-Lin, M. Tone, H. Waldmann, and C. H. Chang. 2005. Enhanced production of IL-10 by dendritic cells deficient in CIITA. J Immunol. 174: 1222-1229.

79. Chomarat, P., M. C. Rissoan, J. Banchereau, and P. Miossec. 1993. Interferon gamma inhibits interleukin 10 production by monocytes. $J$ Exp Med. 177: 523-527.

80. Hu, X., P. K. Paik, J. Chen, A. Yarilina, L. Kockeritz, T. T. Lu, J. R. Woodgett, and L. B. Ivashkiv. 2006. IFN-gamma suppresses IL-10 production and synergizes with TLR2 by regulating GSK3 and CREB/AP-1 proteins. Immunity. 24: 563-574.

81. Johnson, G. L., and R. Lapadat. 2002. Mitogen-activated protein kinase pathways mediated by ERK, JNK, and p38 protein kinases. Science. 298: 1911-1912.

82. Kyriakis, J. M., and J. Avruch. 2012. Mammalian MAPK signal transduction pathways activated by stress and inflammation: a 10-year update. Physiol Rev. 92: 689-737.

83. Raman, M., W. Chen, and M. H. Cobb. 2007. Differential regulation and properties of MAPKs. Oncogene. 26: 3100-3112.

84. Davis, R. J. 2000. Signal transduction by the JNK group of MAP kinases. Cell. 103: 239-252.

85. Wada, T., N. Joza, H. Y. Cheng, T. Sasaki, I. Kozieradzki, K. Bachmaier, T. Katada, M. Schreiber, E. F. Wagner, H. Nishina, and J. M. Penninger. 2004. MKK7 couples stress signalling to G2/M cell-cycle progression and cellular senescence. Nat Cell Biol. 6: 215-226. Epub 2004 Feb 2022.

86. Lawler, S., Y. Fleming, M. Goedert, and P. Cohen. 1998. Synergistic activation of SAPK1/JNK1 by two MAP kinase kinases in vitro. Curr Biol. 8: $1387-1390$.

87. Dumitru, C. D., J. D. Ceci, C. Tsatsanis, D. Kontoyiannis, K. Stamatakis, J. H. Lin, C. Patriotis, N. A. Jenkins, N. G. Copeland, G. Kollias, and P. N. Tsichlis. 2000. TNF-alpha induction by LPS is regulated posttranscriptionally via a Tpl2/ERK-dependent pathway. Cell. 103: 10711083.

88. Rousseau, S., M. Papoutsopoulou, A. Symons, D. Cook, J. M. Lucocq, A. R. Prescott, A. O'Garra, S. C. Ley, and P. Cohen. 2008. TPL2-mediated activation of ERK1 and ERK2 regulates the processing of pre-TNF alpha in LPS-stimulated macrophages. J Cell Sci. 121: 149-154. 
89. Eliopoulos, A. G., C. D. Dumitru, C. C. Wang, J. Cho, and P. N. Tsichlis. 2002. Induction of COX-2 by LPS in macrophages is regulated by Tpl2dependent CREB activation signals. EMBO J. 21: 4831-4840.

90. Bode, J. G., C. Ehlting, and D. Haussinger. 2012. The macrophage response towards LPS and its control through the p38(MAPK)-STAT3 axis. Cell Signal. 24: 1185-1194. Epub 2012 Feb 1184.

91. Kang, Y. J., J. Chen, M. Otsuka, J. Mols, S. Ren, Y. Wang, and J. Han. 2008. Macrophage deletion of p38alpha partially impairs lipopolysaccharide-induced cellular activation. J Immunol. 180: 50755082.

92. Mellett, M., P. Atzei, R. Jackson, L. A. O'Neill, and P. N. Moynagh. 2011. Mal mediates TLR-induced activation of CREB and expression of IL-10. J Immunol. 186: 4925-4935. Epub 2011 Mar 4911.

93. Valledor, A. F., E. Sanchez-Tillo, L. Arpa, J. M. Park, C. Caelles, J. Lloberas, and A. Celada. 2008. Selective roles of MAPKs during the macrophage response to IFN-gamma. J Immunol. 180: 4523-4529.

94. Roy, S. K., J. Hu, Q. Meng, Y. Xia, P. S. Shapiro, S. P. Reddy, L. C. Platanias, D. J. Lindner, P. F. Johnson, C. Pritchard, G. Pages, J. Pouyssegur, and D. V. Kalvakolanu. 2002. MEKK1 plays a critical role in activating the transcription factor C/EBP-beta-dependent gene expression in response to IFN-gamma. Proc Natl Acad Sci U S A. 99: 7945-7950. Epub 2002 Jun 7944.

95. Balkwill, F., and A. Mantovani. 2001. Inflammation and cancer: back to Virchow? Lancet. 357: 539-545.

96. Rook, G. 1992. Tumours and Coley's toxins. Nature. 357: 545.

97. James, K., R. T. Cullen, I. Milne, and M. Norval. 1978. Antitumour responses induced by short-term pretreatment with tumour cells. $\mathrm{Br} \mathrm{J}$ Cancer. 37: 269-281.

98. Hanahan, D., and R. A. Weinberg. 2011. Hallmarks of cancer: the next generation. Cell. 144: 646-674.

99. Cavallo, F., C. De Giovanni, P. Nanni, G. Forni, and P. L. Lollini. 2011. 2011: the immune hallmarks of cancer. Cancer Immunol Immunother. 60: 319-326. Epub 2011 Jan 2026.

100. Cai, Q. C., H. Liao, S. X. Lin, Y. Xia, X. X. Wang, Y. Gao, Z. X. Lin, J. B. $\mathrm{Lu}$, and H. Q. Huang. 2011. High expression of tumor-infiltrating macrophages correlates with poor prognosis in patients with diffuse large B-cell lymphoma. Med Oncol 24: 24.

101. Komohara, Y., H. Hasita, K. Ohnishi, Y. Fujiwara, S. Suzu, M. Eto, and M. Takeya. 2011. Macrophage infiltration and its prognostic relevance in clear cell renal cell carcinoma. Cancer Sci. 102: 1424-1431. doi: 1410.1111/j.1349-7006.2011.01945.x. Epub 02011 May 01949.

102. Campbell, M. J., N. Y. Tonlaar, E. R. Garwood, D. Huo, D. H. Moore, A. I. Khramtsov, A. Au, F. Baehner, Y. Chen, D. O. Malaka, A. Lin, O. O. Adeyanju, S. Li, C. Gong, M. McGrath, O. I. Olopade, and L. J. Esserman. 2011. Proliferating macrophages associated with high grade, hormone 
receptor negative breast cancer and poor clinical outcome. Breast Cancer Res Treat. 128: 703-711. Epub 2010 Sep 2015.

103. Zhang, B. C., J. Gao, J. Wang, Z. G. Rao, B. C. Wang, and J. F. Gao. 2011. Tumor-associated macrophages infiltration is associated with peritumoral lymphangiogenesis and poor prognosis in lung adenocarcinoma. Med Oncol. 28: 1447-1452. Epub 2010 Jul 1430.

104. Rigby, R. J., J. G. Simmons, C. J. Greenhalgh, W. S. Alexander, and P. K. Lund. 2007. Suppressor of cytokine signaling 3 (SOCS3) limits damageinduced crypt hyper-proliferation and inflammation-associated tumorigenesis in the colon. Oncogene. 26: 4833-4841. Epub 2007 Feb 4812.

105. Mayi, T. H., M. Daoudi, B. Derudas, B. Gross, G. Bories, K. Wouters, J. Brozek, R. Caiazzo, V. Raverdi, M. Pigeyre, P. Allavena, A. Mantovani, F. Pattou, B. Staels, and G. Chinetti-Gbaguidi. 2012. Human adipose tissue macrophages display activation of cancer-related pathways. $J$ Biol Chem 17: 17.

106. Hammes, L. S., R. R. Tekmal, P. Naud, M. I. Edelweiss, N. Kirma, P. T. Valente, K. J. Syrjanen, and J. S. Cunha-Filho. 2007. Macrophages, inflammation and risk of cervical intraepithelial neoplasia (CIN) progression--clinicopathological correlation. Gynecol Oncol. 105: 157-165. Epub 2007 Jan 2016.

107. Mantovani, A. 2010. The growing diversity and spectrum of action of myeloid-derived suppressor cells. Eur J Immunol. 40: 3317-3320.

108. Youn, J. I., S. Nagaraj, M. Collazo, and D. I. Gabrilovich. 2008. Subsets of myeloid-derived suppressor cells in tumor-bearing mice. J Immunol. 181: 5791-5802.

109. Movahedi, K., M. Guilliams, J. Van den Bossche, R. Van den Bergh, C. Gysemans, A. Beschin, P. De Baetselier, and J. A. Van Ginderachter. 2008. Identification of discrete tumor-induced myeloid-derived suppressor cell subpopulations with distinct $\mathrm{T}$ cell-suppressive activity. Blood. 111: 4233-4244. Epub 2008 Feb 4213.

110. Lesokhin, A. M., T. M. Hohl, S. Kitano, C. Cortez, D. HirschhornCymerman, F. Avogadri, G. A. Rizzuto, J. J. Lazarus, E. G. Pamer, A. N. Houghton, T. Merghoub, and J. D. Wolchok. 2012. Monocytic CCR2(+) myeloid-derived suppressor cells promote immune escape by limiting activated CD8 T-cell infiltration into the tumor microenvironment. Cancer Res. 72: 876-886. Epub 2011 Dec 2015.

111. Daurkin, I., E. Eruslanov, T. Stoffs, G. Q. Perrin, C. Algood, S. M. Gilbert, C. J. Rosser, L. M. Su, J. Vieweg, and S. Kusmartsev. 2011. Tumorassociated macrophages mediate immunosuppression in the renal cancer microenvironment by activating the 15-lipoxygenase-2 pathway. Cancer Res. 71: 6400-6409. Epub 2011 Sep 6407.

112. Lin, E. Y., A. V. Nguyen, R. G. Russell, and J. W. Pollard. 2001. Colonystimulating factor 1 promotes progression of mammary tumors to malignancy. J Exp Med. 193: 727-740. 
113. Lewis, J. S., R. J. Landers, J. C. Underwood, A. L. Harris, and C. E. Lewis. 2000. Expression of vascular endothelial growth factor by macrophages is up-regulated in poorly vascularized areas of breast carcinomas. J Pathol. 192: 150-158.

114. De Palma, M., M. A. Venneri, R. Galli, L. Sergi Sergi, L. S. Politi, M. Sampaolesi, and L. Naldini. 2005. Tie2 identifies a hematopoietic lineage of proangiogenic monocytes required for tumor vessel formation and a mesenchymal population of pericyte progenitors. Cancer Cell. 8: 211-226.

115. Welgus, H. G., E. J. Campbell, J. D. Cury, A. Z. Eisen, R. M. Senior, S. M. Wilhelm, and G. I. Goldberg. 1990. Neutral metalloproteinases produced by human mononuclear phagocytes. Enzyme profile, regulation, and expression during cellular development. J Clin Invest. 86: 1496-1502.

116. Wang, R., J. Zhang, S. Chen, M. Lu, X. Luo, S. Yao, S. Liu, Y. Qin, and H. Chen. 2011. Tumor-associated macrophages provide a suitable microenvironment for non-small lung cancer invasion and progression. Lung Cancer. 74: 188-196. Epub 2011 May 2020.

117. Qian, B., Y. Deng, J. H. Im, R. J. Muschel, Y. Zou, J. Li, R. A. Lang, and J. W. Pollard. 2009. A distinct macrophage population mediates metastatic breast cancer cell extravasation, establishment and growth. PLoS One. 4: e6562.

118. Qian, B. Z., J. Li, H. Zhang, T. Kitamura, J. Zhang, L. R. Campion, E. A. Kaiser, L. A. Snyder, and J. W. Pollard. 2011. CCL2 recruits inflammatory monocytes to facilitate breast-tumour metastasis. Nature. 475: 222-225. doi: 210.1038/nature10138.

119. Gil-Bernabe, A. M., S. Ferjancic, M. Tlalka, L. Zhao, P. D. Allen, J. H. Im, K. Watson, S. A. Hill, A. Amirkhosravi, J. L. Francis, J. W. Pollard, W. Ruf, and R. J. Muschel. 2012. Recruitment of monocytes/macrophages by tissue factor-mediated coagulation is essential for metastatic cell survival and premetastatic niche establishment in mice. Blood. 119: 3164-3175. Epub 2012 Feb 3110.

120. Kantoff, P. W., C. S. Higano, N. D. Shore, E. R. Berger, E. J. Small, D. F. Penson, C. H. Redfern, A. C. Ferrari, R. Dreicer, R. B. Sims, Y. Xu, M. W. Frohlich, and P. F. Schellhammer. 2010. Sipuleucel-T immunotherapy for castration-resistant prostate cancer. N Engl J Med. 363: 411-422.

121. Small, E. J., P. F. Schellhammer, C. S. Higano, C. H. Redfern, J. J. Nemunaitis, F. H. Valone, S. S. Verjee, L. A. Jones, and R. M. Hershberg. 2006. Placebo-controlled phase III trial of immunologic therapy with sipuleucel-T (APC8015) in patients with metastatic, asymptomatic hormone refractory prostate cancer. J Clin Oncol. 24: 3089-3094.

122. Leach, D. R., M. F. Krummel, and J. P. Allison. 1996. Enhancement of antitumor immunity by CTLA-4 blockade. Science. 271: 1734-1736.

123. Robert, C., L. Thomas, I. Bondarenko, S. O'Day, D. J. M, C. Garbe, C. Lebbe, J. F. Baurain, A. Testori, J. J. Grob, N. Davidson, J. Richards, M. Maio, A. Hauschild, W. H. Miller, Jr., P. Gascon, M. Lotem, K. Harmankaya, R. Ibrahim, S. Francis, T. T. Chen, R. Humphrey, A. Hoos, and J. D. Wolchok. 2011. Ipilimumab plus dacarbazine for previously 
untreated metastatic melanoma. $N$ Engl $J$ Med. 364: 2517-2526. Epub 2011 Jun 2515.

124. Kobayashi, M., L. Fitz, M. Ryan, R. M. Hewick, S. C. Clark, S. Chan, R. Loudon, F. Sherman, B. Perussia, and G. Trinchieri. 1989. Identification and purification of natural killer cell stimulatory factor (NKSF), a cytokine with multiple biologic effects on human lymphocytes. J Exp Med. 170: 827-845.

125. Gubler, U., A. O. Chua, D. S. Schoenhaut, C. M. Dwyer, W. McComas, R. Motyka, N. Nabavi, A. G. Wolitzky, P. M. Quinn, P. C. Familletti, and et al. 1991. Coexpression of two distinct genes is required to generate secreted bioactive cytotoxic lymphocyte maturation factor. Proc Natl Acad Sci U S A. 88: 4143-4147.

126. Wolf, S. F., P. A. Temple, M. Kobayashi, D. Young, M. Dicig, L. Lowe, R. Dzialo, L. Fitz, C. Ferenz, R. M. Hewick, and et al. 1991. Cloning of cDNA for natural killer cell stimulatory factor, a heterodimeric cytokine with multiple biologic effects on $\mathrm{T}$ and natural killer cells. J Immunol. 146: 3074-3081.

127. Watford, W. T., M. Moriguchi, A. Morinobu, and J. J. O'Shea. 2003. The biology of IL-12: coordinating innate and adaptive immune responses. Cytokine Growth Factor Rev. 14: 361-368.

128. Gately, M. K., D. M. Carvajal, S. E. Connaughton, S. Gillessen, R. R. Warrier, K. D. Kolinsky, V. L. Wilkinson, C. M. Dwyer, G. F. Higgins, Jr., F. J. Podlaski, D. A. Faherty, P. C. Familletti, A. S. Stern, and D. H. Presky. 1996. Interleukin-12 antagonist activity of mouse interleukin-12 p40 homodimer in vitro and in vivo. Ann N Y Acad Sci. 795: 1-12.

129. Trinchieri, G., and F. Gerosa. 1996. Immunoregulation by interleukin-12. J Leukoc Biol. 59: 505-511.

130. Murphy, T. L., M. G. Cleveland, P. Kulesza, J. Magram, and K. M. Murphy. 1995. Regulation of interleukin 12 p40 expression through an NF-kappa B half-site. Mol Cell Biol. 15: 5258-5267.

131. Ma, X., J. M. Chow, G. Gri, G. Carra, F. Gerosa, S. F. Wolf, R. Dzialo, and G. Trinchieri. 1996. The interleukin 12 p40 gene promoter is primed by interferon gamma in monocytic cells. J Exp Med. 183: 147-157.

132. Ma, X., M. Neurath, G. Gri, and G. Trinchieri. 1997. Identification and characterization of a novel Ets-2-related nuclear complex implicated in the activation of the human interleukin-12 p40 gene promoter. J Biol Chem. 272: 10389-10395.

133. Plevy, S. E., J. H. Gemberling, S. Hsu, A. J. Dorner, and S. T. Smale. 1997. Multiple control elements mediate activation of the murine and human interleukin 12 p40 promoters: evidence of functional synergy between C/EBP and Rel proteins. Mol Cell Biol. 17: 4572-4588.

134. Wang, I. M., C. Contursi, A. Masumi, X. Ma, G. Trinchieri, and K. Ozato. 2000. An IFN-gamma-inducible transcription factor, IFN consensus sequence binding protein (ICSBP), stimulates IL-12 p40 expression in macrophages. J Immunol. 165: 271-279. 
135. Gri, G., D. Savio, G. Trinchieri, and X. Ma. 1998. Synergistic regulation of the human interleukin-12 p40 promoter by NFkappaB and Ets transcription factors in Epstein-Barr virus-transformed B cells and macrophages. $J$ Biol Chem. 273: 6431-6438.

136. Babik, J. M., E. Adams, Y. Tone, P. J. Fairchild, M. Tone, and H. Waldmann. 1999. Expression of murine IL-12 is regulated by translational control of the p35 subunit. J Immunol. 162: 4069-4078.

137. Akira, S., K. Takeda, and T. Kaisho. 2001. Toll-like receptors: critical proteins linking innate and acquired immunity. Nat Immunol. 2: 675-680.

138. Scanga, C. A., J. Aliberti, D. Jankovic, F. Tilloy, S. Bennouna, E. Y. Denkers, R. Medzhitov, and A. Sher. 2002. Cutting edge: MyD88 is required for resistance to Toxoplasma gondii infection and regulates parasite-induced IL-12 production by dendritic cells. J Immunol. 168: 5997-6001.

139. Cella, M., D. Scheidegger, K. Palmer-Lehmann, P. Lane, A. Lanzavecchia, and G. Alber. 1996. Ligation of CD40 on dendritic cells triggers production of high levels of interleukin-12 and enhances $T$ cell stimulatory capacity: T-T help via APC activation. J Exp Med. 184: 747752.

140. Yoshida, A., Y. Koide, M. Uchijima, and T. O. Yoshida. 1994. IFN-gamma induces IL-12 mRNA expression by a murine macrophage cell line, J774. Biochem Biophys Res Commun. 198: 857-861.

141. Takenaka, H., S. Maruo, N. Yamamoto, M. Wysocka, S. Ono, M. Kobayashi, H. Yagita, K. Okumura, T. Hamaoka, G. Trinchieri, and H. Fujiwara. 1997. Regulation of T cell-dependent and -independent IL-12 production by the three Th2-type cytokines IL-10, IL-6, and IL-4. J Leukoc Biol. 61: 80-87.

142. McRae, B. L., R. T. Semnani, M. P. Hayes, and G. A. van Seventer. 1998. Type I IFNs inhibit human dendritic cell IL-12 production and Th1 cell development. J Immunol. 160: 4298-4304.

143. Leng, S. X., and J. A. Elias. 1997. Interleukin-11 inhibits macrophage interleukin-12 production. J Immunol. 159: 2161-2168.

144. Omata, N., M. Yasutomi, A. Yamada, H. Iwasaki, M. Mayumi, and Y. Ohshima. 2002. Monocyte chemoattractant protein-1 selectively inhibits the acquisition of CD40 ligand-dependent IL-12-producing capacity of monocyte-derived dendritic cells and modulates Th1 immune response. $J$ Immunol. 169: 4861-4866.

145. Mitsuhashi, M., J. Liu, S. Cao, X. Shi, and X. Ma. 2004. Regulation of interleukin-12 gene expression and its anti-tumor activities by prostaglandin E2 derived from mammary carcinomas. J Leukoc Biol. 76: 322-332. Epub 2004 May 2003.

146. Azuma, Y., M. Shinohara, P. L. Wang, A. Hidaka, and K. Ohura. 2001. Histamine inhibits chemotaxis, phagocytosis, superoxide anion production, and the production of TNFalpha and IL-12 by macrophages via $\mathrm{H} 2$ receptors. Int Immunopharmacol. 1: 1867-1875. 
147. van der Pouw Kraan, T. C., A. Snijders, L. C. Boeije, E. R. de Groot, A. E. Alewijnse, R. Leurs, and L. A. Aarden. 1998. Histamine inhibits the production of interleukin-12 through interaction with $\mathrm{H} 2$ receptors. J Clin Invest. 102: 1866-1873.

148. Hahm, B., J. H. Cho, and M. B. Oldstone. 2007. Measles virus-dendritic cell interaction via SLAM inhibits innate immunity: selective signaling through TLR4 but not other TLRs mediates suppression of IL-12 synthesis. Virology. 358: 251-257. Epub 2006 Oct 2027.

149. Atabani, S. F., A. A. Byrnes, A. Jaye, I. M. Kidd, A. F. Magnusen, H. Whittle, and C. L. Karp. 2001. Natural measles causes prolonged suppression of interleukin-12 production. J Infect Dis. 184: 1-9. Epub 2001 May 2030.

150. Braun, M. C., J. He, C. Y. Wu, and B. L. Kelsall. 1999. Cholera toxin suppresses interleukin (IL)-12 production and IL-12 receptor beta1 and beta2 chain expression. J Exp Med. 189: 541-552.

151. Coccia, E. M., M. E. Remoli, C. Di Giacinto, B. Del Zotto, E. Giacomini, G. Monteleone, and M. Boirivant. 2005. Cholera toxin subunit B inhibits IL-12 and IFN-\{gamma\} production and signaling in experimental colitis and Crohn's disease. Gut. 54: 1558-1564. Epub 2005 Aug 1516.

152. Presky, D. H., H. Yang, L. J. Minetti, A. O. Chua, N. Nabavi, C. Y. Wu, M. K. Gately, and U. Gubler. 1996. A functional interleukin 12 receptor complex is composed of two beta-type cytokine receptor subunits. Proc Natl Acad Sci U S A. 93: 14002-14007.

153. Trinchieri, G. 2003. Interleukin-12 and the regulation of innate resistance and adaptive immunity. Nat Rev Immunol. 3: 133-146.

154. Bacon, C. M., D. W. McVicar, J. R. Ortaldo, R. C. Rees, J. J. O'Shea, and J. A. Johnston. 1995. Interleukin 12 (IL-12) induces tyrosine phosphorylation of JAK2 and TYK2: differential use of Janus family tyrosine kinases by IL-2 and IL-12. J Exp Med. 181: 399-404.

155. Zou, J., D. H. Presky, C. Y. Wu, and U. Gubler. 1997. Differential associations between the cytoplasmic regions of the interleukin-12 receptor subunits beta1 and beta2 and JAK kinases. J Biol Chem. 272: 6073-6077.

156. Kaplan, M. H., Y. L. Sun, T. Hoey, and M. J. Grusby. 1996. Impaired IL-12 responses and enhanced development of Th2 cells in Stat4-deficient mice. Nature. 382: 174-177.

157. Thierfelder, W. E., J. M. van Deursen, K. Yamamoto, R. A. Tripp, S. R. Sarawar, R. T. Carson, M. Y. Sangster, D. A. Vignali, P. C. Doherty, G. C. Grosveld, and J. N. Ihle. 1996. Requirement for Stat4 in interleukin-12mediated responses of natural killer and T cells. Nature. 382: 171-174.

158. Xu, X., Y. L. Sun, and T. Hoey. 1996. Cooperative DNA binding and sequence-selective recognition conferred by the STAT amino-terminal domain. Science. 273: 794-797.

159. Nguyen, K. B., W. T. Watford, R. Salomon, S. R. Hofmann, G. C. Pien, A. Morinobu, M. Gadina, J. J. O'Shea, and C. A. Biron. 2002. Critical role for 
STAT4 activation by type 1 interferons in the interferon-gamma response to viral infection. Science. 297: 2063-2066.

160. Pignata, C., K. V. Prasad, M. Hallek, B. Druker, C. E. Rudd, M. J. Robertson, and J. Ritz. 1995. Phosphorylation of src family lck tyrosine kinase following interleukin-12 activation of human natural killer cells. Cell Immunol. 165: 211-216.

161. Visconti, R., M. Gadina, M. Chiariello, E. H. Chen, L. F. Stancato, J. S. Gutkind, and J. J. O'Shea. 2000. Importance of the MKK6/p38 pathway for interleukin-12-induced STAT4 serine phosphorylation and transcriptional activity. Blood. 96: 1844-1852.

162. Morinobu, A., M. Gadina, W. Strober, R. Visconti, A. Fornace, C. Montagna, G. M. Feldman, R. Nishikomori, and J. J. O'Shea. 2002. STAT4 serine phosphorylation is critical for IL-12-induced IFN-gamma production but not for cell proliferation. Proc Natl Acad Sci U S A. 99: 12281-12286. Epub 12002 Sep 12284.

163. Tanaka, T., M. A. Soriano, and M. J. Grusby. 2005. SLIM is a nuclear ubiquitin E3 ligase that negatively regulates STAT signaling. Immunity. 22: 729-736.

164. Trinchieri, G. 1998. Interleukin-12: a cytokine at the interface of inflammation and immunity. Adv Immunol 70: 83-243.

165. Bastos, K. R. B., C. R. F. Marinho, R. Barboza, M. Russo, J. M. ¡lvarez, and M. R. D'ImpĖrio Lima. 2004. What kind of message does IL-12/IL-23 bring to macrophages and dendritic cells? Microbes and Infection 6: 630636.

166. Micallef, M. J., T. Ohtsuki, K. Kohno, F. Tanabe, S. Ushio, M. Namba, T. Tanimoto, K. Torigoe, M. Fujii, M. Ikeda, S. Fukuda, and M. Kurimoto. 1996. Interferon-gamma-inducing factor enhances $T$ helper 1 cytokine production by stimulated human T cells: synergism with interleukin-12 for interferon-gamma production. Eur J Immunol. 26: 1647-1651.

167. Lauwerys, B. R., J. C. Renauld, and F. A. Houssiau. 1999. Synergistic proliferation and activation of natural killer cells by interleukin 12 and interleukin 18. Cytokine. 11: 822-830.

168. Yoshimoto, T., H. Okamura, Y. I. Tagawa, Y. Iwakura, and K. Nakanishi. 1997. Interleukin 18 together with interleukin 12 inhibits IgE production by induction of interferon-gamma production from activated B cells. Proc Natl Acad Sci U S A. 94: 3948-3953.

169. Xing, Z., A. Zganiacz, and M. Santosuosso. 2000. Role of IL-12 in macrophage activation during intracellular infection: $\mathrm{IL}-12$ and mycobacteria synergistically release TNF-alpha and nitric oxide from macrophages via IFN-gamma induction. J Leukoc Biol. 68: 897-902.

170. Zilocchi, C., A. Stoppacciaro, C. Chiodoni, M. Parenza, N. Terrazzini, and M. P. Colombo. 1998. Interferon gamma-independent rejection of interleukin 12-transduced carcinoma cells requires CD4+ $\mathrm{T}$ cells and Granulocyte/Macrophage colony-stimulating factor. J Exp Med. 188: 133143. 
171. Grohmann, U., M. L. Belladonna, C. Vacca, R. Bianchi, F. Fallarino, C. Orabona, M. C. Fioretti, and P. Puccetti. 2001. Positive regulatory role of IL-12 in macrophages and modulation by IFN-gamma. $J$ Immunol. 167: 221-227.

172. Bastos, K. R., J. M. Alvarez, C. R. Marinho, L. V. Rizzo, and M. R. Lima. 2002. Macrophages from IL-12p40-deficient mice have a bias toward the M2 activation profile. J Leukoc Biol. 71: 271-278.

173. Watkins, S. K., B. Li, K. S. Richardson, K. Head, N. K. Egilmez, Q. Zeng, J. Suttles, and R. D. Stout. 2009. Rapid release of cytoplasmic IL-15 from tumor-associated macrophages is an initial and critical event in IL-12initiated tumor regression. European Journal of Immunology 39: 21262135.

174. Pan, W. Y., C. H. Lo, C. C. Chen, P. Y. Wu, S. R. Roffler, S. K. Shyue, and M. H. Tao. 2012. Cancer immunotherapy using a membrane-bound interleukin-12 with B7-1 transmembrane and cytoplasmic domains. $\mathrm{Mol}$ Ther. 20: 927-937. doi: 910.1038/mt.2012.1010. Epub 2012 Feb 1014.

175. Kerkar, S. P., R. S. Goldszmid, P. Muranski, D. Chinnasamy, Z. Yu, R. N. Reger, A. J. Leonardi, R. A. Morgan, E. Wang, F. M. Marincola, G. Trinchieri, S. A. Rosenberg, and N. P. Restifo. 2011. IL-12 triggers a programmatic change in dysfunctional myeloid-derived cells within mouse tumors. J Clin Invest. 121: 4746-4757. doi: 4710.1172/JCI58814. Epub 52011 Nov 58817.

176. Pegram, H. J., J. C. Lee, E. G. Hayman, G. H. Imperato, T. F. Tedder, M. Sadelain, and R. J. Brentjens. 2012. Tumor-targeted T cells modified to secrete IL-12 eradicate systemic tumors without need for prior conditioning. Blood. 119: 4133-4141. Epub 2012 Feb 4121.

177. Eisenring, M., J. vom Berg, G. Kristiansen, E. Saller, and B. Becher. 2010. IL-12 initiates tumor rejection via lymphoid tissue-inducer cells bearing the natural cytotoxicity receptor NKp46. Nat Immunol. 11: 1030-1038. Epub 2010 Oct 1010.

178. Shi, F., A. L. Rakhmilevich, C. P. Heise, K. Oshikawa, P. M. Sondel, N. S. Yang, and D. M. Mahvi. 2002. Intratumoral injection of interleukin-12 plasmid DNA, either naked or in complex with cationic lipid, results in similar tumor regression in a murine model. Mol Cancer Ther. 1: 949-957.

179. Leonard, J. P., M. L. Sherman, G. L. Fisher, L. J. Buchanan, G. Larsen, M. B. Atkins, J. A. Sosman, J. P. Dutcher, N. J. Vogelzang, and J. L. Ryan. 1997. Effects of single-dose interleukin-12 exposure on interleukin-12associated toxicity and interferon-gamma production. Blood. 90: 25412548.

180. Watkins, S. K., N. K. Egilmez, J. Suttles, and R. D. Stout. 2007. IL-12 Rapidly Alters the Functional Profile of Tumor-Associated and TumorInfiltrating Macrophages In Vitro and In Vivo. The Journal of Immunology 178: $1357-1362$.

181. DeSantis, C., R. Siegel, P. Bandi, and A. Jemal. 2011. Breast cancer statistics, 2011. CA Cancer J Clin. 61: 409-418. doi: 410.3322/caac.20134. Epub 22011 Oct 20133. 
182. Siegel, R., C. Desantis, K. Virgo, K. Stein, A. Mariotto, T. Smith, D. Cooper, T. Gansler, C. Lerro, S. Fedewa, C. Lin, C. Leach, R. S. Cannady, H. Cho, S. Scoppa, M. Hachey, R. Kirch, A. Jemal, and E. Ward. 2012. Cancer treatment and survivorship statistics, 2012. CA Cancer J Clin 14: 21149.

183. Tao, K., M. Fang, J. Alroy, and G. G. Sahagian. 2008. Imagable 4T1 model for the study of late stage breast cancer. BMC Cancer. 8: 228.

184. Kuriakose, M. A., F. A. Chen, N. K. Egilmez, Y. S. Jong, E. Mathiowitz, M. D. DeLacure, W. L. Hicks, Jr., T. L. Loree, and R. B. Bankert. 2000. Interleukin-12 delivered by biodegradable microspheres promotes the antitumor activity of human peripheral blood lymphocytes in a human head and neck tumor xenograft/SCID mouse model. Head Neck. 22: 57-63.

185. Avigan, D., J. Rosenblatt, and D. Kufe. 2012. Dendritic/tumor fusion cells as cancer vaccines. Semin Oncol. 39: 287-295.

186. Avigan, D., B. Vasir, J. Gong, V. Borges, Z. Wu, L. Uhl, M. Atkins, J. Mier, D. McDermott, T. Smith, N. Giallambardo, C. Stone, K. Schadt, J. Dolgoff, J. C. Tetreault, M. Villarroel, and D. Kufe. 2004. Fusion cell vaccination of patients with metastatic breast and renal cancer induces immunological and clinical responses. Clin Cancer Res. 10: 4699-4708.

187. Avigan, D. E., B. Vasir, D. J. George, W. K. Oh, M. B. Atkins, D. F. McDermott, P. W. Kantoff, R. A. Figlin, M. J. Vasconcelles, Y. Xu, D. Kufe, and R. M. Bukowski. 2007. Phase I/II study of vaccination with electrofused allogeneic dendritic cells/autologous tumor-derived cells in patients with stage IV renal cell carcinoma. J Immunother. 30: 749-761.

188. Rosenblatt, J., B. Vasir, L. Uhl, S. Blotta, C. Macnamara, P. Somaiya, Z. Wu, R. Joyce, J. D. Levine, D. Dombagoda, Y. E. Yuan, K. Francoeur, D. Fitzgerald, P. Richardson, E. Weller, K. Anderson, D. Kufe, N. Munshi, and D. Avigan. 2011. Vaccination with dendritic cell/tumor fusion cells results in cellular and humoral antitumor immune responses in patients with multiple myeloma. Blood. 117: 393-402. Epub 2010 Oct 2028.

189. Egilmez, N. K., J. L. Harden, L. P. Virtuoso, R. A. Schwendener, and M. O. Kilinc. 2011. Nitric oxide short-circuits interleukin-12-mediated tumor regression. Cancer Immunol Immunother. 60: 839-845. Epub 2011 Mar 2019.

190. Gu, T., R. B. Rowswell-Turner, M. O. Kilinc, and N. K. Egilmez. 2010. Central role of IFNgamma-indoleamine 2,3-dioxygenase axis in regulation of interleukin-12-mediated antitumor immunity. Cancer Res. 70: 129-138. Epub 2009 Dec 2022.

191. Zhang, W., X. D. Zhu, H. C. Sun, Y. Q. Xiong, P. Y. Zhuang, H. X. Xu, L. Q. Kong, L. Wang, W. Z. Wu, and Z. Y. Tang. 2010. Depletion of tumorassociated macrophages enhances the effect of sorafenib in metastatic liver cancer models by antimetastatic and antiangiogenic effects. Clin Cancer Res. 16: 3420-3430. Epub 2010 Jun 3422.

192. Nakasone, E. S., H. A. Askautrud, T. Kees, J. H. Park, V. Plaks, A. J. Ewald, M. Fein, M. G. Rasch, Y. X. Tan, J. Qiu, J. Park, P. Sinha, M. J. Bissell, E. Frengen, Z. Werb, and M. Egeblad. 2012. Imaging tumor- 
stroma interactions during chemotherapy reveals contributions of the microenvironment to resistance. Cancer Cell. 21: 488-503. doi: 410.1016/j.ccr.2012.1002.1017.

193. Shree, T., O. C. Olson, B. T. Elie, J. C. Kester, A. L. Garfall, K. Simpson, K. M. Bell-McGuinn, E. C. Zabor, E. Brogi, and J. A. Joyce. 2011. Macrophages and cathepsin proteases blunt chemotherapeutic response in breast cancer. Genes Dev. 25: 2465-2479.

194. Colotta, F., P. Allavena, A. Sica, C. Garlanda, and A. Mantovani. 2009. Cancer-related inflammation, the seventh hallmark of cancer: links to genetic instability. Carcinogenesis. 30: 1073-1081. Epub 2009 May 1025.

195. Mantovani, A., P. Allavena, A. Sica, and F. Balkwill. 2008. Cancer-related inflammation. Nature. 454: 436-444.

196. Pang, B., X. Zhou, H. Yu, M. Dong, K. Taghizadeh, J. S. Wishnok, S. R. Tannenbaum, and P. C. Dedon. 2007. Lipid peroxidation dominates the chemistry of DNA adduct formation in a mouse model of inflammation. Carcinogenesis. 28: 1807-1813. Epub 2007 Mar 1807.

197. Meira, L. B., J. M. Bugni, S. L. Green, C. W. Lee, B. Pang, D. Borenshtein, B. H. Rickman, A. B. Rogers, C. A. Moroski-Erkul, J. L. McFaline, D. B. Schauer, P. C. Dedon, J. G. Fox, and L. D. Samson. 2008. DNA damage induced by chronic inflammation contributes to colon carcinogenesis in mice. J Clin Invest. 118: 2516-2525.

198. Kulbe, H., R. Thompson, J. L. Wilson, S. Robinson, T. Hagemann, R. Fatah, D. Gould, A. Ayhan, and F. Balkwill. 2007. The inflammatory cytokine tumor necrosis factor-alpha generates an autocrine tumorpromoting network in epithelial ovarian cancer cells. Cancer Res. 67: 585592.

199. Sica, A., and A. Mantovani. 2012. Macrophage plasticity and polarization: in vivo veritas. J Clin Invest. 122: 787-795. doi: 710.1172/JCl59643. Epub 52012 Mar 59641.

200. Bergenfelz, C., C. Medrek, E. Ekstrom, K. Jirstrom, H. Janols, M. Wullt, A. Bredberg, and K. Leandersson. 2012. Wnt5a induces a tolerogenic phenotype of macrophages in sepsis and breast cancer patients. $J$ Immunol. 188: 5448-5458. Epub 2012 Apr 5430.

201. Cao, S., X. Zhang, J. P. Edwards, and D. M. Mosser. 2006. NF-kappaB1 (p50) homodimers differentially regulate pro- and anti-inflammatory cytokines in macrophages. J Biol Chem. 281: 26041-26050. Epub 22006 Jul 26011.

202. Porta, C., M. Rimoldi, G. Raes, L. Brys, P. Ghezzi, D. Di Liberto, F. Dieli, S. Ghisletti, G. Natoli, P. De Baetselier, A. Mantovani, and A. Sica. 2009. Tolerance and M2 (alternative) macrophage polarization are related processes orchestrated by p50 nuclear factor kappaB. Proc Natl Acad Sci U S A. 106: 14978-14983. Epub 12009 Aug 14917.

203. Biswas, S. K., L. Gangi, S. Paul, T. Schioppa, A. Saccani, M. Sironi, B. Bottazzi, A. Doni, B. Vincenzo, F. Pasqualini, L. Vago, M. Nebuloni, A. Mantovani, and A. Sica. 2006. A distinct and unique transcriptional program expressed by tumor-associated macrophages (defective NF- 
kappaB and enhanced IRF-3/STAT1 activation). Blood. 107: 2112-2122. Epub 2005 Nov 2113.

204. Banerjee, S., K. Halder, A. Bose, P. Bhattacharya, G. Gupta, S. Karmahapatra, S. Das, S. Chaudhuri, S. Bhattacharyya Majumdar, and S. Majumdar. 2011. TLR signaling-mediated differential histone modification at IL-10 and IL-12 promoter region leads to functional impairments in tumor-associated macrophages. Carcinogenesis. 32: 1789-1797. doi: 1710.1093/carcin/bgr1208. Epub 2011 Sep 1716.

205. Steele, R. J., O. Eremin, M. Brown, and R. A. Hawkins. 1984. A high macrophage content in human breast cancer is not associated with favourable prognostic factors. Br J Surg. 71: 456-458.

206. Zeisberger, S. M., B. Odermatt, C. Marty, A. H. Zehnder-Fjallman, K. Ballmer-Hofer, and R. A. Schwendener. 2006. Clodronate-liposomemediated depletion of tumour-associated macrophages: a new and highly effective antiangiogenic therapy approach. $\mathrm{Br} J$ Cancer. 95: 272-281. Epub 2006 Jul 2011.

207. Diel, I. J., R. Bergner, and K. A. Grotz. 2007. Adverse effects of bisphosphonates: current issues. J Support Oncol. 5: 475-482.

208. Magram, J., S. E. Connaughton, R. R. Warrier, D. M. Carvajal, C. Y. Wu, J. Ferrante, C. Stewart, U. Sarmiento, D. A. Faherty, and M. K. Gately. 1996. IL-12-deficient mice are defective in IFN gamma production and type 1 cytokine responses. Immunity 4: 471-481.

209. Standiford, T. J., R. Kuick, U. Bhan, J. Chen, M. Newstead, and V. G. Keshamouni. 2011. TGF-beta-induced IRAK-M expression in tumorassociated macrophages regulates lung tumor growth. Oncogene. 30: 2475-2484. doi: 2410.1038/onc.2010.2619. Epub 2011 Jan 2431.

210. Cao, X., K. Leonard, L. I. Collins, S. F. Cai, J. C. Mayer, J. E. Payton, M. J. Walter, D. Piwnica-Worms, R. D. Schreiber, and T. J. Ley. 2009. Interleukin 12 stimulates IFN-gamma-mediated inhibition of tumor-induced regulatory T-cell proliferation and enhances tumor clearance. Cancer Res 69: 8700-8709.

211. Bhattacharya, M., N. Ojha, S. Solanki, C. K. Mukhopadhyay, R. Madan, N. Patel, G. Krishnamurthy, S. Kumar, S. K. Basu, and A. Mukhopadhyay. 2006. IL-6 and IL-12 specifically regulate the expression of Rab5 and Rab7 via distinct signaling pathways. EMBO J. 25: 2878-2888. Epub 2006 Jun 2878.

212. Zhang, S., and M. H. Kaplan. 2000. The p38 mitogen-activated protein kinase is required for IL-12-induced IFN-gamma expression. J Immunol. 165: 1374-1380.

213. Gabrilovich, D. I., S. Ostrand-Rosenberg, and V. Bronte. 2012. Coordinated regulation of myeloid cells by tumours. Nat Rev Immunol 12: 253-268.

214. Qian, B.-Z., and J. W. Pollard. 2010. Macrophage Diversity Enhances Tumor Progression and Metastasis. Cell 141: 39-51.

215. De Palma, M., and Claire E. Lewis. 2013. Macrophage Regulation of Tumor Responses to Anticancer Therapies. Cancer Cell 23: 277-286. 
216. Altevogt, P., N. P. Bretz, J. Ridinger, J. Utikal, and V. Umansky. 2014. Novel insights into exosome-induced, tumor-associated inflammation and immunomodulation. Semin Cancer Biol.

217. Puddu, P., L. Fantuzzi, P. Borghi, B. Varano, G. Rainaldi, E. Guillemard, W. Malorni, P. Nicaise, S. F. Wolf, F. Belardelli, and S. Gessani. 1997. IL12 induces IFN-gamma expression and secretion in mouse peritoneal macrophages. Journal of immunology 159: 3490-3497.

218. Ngiow, S. F., M. W. L. Teng, and M. J. Smyth. 2013. A balance of interleukin-12 and -23 in cancer. Trends in Immunology 34: 548-555.

219. Mountford, A. P., P. S. Coulson, A. W. Cheever, A. Sher, R. A. Wilson, and T. A. Wynn. 1999. Interleukin-12 can directly induce T-helper 1 responses in interferon-gamma (IFN-gamma) receptor-deficient mice, but requires IFN-gamma signalling to downregulate T-helper 2 responses. Immunology 97: 588-594.

220. Hafner, M., W. Falk, B. Echtenacher, and D. N. Mannel. 1999. Interleukin12 activates NK cells for IFN-gamma-dependent and NKT cells for IFNgamma-independent antimetastatic activity. European cytokine network 10: 541-548.

221. Bellora, F., R. Castriconi, A. Dondero, A. Pessino, A. Nencioni, G. Liggieri, L. Moretta, A. Mantovani, A. Moretta, and C. Bottino. 2014. TLR activation of tumor-associated macrophages from ovarian cancer patients triggers cytolytic activity of NK cells. Eur J Immunol: n/a-n/a.

222. Klug, F., H. Prakash, P. E. Huber, T. Seibel, N. Bender, N. Halama, C. Pfirschke, R. H. Voss, C. Timke, L. Umansky, K. Klapproth, K. Schakel, N. Garbi, D. Jager, J. Weitz, H. Schmitz-Winnenthal, G. J. Hammerling, and P. Beckhove. 2013. Low-dose irradiation programs macrophage differentiation to an iNOS(+)/M1 phenotype that orchestrates effective T cell immunotherapy. Cancer Cell 24: 589-602.

223. Chakrabarti, A., D. Talukdar, A. Pal, and M. Ray. 2014. Immunomodulation of macrophages by methylglyoxal conjugated with chitosan nanoparticles against Sarcoma-180 tumor in mice. Cellular immunology 287: 27-35.

224. Bastos, K. R., C. R. Marinho, R. Barboza, M. Russo, J. M. Alvarez, and M. R. D'Imperio Lima. 2004. What kind of message does IL-12/IL-23 bring to macrophages and dendritic cells? Microbes and infection / Institut Pasteur 6: 630-636.

225. Grohmann, U., M. L. Belladonna, C. Vacca, R. Bianchi, F. Fallarino, C. Orabona, M. C. Fioretti, and P. Puccetti. 2001. Positive Regulatory Role of $\mathrm{IL}-12$ in Macrophages and Modulation by IFN-OE $\geq$. The Journal of Immunology 167: 221-227.

226. Koerner, T. J., D. O. Adams, and T. A. Hamilton. 1987. Regulation of tumor necrosis factor (TNF) expression: interferon-gamma enhances the accumulation of mRNA for TNF induced by lipopolysaccharide in murine peritoneal macrophages. Cellular immunology 109: 437-443.

227. Sariban, E., K. Imamura, R. Luebbers, and D. Kufe. 1988. Transcriptional and posttranscriptional regulation of tumor necrosis factor gene 
expression in human monocytes. The Journal of clinical investigation 81: 1506-1510.

228. Vila-del Sol, V., C. Punzón, and M. Fresno. 2008. IFN- - -Induced TNF- $\alpha$ Expression Is Regulated by Interferon Regulatory Factors 1 and 8 in Mouse Macrophages. The Journal of Immunology 181: 4461-4470.

229. Wongchana, W., and T. Palaga. 2012. Direct regulation of interleukin-6 expression by Notch signaling in macrophages. Cellular \& molecular immunology 9: 155-162.

230. Matsusaka, T., K. Fujikawa, Y. Nishio, N. Mukaida, K. Matsushima, T. Kishimoto, and S. Akira. 1993. Transcription factors NF-IL6 and NF-kappa $B$ synergistically activate transcription of the inflammatory cytokines, interleukin 6 and interleukin 8. Proceedings of the National Academy of Sciences of the United States of America 90: 10193-10197.

231. Rosztoczy, I., and J. Content. 1990. The Effects of Various Cytokines on Interleukin-6 and Interferon-Alpha Synthesis in Human Peripheral-Blood Mononuclear-Cells. J Interferon Res 10: 637-645.

232. van Wissen, M., M. Snoek, B. Smids, H. M. Jansen, and R. Lutter. 2002. IFN-gamma amplifies IL-6 and IL-8 responses by airway epithelial-like cells via indoleamine 2,3-dioxygenase. Journal of immunology 169: 70397044.

233. Saraiva, M., and A. O'Garra. 2010. The regulation of IL-10 production by immune cells. Nat Rev Immunol 10: 170-181.

234. Teixeira-Coelho, M., J. Guedes, P. Ferreirinha, A. Howes, J. Pedrosa, F. Rodrigues, W. S. Lai, P. J. Blackshear, A. O'Garra, A. G. Castro, and M. Saraiva. 2013. Differential post-transcriptional regulation of IL-10 by TLR2 and TLR4-activated macrophages. Eur J Immunol.

235. Sinha, P., L. Parker Kh Fau - Horn, S. Horn L Fau - Ostrand-Rosenberg, and S. Ostrand-Rosenberg. 2012. Tumor-induced myeloid-derived suppressor cell function is independent of IFN-gamma and IL-4Ralpha. In Eur J Immunol.

236. Sinha, P., V. K. Clements, S. K. Bunt, S. M. Albelda, and S. OstrandRosenberg. 2007. Cross-talk between myeloid-derived suppressor cells and macrophages subverts tumor immunity toward a type 2 response. $J$ Immunol 179: 977-983.

237. Hu, X., B. Li, X. Li, X. Zhao, L. Wan, G. Lin, M. Yu, J. Wang, X. Jiang, W. Feng, Z. Qin, B. Yin, and Z. Li. 2014. Transmembrane TNF-alpha promotes suppressive activities of myeloid-derived suppressor cells via TNFR2. Journal of immunology 192: 1320-1331.

238. Cargnello, M., and P. P. Roux. 2011. Activation and Function of the MAPKs and Their Substrates, the MAPK-Activated Protein Kinases. Microbiology and Molecular Biology Reviews 75: 50-83.

239. Carroll, K. C., B. Viollet, and J. Suttles. 2013. AMPKalpha1 deficiency amplifies proinflammatory myeloid APC activity and CD40 signaling. $J$ Leukoc Biol 94: 1113-1121. 
240. Sag, D., R. D. Carling D Fau - Stout, J. Stout Rd Fau - Suttles, and J. Suttles. Adenosine 5'-monophosphate-activated protein kinase promotes macrophage polarization to an anti-inflammatory functional phenotype.

241. Mumm, J. B., and M. Oft. 2013. Pegylated IL-10 induces cancer immunity: the surprising role of IL-10 as a potent inducer of IFN-gamma-mediated CD8(+) T cell cytotoxicity. Bioessays 35: 623-631.

242. Fujii, S., K. Shimizu, T. Shimizu, and M. T. Lotze. 2001. Interleukin-10 promotes the maintenance of antitumor CD8(+) T-cell effector function in situ. Blood 98: 2143-2151. 


\section{CURRICULUM VITAE}

Courtney Mitchell

University of Louisville School of Medicine

Department of Microbiology and Immunology

31. Abraham Flexner Way, Building 55A, Room 313

cjgeor02.louisville.edu, cjgeorge662.gmail.com

(502).852.4622

\section{Education}

University of Louisville School of Medicine

MD (May 2014)

University of Louisville School of Medicine

PhD in Microbiology and Immunology (Defense: May 2014, Conferment: August 2014)

Clark Atlanta University,

BS in Biological Sciences (May 2007)

Summa cum laude

\section{Research Experience}

Graduate Student, Department of Microbiology and Immunology, University of Louisville School of Medicine, (Fall 2009-present)

Mentors: Robert Stout, PhD and Jill Suttles, PhD

Project title: IL-12 induced immune competence and macrophage functional

plasticity and cancer

Student Researcher, Department of Biochemistry and Molecular Biology, University of Louisville School of Medicine, (Summer 2008)

Mentor: Binks Wattenberg, PhD

Project title: "Effects of Sphingosine Kinase Localization on Anchorage Independent Growth"

Investigated the transforming ability of over-expressed sphingosine kinase targeted to various cellular membranes via anchorage independent growth assays.

Student Researcher, Department of Microbiology and Immunology, University of Louisville School of Medicine, (Summer 2007)

Mentor: James Lillard, PhD 
Project title: "Transfection and Characterization of CXCR7 expression in Rat Basophilic Leukemia Cells

Rat basophilic leukemia (RBL) cells were transfected with pcDNA-CXCR7, and preliminary FACS was performed with the ultimate goal of identifying biological antagonist for CXCR7.

Student Researcher, Center for Cancer Research and Therapeutic Development, Clark Atlanta University, (Fall 2006-Spring 2007)

Mentor: Shafiq Khan, PhD

Project title: "Biochemical Characterization of Steroidogenesis Inducing Protein (S1P) secreted by ovarian cancer cells"

Worked to characterize steroidogenesis-inducing protein (SIP) from an ovarian cancer cell line to compare with SIP isolated from human follicular fluid

Student Researcher, Pediatric Rheumatology Section, Baylor College of Medicine/Texas Children's Hospital (Summer 2006)

Mentor: Barry Myones, MD

Project title: "Isolation of the Active Moiety in Lactobacillus casei Cell Wall Extracts Responsible for the Development of Coronary Arteritis"

Analyzed Lactobacillus casei cell wall (LCCW) to isolate and ultimately identify the dynamic element responsible for inducing coronary arteritis using biochemical experimentation

Student Researcher, Center for Biomolecular Science and Engineering, Naval Research Laboratory (Summer 2005)

Mentor: Jinny Lin Liu, PhD

Project entitled "Selection Single Domain Antibodies by Phage Display"

Displayed single domain antibodies from smooth dogfish shark in bacteriophage, transfected E.coli, and then used isolated antibodies to test their affinity for possible biohazardous toxins including cholera, Staphylococcus enterotoxin B, and ricin

\section{Clinical Experience}

Resident Physician, Department of Obstetrics and Gynecology, University of Alabama Birmingham (June 2014-June2018)

\section{Grants}

Grant ID: F31CA142317-01

$\$ 173,239$

07/2009-07/2014

Functional conversion of tumor associated macrophages via cytokine therapy National Cancer Institute, National Institutes of Health

\section{Publications}

IL-12 modification of tumor infiltrating macrophage responsiveness via IFNYdependent and independent mechanisms (2013) C. Mitchell, K. Head, J. Suttles, and R.D. Stout. in preparation 


\section{Abstracts}

George, CJ, K. Head, L. Zhang, J. Suttles and R.D. Stout. Modification of tumorassociated macrophage responsiveness via IFNY-dependent and independent mechanisms. 2012. J. Leuk. Biol. S49 Abst. 122.

George, CJ, K. Hobbing, J. Suttles, and R.D. Stout. IL-12 modulates NFk-B p50 Over-expression in tumor-associated and tumor infiltrating macrophages. 2011. J. Leuk. Biol. S38. Abst.109.

Hobbing, K.,George CJ, J. Suttles, and R.D. Stout. Roles for CD40 in tumormacrophage interaction and tumor metastasis. 2010. SLB/IEEIS Abst. 71.

Salazar RL, George CJ, O'Brien III WG, Hicks MJ, Myones BL. Separation of organ specificity in a murine model of vasculitis by modification of isolation and purification of Lactobacillus casei cell wall extracts. American College of Rheumatology National Meeting - San Francisco CA. Arthritis Rheum 2008; 58:S391.

\section{Presentations}

Poster Presenter, National MD/PhD Conference (2013)

Poster presenter, Society for Leukocyte Biology Annual Meeting $(2011,2012)$

Poster presenter, Research Louisville, $(2007,2008,2011)$

Poster presenter, $3^{\text {rd }}$ Annual National Symposium on Prostate Cancer, CCRTDCAU (2007)

Poster presenter, Annual Biomedical Research Conference for Minority Students (2005, 2006)

\section{Certifications}

Advanced Cardiac Life Support (American Heart Association)

Basic Life Support (American Heart Association)

\section{Honors and Awards}

ULSOM Outstanding Student in OB/Gyn Clerkship Award (2014)

John Gibbons Medical Student Award, District V ACOG (2013)

Melvin Denis Travel Award, National MD/PhD Conference (2013)

Doctoral Scholar, Southern Regional Educational Board (2010-present)

Student of Year Award, Department of Biological Sciences, Clark Atlanta

University (2007)

Nominated participant, Current Research Topics in Genetics Short Course, National Human Genome Research Institute, National Institutes of Health (2006) MARC U*STAR Research Program participant, Atlanta University Center (20052007)

Provost Scholarship Recipient, Clark Atlanta University (2003-2007)

Academic Dean's List, Clark Atlanta University (2003-2007)

\section{Memberships/ Committees}

University of Louisville School of Medicine Diversity Committee (2012-present) 
American College of Obstetricians and Gynecologists, junior fellow (2012present)

Black Biomedical Graduate Student Organization, president (2010-2011)

Society of Leukocyte Biology, student member (2010-2012)

American Association of Cancer Researchers (2010-2011)

University of Louisville Medical School Student Senate, member (2008-2009)

Student National Medical Association, social chairman (2008-2009)

American College of Physicians, student member (2007-2009)

American Medical Association, student member (2007-2009)

American Medical Women's Association (2007-2009)

\section{Community Service}

BBGSO After-School Science Enrichment coordinator (Spring 2010)

Relay for Life Jefferson County, KY (Team captain) (2010)

Black Achievers Louisville volunteer (2007-2008)

Drive Cancer Out volunteer (Spring 2008) 